\title{
Innovations in primary unicompartmental knee surgery and unicompartmental to total knee revisionsurgery and unicompartmental to total knee revision surgery
}

Citation for published version (APA):

Kerens, B. (2017). Innovations in primary unicompartmental knee surgery and unicompartmental to total knee revisionsurgery and unicompartmental to total knee revision surgery. [Doctoral Thesis, Maastricht University]. Datawyse / Universitaire Pers Maastricht. https://doi.org/10.26481/dis.20170217bk

Document status and date:

Published: 01/01/2017

DOI:

10.26481/dis.20170217bk

Document Version:

Publisher's PDF, also known as Version of record

Please check the document version of this publication:

- A submitted manuscript is the version of the article upon submission and before peer-review. There can be important differences between the submitted version and the official published version of record. People interested in the research are advised to contact the author for the final version of the publication, or visit the DOI to the publisher's website.

- The final author version and the galley proof are versions of the publication after peer review.

- The final published version features the final layout of the paper including the volume, issue and page numbers.

Link to publication

\footnotetext{
General rights rights.

- You may freely distribute the URL identifying the publication in the public portal. please follow below link for the End User Agreement:

www.umlib.nl/taverne-license

Take down policy

If you believe that this document breaches copyright please contact us at:

repository@maastrichtuniversity.nl

providing details and we will investigate your claim.
}

Copyright and moral rights for the publications made accessible in the public portal are retained by the authors and/or other copyright owners and it is a condition of accessing publications that users recognise and abide by the legal requirements associated with these

- Users may download and print one copy of any publication from the public portal for the purpose of private study or research.

- You may not further distribute the material or use it for any profit-making activity or commercial gain

If the publication is distributed under the terms of Article 25fa of the Dutch Copyright Act, indicated by the "Taverne" license above, 


\section{Innovations in primary unicompartmental knee surgery and unicompartmental to total knee revision surgery}

Bart Kerens

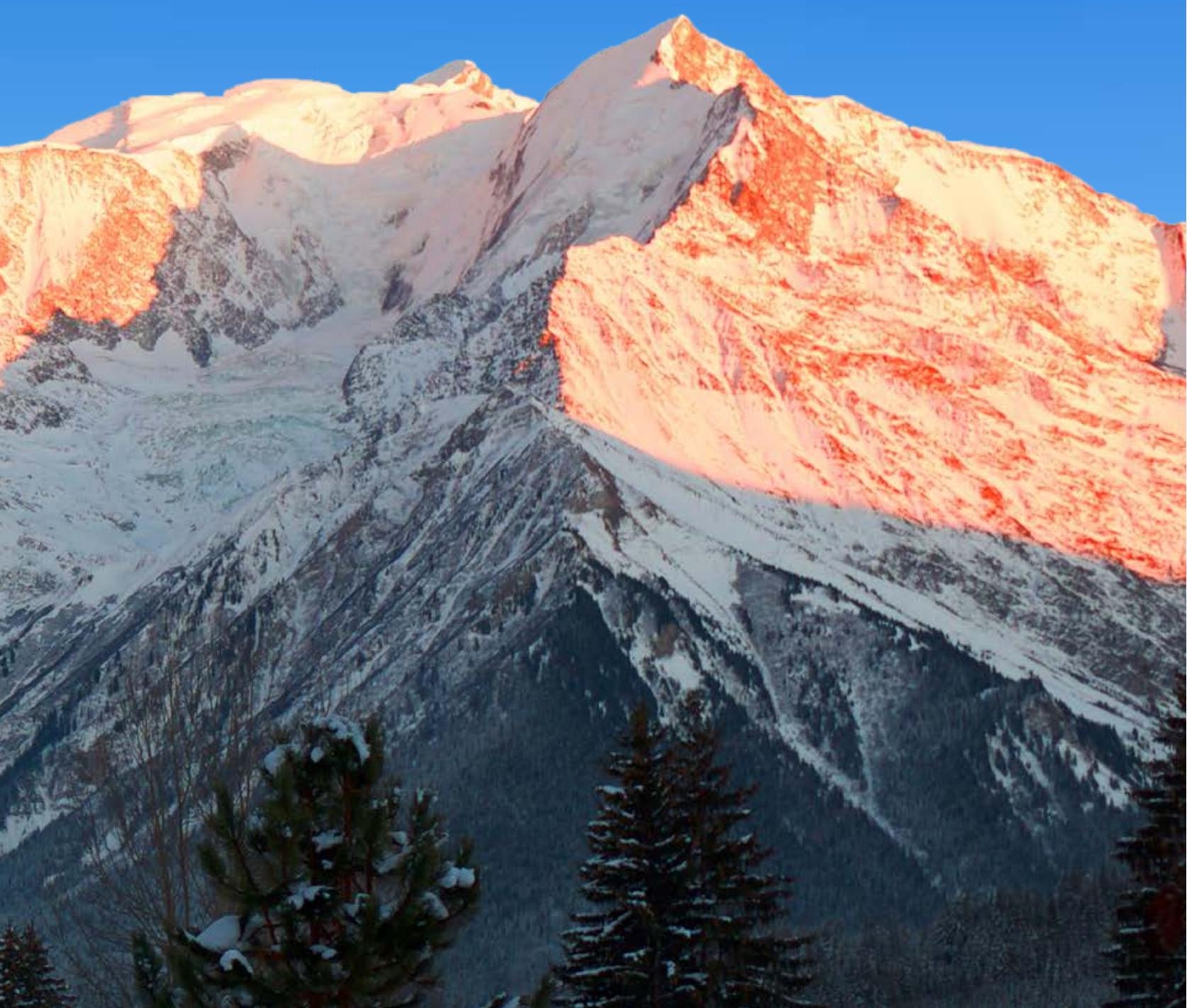


The publication of this thesis was kindly supported by:

Nederlandse Orthopaedische Vereniging

Stichting Kliniek en Wetenschap Orthopedie, MUMC+

Maastricht University

Spronken Orthopedie

Smeets loopcomfort

Sportho

Hanssen footcare

Footlife Nederland

Anna Fonds

Livit

Wellspect Healthcare

ZimmerBiomet

Vigo Heerlen

Bauerfeind Nederland

Zuyderland Medisch Centrum

Production/print: Datawyse | Universitaire Pers Maastricht

ISBN: 9789461596611

C Bart Kerens, 2016

All rights reserved. No part of this publication may be reproduced or transmitted in any form by any means, without permission of the author. 


\title{
Innovations in primary unicompartmental knee surgery and unicompartmental to total knee revision surgery
}

\author{
Proefschrift \\ ter verkrijging van de graad van doctor aan de Universiteit Maastricht, \\ op gezag van de Rector Magnificus, Prof. dr. Rianne M. Letschert, \\ volgens het besluit van het College van Decanen, \\ in het openbaar te verdedigen \\ op vrijdag 17 februari 2017 om 12:00 uur
}

door

Bart Kerens 


\section{Promotor}

Prof. dr. L.W. van Rhijn

\section{Copromotoren}

Dr. N.P. Kort (Zuyderland medisch centrum, Sittard-Geleen)

Dr. P.J. Emans

Beoordelingscommissie:

Prof. dr. I.C. Heyligers (voorzitter)

Prof. dr. H.P. Delport

Prof. dr. R. G. T. Geesink

Prof dr R.J.E.M. Smeets

Prof. dr. P. Verdonk (UZA, Antwerpen, België) 


\section{Table of contents}

Chapter 1 Introduction and aims

Chapter 2 Cementless versus cemented Oxford unicompartmental knee arthroplasty. Early results of a non-designer user group

Knee Surg Sports Traumatol Arthrosc. 2016 May 9. [Epub ahead of print]

Chapter 3 Patient-specific guiding for Oxford UKA surgery is accurate. A prospective CT-based shape matching study

Submitted

Chapter 4 No radiographic difference between patient specific guiding and conventional Oxford UKA surgery

Knee Surg Sports Traumatol Arthrosc. 2015 May;23(5):1324-9.

Chapter 5 Overstuffed medial compartment after mobile bearing unicompartmental knee arthroplasty

Knee Surg Sports Traumatol Arthrosc. 2011 Jun;19(6):952-4.

Chapter 6 Revision from unicompartmental to total knee arthroplasty; clinical outcome depends on reason for revision Bone Joint J. 2013 Sep;95-B(9):1204-8.

Chapter 7 Patient specific guiding for revision of medial unicondylar knee arthroplasty to total knee arthroplasty. Beneficial first results of a new operating technique performed on 10 patients

Acta Orthop. 2013 Apr;84(2):165-9.

Chapter 8 Popliteal lesion due to traction during unicompartmental knee revision surgery. Case report and literature overview J Orthop. 2013 Mar 1;10(1):38-40.

Chapter 9 Conclusion

Chapter 10 Summary and valorisation 103

Dankwoord 107

Curriculum vitae

Publications 



\section{Chapter}

Introduction and aims

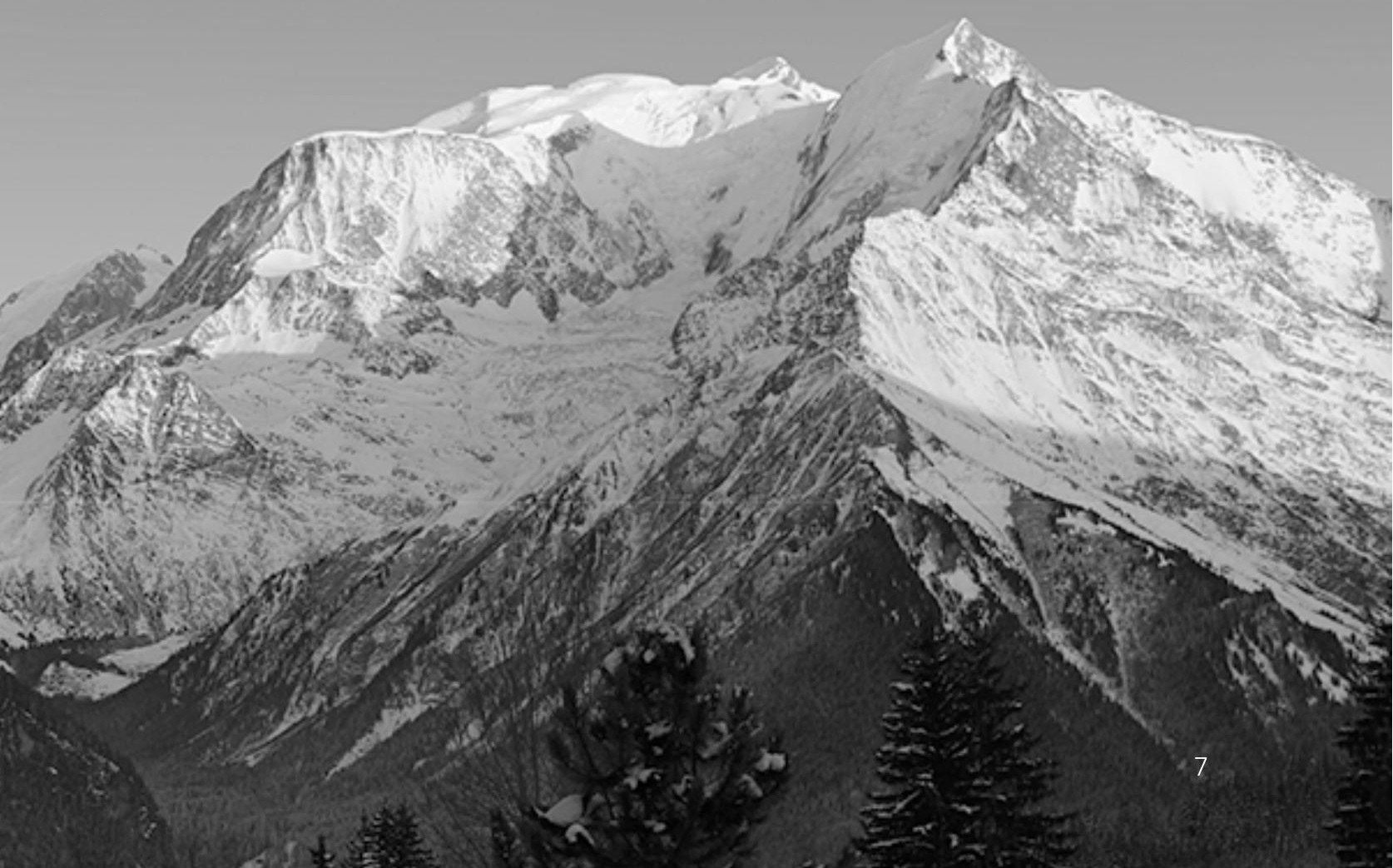





\section{OSTEOARTHRITIS OF THE KNEE}

Osteoarthritis of the knee is a painful condition that mainly affects the elderly. The quality of the cartilage is reduced, and synovial reaction can be present. It is a chronic and progressive disease that can impair the function of the joint and decrease the quality of life of the patient.[1] Patients mainly complain of pain during weight-bearing and at night. The range of motion of the joint and smoothness of joint motion may decrease.[1] The cause of osteoarthritis of the knee can be primary or secondary, for example trauma, axis anomalies or rheumatological conditions.[6]

\section{UNICOMPARTMENTAL OSTEOARTHRITIS OF THE KNEE}

The knee joint includes four compartments. The medial and lateral compartment transfer load from the femur to the tibia and are both important during weight-bearing. When the knee is not straight but in a varus configuration, the medial compartment will bear more of the load, and in a valgus knee configuration the lateral compartment will bear more of the load. The third or patellofemoral compartment is situated on the anterior side of the knee between the femur and the patella. This compartment is loaded during exercises in which the knee is in flexion, such as stair climbing, cycling and standing up from a chair. The fourth and last compartment is situated in the middle of the knee between both femoral condyles. In this compartment the anterior cruciate ligament $(A C L)$ and posterior cruciate ligament $(P C L)$ function as stabilisers of the knee. The bone in the medial, lateral and patellofemoral compartments is covered with cartilage, and these three compartments can all individually show signs of osteoarthritis while other compartments in the same knee can be good.

Osteoarthritis of only one compartment is often due to an increased load in this compartment. This increase in load can be constitutionally determined but it can also be due to trauma with axis deviations or simple meniscectomy in the past. When the meniscus is removed, the cartilage will additionally have to absorb more strain and it is more prone to develop early osteoarthritis.

\section{MEDIAL OSTEOARTHRITIS OF THE KNEE}

Medial osteoarthritis of the knee is osteoarthritis in solely the medial compartment of the knee. It is more common in patients with a varus constitution. In these patients, a larger part of the load is transferred through this medial compartment, which can result in increased cartilage wear and osteoarthritis. Due to this wear of the medial cartilage, the varus can increase and osteoarthritis progression is more likely. Another important factor in medial arthritis is previous medial meniscectomy, as stated in the previous paragraph. 


\section{OSTEOARTHRITIS TREATMENT}

Treatment options of osteoarthritis of the knee are divided into two categories: nonoperative or conservative treatment and operative treatment.

\section{Conservative treatment}

Conservative treatment is preferable, and can take various forms. Patient education and explanation of the impact of the condition on daily life can be helpful.[5] Physiotherapy can keep the joint mobile and increase muscle strength, which can improve smooth joint movement.[5] Aids, such as braces and insoles, can be applied but have not been proven to be effective in the literature.[5] NSAID and painkillers can help relieve pain.[5] Local infiltration in the joint with corticosteriods can be used in an acute phase, and infiltration with hyaluronic acid derivates can be used to improve complaints when the acute phase has passed, although this has not been proven to be effective in all cases in recent literature.[5]

\section{Operative treatment}

When the complaints of the patient cannot be managed with this conservative treatment, the next step to consider is operative treatment. Operative treatment can also take various forms. In some patients, the complaints can be decreased by performing an arthroscopy of the joint. But this does not increase the quality of the cartilage, and most patients are not satisfied with the results.[5] Another operative treatment, which is indicated for unicompartmental osteoarthritis, can be an osteotomy. $[5,12]$ In this procedure the bone next to the joint is realigned (more varus or valgus) during surgery, in order to try to transfer loads from one part of the knee (where the quality of the cartilage is bad) to another part of the knee (where the quality of the cartilage is better) and thus reduce complaints.[12] This procedure can only be performed when the initial load is mostly in the osteoarthritic compartment and when the quality of the cartilage in the compartment in which the load will increase after surgery is still good.[12] Recent literature suggests that distraction of the joint during two months can improve the complaints due to osteoarthritis and that the cartilage shows a tendency to repair itself.[24] The results are worse when the patellofemoral compartment is affected.[24]

A final option is knee arthroplasty. During knee arthroplasty surgery, the part of the knee with bad cartilage is removed and replaced by a prosthetic component. When all compartments of the knee are affected, a total knee arthroplasty (TKA) can be performed with good results. When only one compartment is affected a partial or unicompartmental knee arthroplasty (UKA) can be performed. For the patellofemoral compartment specially designed prostheses are available, as well as for the medial and lateral compartment. The medial compartment differs from the lateral compartment bio- 
mechanically. While the medial compartment remains more stable and functions as a pivot, the lateral compartment is more mobile; the femoral condyle rolls backwards far more than in the medial compartment. The lateral compartment thus shows less intrinsic stability than the medial compartment, which means that there are differences in design for prostheses for either compartment.

\section{Medial osteoartrhritis treatment}

Medial osteoarthritis can be treated conservatively as stated above or operatively with high tibial valgisation osteotomy, medial UKA or TKA. The main advantage of an osteotomy is that no artificial joint needs to be implanted and that the native knee is kept. The disadvantage of this procedure is that the rehabilitation after surgery can be difficult and that the bone has to heal in the new position. The knee is also in another position, which can cause initial difficulties in coordination. This type of surgery is performed more often in young patients. A TKA procedure can also be performed in patients with only medial osteoarthritis. In these patients, the lateral and patellofemoral compartments are also replaced, although the cartilage there is good. In patients suffering from medial osteoartritis with reumatoid arthritis or patients with anterior cruciate ligament insufficiency, a TKA is a valuable and good option. The kinematics of a TKA, however, are completely different compared to the kinematics of a native knee joint. Since the $\mathrm{ACL}$ is conserved and the rol-back of the lateral femoral condyle is preserved, the kinematics of a UKA are more similar to the kinematics of a native knee joint. In cases with only medial osteoarthritis and no other contraindications for UKA surgery, this is a good option. It is a known procedure for treating medial osteoarthritis of the knee and osteochondritis dissecans lesions of the medial femoral condyl.[8] Patients should have a flexion of the knee of at least 110 degrees and an extension deficit of less than 15 degrees.[8] A varus angle of the knee of 15 degrees or less has to be present and this varus has to be correctable preoperatively.[8] Finally, cruciate and collateral ligaments have to be intact.[8] Exclusion criteria are systemic joint diseases like rheumatoid arthritis and osteoarthritis of the lateral and patellofemoral compartment of the knee, although some report that a certain degree of osteoarthritis of the patellofemoral compartment can be accepted. When these criteria are met, good short-term, mediumterm and long-term results of UKA surgery are reported.[11,15,18,26] Which of these options is preferable differs and depends on the individual patient. Older patients are treated more often using a TKA since the life span of the prosthesis is probably longer than the life span of the patient. In young patients, however, it is preferred to preserve as much native bone as possible since revision surgery might be necessary in future, and during every revision knee arthroplasty surgery, bone is potentially lost. In these patients, an osteotomy or UKA may be more appropriate in order to have options left during the longer lifespan of these patients. 


\section{INNOVATIONS IN PRIMARY UKA SURGERY}

\section{Introduction}

Although UKA surgery shows good results, innovations to improve these results continue to be introduced. $[19,25]$ The aim of these innovations is to reduce revision rates and increase patient satisfaction. The primary innovations discussed in this dissertation concern component fixation and component positioning.

\section{Fixation in primary UKA surgery}

A first interesting point regarding primary UKA is the type of fixation. The fixation of the component to the bone determines the survival rate of the prosthesis, since the most common reason for revision is aseptic loosening. [14] Fixation can be done with bone cement, or with biomimetic coatings or metallic surfaces of prosthesis components, which promote bone on- and ingrowth to the prosthesis. UKA is mostly performed using cemented fixation. In many cases, radiolucent lines can be seen under the tibial plateau when using this cemented technique.[9] These lines appear to be normal and are not associated with loosening.[9] These lines seem to be seen less frequently in cementless UKA. This and other factors, such as a shorter operation time in cementless UKA, have recently led to increased attention for cementless fixation of UKA.[21] In case of cementless fixation a coating, which stimulates bone ingrowth is present on the prosthesis.[20] The first aim of this dissertation is to answer the question: "Does cementless Oxford UKA show similar clinical and radiological results when compared to cemented Oxford UKA?" A multicentre retrospective study was conducted. The methodology and results of this study are described in chapter 2 of this dissertation.

\section{Patient-specific guiding in primary UKA surgery}

Another important factor in UKA survival is component position. The conventional way of component positioning uses intramedullary and extramedullary devices to determine the component position. This can be technically demanding. Recently, new techniques such as computer-assisted surgery (CAS) and patient-specific guiding (PSG) were introduced to aid in this component positioning. During CAS, markers are placed in the tibial and femur and defined anatomical landmarks are identified by the surgeon and provided to the navigation software on a computer during surgery. The navigation software and the position of the placed markers offers the surgeon insight into the position of the bone and jig-guides. As such, the surgeon is assisted by the computer to make the proper bone cuts and as a consequence, ideally, the components are placed in the proper position. The disadvantages of this technique include a longer operation time, problems related to input of landmarks in the computer and high costs of the hardware. 
PSG is a new technique in UKA surgery. This technique also has the disadvantage that costs are added to the procedure but surgery time could decrease. If the use of these techniques improves the position of the components, a decrease of revision rates might be expected in future. PSG is reliable and safe in TKA surgery.[4] It helps place the prosthesis in the proper position by performing preoperative MRI or CT imaging of the leg. The images are translated into a three dimensional (3D) plan of the anatomy of the knee. In this plan, components of the prosthesis can be placed correctly before surgery. With this plan, which includes the desired position of the prosthesis, guides specific to the anatomy of the patient are formed. These guides are then used during surgery. Once in the fit position, the guides determine the position of the cutting blocks. Formerly, the position of these cutting blocks was determined by the surgeon using intra- or extramedullar guiding systems.

An important factor in PSG surgery is the pre-operative planning. This is an essential step in performing this type of surgery. In order to perform this planning, the surgeon logs on onto a web-based module in which the patient-specific images of the patient are uploaded as a 3D plan. A 3D plan of the prosthesis component to be inserted is also available in this module. The surgeon can position the components on the anatomy of the patient in the desired position. This step is now performed before the surgery, whereas it used to be performed during surgery when using conventional outlining equipment. This splitting of the timing of planning component position and actual positioning of the components creates a new step in surgery, translating the digital plan to the actual anatomy. Guides that fit to the anatomy of the patient in only one single way effectuate this translation. These guides then determine the position of the cutting blocks. The accuracy of the guides is a key step in the translation from the digital plan to the actual position. This suggests the next aim of this dissertation: "Is the position of prosthesis components on the digital plan the actual position of the components after UKA surgery using PSG?" A prospective single centre CT-based study was conducted; the methodology and results of this study are described in chapter 3 of this dissertation.

Since the guides prove to be accurate in translating the preoperative plan into actual component position in Oxford UKA, and PSG is reliable and safe in primary TKA according to the literature, [4] it might also be helpful in primary UKA surgery, in which at some point three dimensions have to be checked at the same time. The next aim is thus: "Is PSG a useful and reliable tool in positioning the prosthesis components in primary Oxford UKA surgery?" A prospective single-centre study was conducted to compare both radiological and clinical results of UKAs placed in a conventional manner or with PSG. The methodology and results of this study are described in chapter 4 of this dissertation.

\section{The surgeon as a factor in primary UKA surgery}

Despite these innovations, the surgeon still is an important factor in primary UKA surgery. PSG can help position the components properly, but the proximodistal position of 
the femoral component is determined during surgery by ligament balancing. This process is performed by the surgeon. The problem of medial component overstuffing due to a distal position of the femoral component is discussed in a case report. Revision of this component could have been prevented if proper ligament balancing was performed during primary surgery. This case report in chapter 5 stresses the fact that the surgeon is still an important factor in primary UKA surgery.

\section{INNOVATIONS IN UKA TO TKA REVISION SURGERY}

\section{Introduction}

For the majority of patients with medial osteoarthritis of the knee, primary UKA surgery is the end-point in the treatment cascade with good results. For some patients, however, this is not the case. Problems might be present which warrant a next step in treatment, which is often UKA to TKA revision surgery. In these cases, deciding which patient is a good candidate for revision surgery and which is not can be difficult; and so can the technical procedure due to loss of bony landmarks during primary UKA surgery. Both these problems will be addressed in this dissertation.

\section{Decision-making and results in UKA to TKA revision surgery}

As stated above, the results of UKA surgery are good but in some cases revision surgery to TKA has to be performed. According to the literature, loosening is the most common cause for UKA to TKA revision surgery.[2,10,16,14] Other reported causes are bearing dislocation, periprosthetic fractures, progression of osteoarthritis of another knee compartment and anteromedial pain of unknown origin. $[13,25,14]$ This pain is present in some patients after UKA surgery, but often no cause can be identified.[19,25,14] These patients have a good range of motion of the knee. No effusion is present and joint stability is good. Screened radiographs show normal findings, the position of the components is within the limits described by the operation manual. Fixation can be of concern, although radiolucent lines can be present without indicating loosening. The bearing is in the proper position and not luxated, and no periprosthetic fractures are diagnosed. Infection is excluded by laboratory tests and/or aspiration of the joint, and bone scintigraphy shows normal findings depending on the time after primary surgery.

This pain of unknown origin after UKA surgery is thus difficult to treat, since no cause can be identified. $[19,25,14]$ Simpson et al. report that this pain could be caused by changing strains in the tibial bone after insertion of a UKA and that these strains diminish one year postoperative.[23] The mechanism is not yet fully understood, however. The pain can also be related to the prosthesis, other structures in or around the knee joint (e.g. iliotibial tract) or be referred pain from hip or back. Some report that the 
human psyche is also an important factor in the perception of pain.[3] A crucial point in relation to this unknown pain is that it is generated by an anatomic structure we cannot identify (yet). Another phenomenon is the development of chronic post-surgery pain (CPSP) in a number of patients. In attempts to predict CPSP, at least four categories of variables have been investigated: patient characteristics (e.g. age, education, preoperative pain, etc.), preoperative psychological variables (e.g. pain catastrophizing, mood, etc.), operation-related variables (e.g. type of surgery, analgesia, etc.), and genetic factors (e.g. genepolymorphisms), with suggestions of increased risk related to factors from all categories. Some patients complain of this unexpected pain and ask for UKA to TKA revision surgery to solve this problem. The question is whether this revision surgery is the solution for the complaints, and thus our next aim is to answer the question: "Is UKA to TKA revision for anteromedial pain of unknown origin after UKA a successful procedure?" A multicentre retrospective study was performed, which seeks to answer this question. The methodology and results of this study are described in chapter 6 of this dissertation.

\section{Operation technique in UKA to TKA revision surgery}

Regardless of what the indication for revision surgery is, during revision surgery the unicompartmental prosthesis components are removed and a new total knee prosthesis is inserted. As stated above, UKA to TKA revision surgery can be technically demanding, since bony reference points are lost due to the primary UKA surgery.[7,17,19,22] Proper planning can help in these cases. CAS can also aid, but the landmarks that have to be inserted in the computer during surgery are also often removed during primary UKA surgery. In these cases especially, PSG can be beneficial since a larger part of the bone around the knee can be incorporated in the digital plan and the final position of the components can be planned using these other bony landmarks which cannot be seen during surgery. This is a new application of PSG surgery that has not yet been studied nor described in the literature, and the next aim is to evaluate the question: "IS PSG a useful tool in UKA to TKA revision surgery?" A prospective study was conducted which examines PSG in UKA to TKA revision surgery. The methodology and results of this study are described in chapter 7 of this dissertation.

\section{The surgeon as a factor in UKA to TKA revision surgery}

A case report in chapter 8 stresses that also in UKA to TKA revision surgery, the surgeon is still an important factor. The report describes a case in which a UKA is conversed to a TKA using PSG. This surgery was complicated by a vascular lesion, caused by fibrosis around the popliteal artery due to previous surgery. 


\section{CONCLUSION}

This dissertation examines and discusses questions regarding innovations in primary UKA surgery that might have an impact on UKA to TKA revision surgery rates on the one hand, and innovations regarding decision-making, operation technique and results in case of UKA to TKA revision surgery on the other hand. The aims of this dissertation include answering the following questions.

1: "Does cementless Oxford UKA show similar clinical and radiological results when compared to cemented Oxford UKA?"

2: "Is the position of prosthesis components on the digital plan the actual position of the components after UKA surgery using PSG?"

3: "IS PSG a useful and reliable tool in prosthesis component positioning in primary UKA surgery?"

4: "Is the role of the operating surgeon still an important factor in the outcome of primary UKA surgery?"

5: "Is UKA to TKA revision surgery for anteromedial pain of unknown origin after UKA a successful procedure?"

6: "Does PSG aid in demanding cases of UKA to TKA revision surgery?"

7: "Is the role of the operating surgeon still an important factor in the outcome of UKA to TKA revision surgery?" 


\section{REFERENCES}

1. Abhishek A, Doherty M (2013) Diagnosis and clinical presentation of osteoarthritis. Rheum Dis Clin North Am 39 (1):45-66. doi:S0889-857X(12)00119-6 [pii] 10.1016/j.rdc.2012.10.007

2. Aleto TJ, Berend ME, Ritter MA, Faris PM, Meneghini RM (2008) Early failure of unicompartmental knee arthroplasty leading to revision. J Arthroplasty 23 (2):159-163

3. Ayers DC, Franklin PD, Trief PM, Ploutz-Snyder R, Freund D (2004) How preoperative mcs affects postoperative outcome in joint replacement surgery. J Arthroplasty 19:257

4. Boonen B, Schotanus MG, Kort NP (2012) Preliminary experience with the patient-specific templating total knee arthroplasty. Acta orthopaedica 83 (4):387-393. doi:10.3109/17453674.2012.711700

5. Brown GA (2013) Aaos clinical practice guideline: Treatment of osteoarthritis of the knee: Evidencebased guideline, 2nd edition. J Am Acad Orthop Surg 21 (9):577-579. doi:21/9/577 [pii] 10.5435/JAAOS21-09-577

6. Cerejo R, Dunlop DD, Cahue S, Channin D, Song J, Sharma L (2002) The influence of alignment on risk of knee osteoarthritis progression according to baseline stage of disease. Arthritis Rheum 46 (10):26322636. doi:10.1002/art.10530

7. Dudley TE, Gioe TJ, Sinner P, Mehle S (2008) Registry outcomes of unicompartmental knee arthroplasty revisions. Clin Orthop Relat Res 466 (7):1666-1670. doi:10.1007/s11999-008-0279-3

8. Goodfellow JWOC, J. Dodd,C. Murray, D. (2006) Unicompartmental arthroplasty with the oxford knee. Oxford University Press:190

9. Gulati A, Chau R, Pandit HG, Gray H, Price AJ, Dodd CA, Murray DW (2009) The incidence of physiological radiolucency following oxford unicompartmental knee replacement and its relationship to outcome. The Journal of bone and joint surgery 91 (7):896-902. doi:91-B/7/896 [pii] 10.1302/0301-620X.91B7.21914

10. Knight JL, Atwater RD, Guo J (1997) Early failure of the porous coated anatomic cemented unicompartmental knee arthroplasty. Aids to diagnosis and revision. J Arthroplasty 12 (1):11-20

11. Koskinen E, Paavolainen P, Eskelinen A, Pulkkinen P, Remes V (2007) Unicondylar knee replacement for primary osteoarthritis: A prospective follow-up study of 1,819 patients from the finnish arthroplasty register. Acta orthopaedica 78 (1):128-135

12. Lee DC, Byun SJ (2012) High tibial osteotomy. Knee Surg Relat Res 24 (2):61-69. doi:10.5792/ksrr.2012.24.2.61

13. Lewold S, Goodman S, Knutson K, Robertsson O, Lidgren L (1995) Oxford meniscal bearing knee versus the marmor knee in unicompartmental arthroplasty for arthrosis. A swedish multicenter survival study. J Arthroplasty 10 (6):722-731

14. Liddle AD, Judge A, Pandit H, Murray DW (2014) Adverse outcomes after total and unicompartmental knee replacement in 101,330 matched patients: A study of data from the national joint registry for england and wales. Lancet 384 (9952):1437-1445. doi:S0140-6736(14)60419-0 [pii] 10.1016/S01406736(14)60419-0

15. Lisowski LA, van den Bekerom MP, Pilot P, van Dijk CN, Lisowski AE (2010) Oxford phase 3 unicompartmental knee arthroplasty: Medium-term results of a minimally invasive surgical procedure. Knee Surg Sports Traumatol Arthrosc. doi:10.1007/s00167-010-1213-2

16. Mariani EM, Bourne MH, Jackson RT, Jackson ST, Jones P (2007) Early failure of unicompartmental knee arthroplasty. J Arthroplasty 22 (6 Suppl 2):81-84

17. McAuley JP, Engh GA, Ammeen DJ (2001) Revision of failed unicompartmental knee arthroplasty. Clin Orthop Relat Res (392):279-282

18. Murray DW, Goodfellow JW, O'Connor JJ (1998) The oxford medial unicompartmental arthroplasty: A ten-year survival study. The Journal of bone and joint surgery 80 (6):983-989

19. Oduwole KO, Sayana MK, Onayemi F, McCarthy T, O'Byrne J (2009) Analysis of revision procedures for failed unicondylar knee replacement. Irish journal of medical science 179 (3):361-364. doi:DOI 10.1007/s11845-009-0454-x 
20. Pandit H, Jenkins C, Beard DJ, Gallagher J, Price AJ, Dodd CA, Goodfellow JW, Murray DW (2009) Cementless oxford unicompartmental knee replacement shows reduced radiolucency at one year. The Journal of bone and joint surgery 91 (2):185-189. doi:91-B/2/185 [pii] 10.1302/0301-620X.91B2.21413

21. Pandit H, Liddle AD, Kendrick BJ, Jenkins C, Price AJ, Gill HS, Dodd CA, Murray DW (2013) Improved fixation in cementless unicompartmental knee replacement: Five-year results of a randomized controlled trial. J Bone Joint Surg Am 95 (15):1365-1372. doi:1719859 [pii] 10.2106/JBJS.L.01005

22. Saragaglia D, Estour G, Nemer C, Colle PE (2009) Revision of 33 unicompartmental knee prostheses using total knee arthroplasty: Strategy and results. Int Orthop 33 (4):969-974. doi:10.1007/s00264-008-0585-0

23. Simpson DJ, Price AJ, Gulati A, Murray DW, Gill HS (2009) Elevated proximal tibial strains following unicompartmental knee replacement--a possible cause of pain. Med Eng Phys 31 (7):752-757. doi:S13504533(09)00057-5 [pii] 10.1016/j.medengphy.2009.02.004

24. van der Woude JA, Wiegant K, van Heerwaarden RJ, Spruijt S, van Roermund PM, Custers RJ, Mastbergen SC, Lafeber FP (2016) Knee joint distraction compared with high tibial osteotomy: A randomized controlled trial. Knee Surg Sports Traumatol Arthrosc. doi:10.1007/s00167-016-4131-0 10.1007/s00167016-4131-0 [pii]

25. Vardi G, Strover AE (2004) Early complications of unicompartmental knee replacement: The droitwich experience. The Knee 11 (5):389-394

26. Vorlat P, Verdonk R, Schauvlieghe H (2000) The oxford unicompartmental knee prosthesis: A 5-year follow-up. Knee Surg Sports Traumatol Arthrosc 8 (3):154-158 
Cementless versus cemented Oxford unicompartmental knee arthroplasty. Early results of a non-designer user group

B. Kerens, M.G.M. Schotanus, B. Boonen, P. Boog, P.J. Emans, H. Lacroix, N.P. Kort.

Published:

Knee Surg Sports Traumatol Arthrosc. 2016 May 9. [Epub ahead of print] 


\section{ABSTRACT}

Purpose

Although fewer tibial radiolucent lines are observed in cementless Oxford unicompartmental knee arthroplasty (UKA) compared with cemented Oxford UKA, an independent comparative study on this topic is lacking.

\section{Methods}

In this multicentre retrospective study, a cohort of 60 consecutive cases of cementless Oxford UKA is compared with a cohort of 60 consecutive cases of cemented Oxford UKA. Radiolucent lines, survival, perioperative data and clinical results were compared.

\section{Results}

No complete tibial radiolucent lines were observed in either group. 17\% partial tibial radiolucent lines were observed in the cementless group vs. $21 \%$ in the cemented group (n.s.). The percentage of tibial radiolucent zones was $4 \%$ vs. $9 \%$, respectively $(p=0.036)$. Survival rates were $90 \%$ at 34 months for the cementless group and $84 \%$ at 54 months for the cemented group (n.s.) Mean operation time was 10 minutes shorter in the cementless group $(p<0.001)$, and clinical results were not significantly different.

\section{Conclusions}

Although no significant differences in radiolucent lines were found between both groups, they appear to be more common in the cemented group. This confirms previous results from reports by prosthesis designers. The presence of radiolucent lines after cemented Oxford UKA does not correlate with clinical outcome or survival.

\section{Keywords}

Oxford unicompartmental knee arthroplasty, cementless, cemented, radiolucent lines, survival

Level of evidence III 


\section{INTRODUCTION}

Medial unicompartmental knee arthroplasty (UKA) has been shown to have good results in treating medial osteoarthritis of the knee $[12,16,20,22,25]$. Although some studies report good results with cementless fixation, UKA is mostly performed using bone cement $[4,8]$. The major advantage of cemented UKA is that the initial fixation is good, especially for the tibial component. Since this component is flat, the press-fit in cementless fixation is small, which may lead to early component loosening [5]. The first advantage of cementless UKA is that the implant can be positioned on the cut surface without the interposition of cement, which may influence the definitive position due to the thickness of the cement layer [3]. The second advantage is that no complications due to cement remnants posteriorly or as corpora libra can occur [13]. The third advantage is that, in case of revision, it is not necessary to remove the cement that was pressed into the bone trabeculae during primary surgery [14]. A disadvantage of using bone cement is that, in some cases, radiolucent lines are found at the tibial componentbone interface [7]. In patients with aspecific anterior knee pain after UKA, these lines can be (mis)interpreted as a sign of loosening, which can result in unnecessary revision surgery [15]. Cementless fixation, in which the fixation is based on bony ingrowth, can be a solution for this problem. Some studies on cementless UKA report fewer radiolucent lines at the tibial component-bone interface when compared with cemented UKA $[5,10,12,18,19,21,23,24,25]$. Only two of these studies, which were written by prosthesis designers, directly compare cementless UKA with cemented UKA [23,24].

In this study, which was performed to corroborate the reported results in recent literature, radiolucent lines are evaluated under the hypothesis that the number of these lines is smaller in cementless UKA. In addition, revision rates, operation time and clinical outcome are evaluated.

\section{MATERIALS AND METHODS}

After cementless Oxford UKA was introduced in our hospitals (Orbis Medical Center, Sittard, the Netherlands [OMC] and Elkerliek Hospital, Helmond, the Netherlands), two cohorts of 60 Oxford UKA cases were analysed retrospectively. The first cohort consisted of the last 30 consecutive cemented UKA cases in each hospital before the switch to cementless UKA. The second cohort consisted of the first 30 consecutive cementless UKA cases in each hospital after the switch to cementless UKA. In total, 60 cases (59 patients) of cemented UKA and 60 cases (60 patients) of cementless UKA were included. All patients had primary anteromedial osteoarthritis. All patients were operated on by one surgeon in each hospital (NK and $\mathrm{HL}$ ). All patients met the criteria for Oxford medial UKA [6]. Age, height, weight or body mass index were not used as exclusion criteria. Baseline patient demographics (Table 1) as well as intraoperative data were 
obtained from the patient records for all patients in both groups. Since a tourniquet was used during surgery, we also evaluated preoperative and postoperative $\mathrm{Hb}$ levels as an outcome measure of blood loss.

Table 1. Patient demographics.

\begin{tabular}{llll}
\hline & Cementless $(\mathrm{N}=51)$ & Cemented $(\mathrm{N}=61)$ & $P$ value \\
\hline Age (range) years & $62(45-82)$ & $63(46-88)$ & n.s. \\
Gender M:F & $23: 28$ & $32: 29$ & n.s. \\
Side L:R & $27: 24$ & $37: 24$ & n.s. \\
Height (range) $m$ & $1.69(1.52-1.89)$ & $1.70(1.52-1.86)$ & n.s. \\
Weight (range) kg & $82(56-108)$ & $86(52-121)$ & n.s. \\
BMI (range) & $29(20-37)$ & $30(21-42)$ & n.s. \\
\hline
\end{tabular}

The operating procedure was identical in both hospitals and for both the cemented and cementless group. Except for the final fixation, the cementless version was impacted until stable and the cemented version was fixated, after extensive pulsed lavage, using Optipac bone cement (Biomet Orthopaedics Switzerland GmbH, Dietikon, Switzerland). The shape of the tibial cementless prosthesis is identical to the cemented prosthesis except the bottom surface, which has a porous titanium layer with calcium hydroxyapatite coating. The cementless femoral component is also covered with this porous titanium layer with calcium hydroxyapatite coating. Furthermore, it has a cylindrical instead of a conical peg and an additional anterior peg to improve primary fixation when compared with the cemented femoral component. The postoperative treatment was identical in both groups with early full weight-bearing and a hospital admission period of four to five days.

Radiographic evaluation was performed by three independent observers (MS, PB and $B K$ ) on screened radiographs in which the beam of the radiographs is parallel to the flat underside of the tibial component on the AP view and parallel to the flat posterior surface of the femoral component on the lateral view [26]. On these radiographs the bone implant interfaces can be assessed. The tibial bone component interface was assessed on the AP view according to the technique described by Pandit et al. [24]. The interface was divided into six zones. Zone 1: medial part of plateau medial to the keel; zone 2: lateral part of plateau medial to the keel; zone 3: medial vertical surface of the keel; zone 4: below the keel; zone 5: lateral vertical surface of the keel; and zone 6: plateau lateral to the keel. Complete radiolucent lines and partial radiolucent lines were compared. The number of radiolucencies per zone and the total number of radiolucent zones in both groups were also compared. Complete radiolucent lines were defined as radiolucent lines being present in all zones of the tibial component, and partial radiolucent lines were defined as a radiolucent line that was present in one or more, but not in all zones [24]. The lateral, vertical tibial bone component interface is non-weight bearing and was not studied. The posterior femoral bone component interface can be assessed on the lateral 
view. Since the other femoral bone component interface is spherical it cannot be visualised on plain radiographs. Therefore it was not assessed in this study.

Clinical evaluation was performed by an independent observer in each hospital (BK and PB) using the Oxford Knee score (OKS) (0-48, 48 being the best outcome), Womac (0-100, 100 being the best outcome), Knee Society Score (KSS) (0-100, 100 being the best outcome), VAS health status ( $0-100,100$ being the best outcome) and EQ5D (0-1, 1 being the best outcome). Complications during and after the procedure were recorded. A survival analysis with any reoperation as end point as well as a survival analysis with revision to TKA as end point was performed for both groups. No patients were lost to follow-up.

Complications and time after surgery at which the diagnosis of this complication was made are listed per group (Table 2). This table also shows whether revision to TKA was performed and which of these cases were included and excluded for radiological and clinical evaluation.

Table 2. Complications per group with time after primary surgery at which the complication was treated, indication of revision and inclusion in radiological and clinical evaluation.

\begin{tabular}{|c|c|c|c|c|}
\hline \multicolumn{5}{|l|}{ Cementless group } \\
\hline Complication & $\begin{array}{l}\text { Time after surgery } \\
\text { (months) }\end{array}$ & Revision to TKA & $\begin{array}{l}\text { Radiological } \\
\text { evaluation } \\
\text { possible }\end{array}$ & $\begin{array}{l}\text { Clinical } \\
\text { evaluation } \\
\text { possible }\end{array}$ \\
\hline Periprosthetic tibial fracture & 1 & Yes & No & No \\
\hline Tibial loosening & 2 & Yes & No & No \\
\hline Unexplained pain ( $n=2)$ & 18,24 & Yes & No & No \\
\hline Synovitis due to RA & 21 & Yes & No & No \\
\hline \multicolumn{5}{|l|}{ Cemented group } \\
\hline Complication & $\begin{array}{l}\text { Time after surgery } \\
\text { (months) }\end{array}$ & Revision to TKA & $\begin{array}{l}\text { Radiological } \\
\text { evaluation } \\
\text { possible }\end{array}$ & $\begin{array}{l}\text { Clinical } \\
\text { evaluation } \\
\text { possible }\end{array}$ \\
\hline Periprosthetic tibial fracture & 2 & No & No & No \\
\hline Lateral meniscectomy & 11 & No & Yes & Yes \\
\hline Femoral malpositioning & 11 & Yes & No & No \\
\hline Unexplained pain $(n=5)$ & $13,18,24,36,36$ & Yes & No & No \\
\hline $\begin{array}{l}\text { Progression of osteoarthritis } \\
(n=2)\end{array}$ & 20,31 & Yes & No & No \\
\hline Femoral loosening & 24 & No & Yes & Yes \\
\hline Infection & 26 & Yes & No & No \\
\hline Tibial loosening & 36 & Yes & No & No \\
\hline Bearing dislocation & 36 & No & Yes & Yes \\
\hline
\end{tabular}

In the cementless group, two tibial components and eight femoral components were fixed with cement during primary surgery because the operating surgeon had the im- 
pression the bone was of bad quality. This occurred in one tibial case in the OMC and one tibial and eight femoral cases in the Elkerliek hospital. In eight cases a hybrid fixation was thus performed and in one case a totally cemented fixation. The evaluation of clinical data of this last patient was performed within the cemented group, whereas the hybrid cases were not included in the clinical evaluation. Radiographic evaluation of these cemented components was performed within the cemented group. Since five cases underwent revision to TKA, a remaining 46 cementless UKA cases were clinically evaluated. For radiological evaluation 53 cementless tibial components and 47 cementless femoral components were included.

In the cemented group one patient died due to a mesothelioma at 58 months after surgery, and one patient died at 12 months after surgery due to a lung carcinoma. Both patients had a well- functioning UKA until time of death but were not evaluated clinically. The patient with the lung carcinoma was also not evaluated radiologically, since no screened radiographs were made. In the patient with the mesothelioma, however, screened radiographs of the knee were made two years after surgery. For this patient, these were used for the radiographic evaluation. Another two patients were diagnosed with dementia and were therefore not clinically evaluated. Radiographs however were made for these two patients. Thus, a remaining 46 cemented UKA cases were clinically evaluated. For radiological evaluation, radiographs of 50 patients who received a cemented UKA were examined. The eight femoral and two tibial components from the cementless group cemented during primary surgery were added, and in the end 58 cemented femoral and 52 cemented tibial components were evaluated radiographically. IRB approval was obtained at the MEC Atrium-Orbis-Zuyd with log no. 12-N-44.

\section{STATISTICAL ANALYSIS}

Statistical analysis was performed using SPSS version 19. Continuous outcome variables and their difference were tested with parametrical statistical techniques, such as ttests, unless the normality test showed a non-parametric distribution of the data, in which case a Mann-Whitney test was used. Survival was analysed using the Kaplan Meier survival analysis. Significance for survival was calculated using the Generalized Wilcoxon test. Categorical outcome variables were analysed with the chi-squared test. $P$ values $<0.05$ were considered statistically significant.

The power calculation showed that if the experimental and control partial radiolucency rates are in accordance with the literature $[7,23,24]$, we would need to study at least 38 experimental subjects and 38 control subjects to be able to reject the null hypothesis that the radiolucency rate of the experimental and control groups are equal with probability (power) 0.8 . The Type I error probability associated with the test of this null hypothesis is 0.05 . 


\section{RESULTS}

In the cementless ( $\mathrm{N}=47$ ) group, $0(0 \%)$ femoral radiolucent lines were observed; in the cemented ( $N=58$ ) group $5(9 \%)$ femoral radiolucent lines were observed (n.s.). In both groups, partial tibial radiolucent lines were observed but no complete tibial radiolucent lines (Table 3). All observed radiolucent lines were smaller than $2 \mathrm{~mm}$, and all patients with radiolucent lines were asymptomatic. The total number of zones with a radiolucent line was significantly smaller in the cementless group $(p=0.036)$ (Table 3$)$.

Table 3. Incidence of radiolucency of tibia.

\begin{tabular}{|c|c|c|c|}
\hline Radiolucent line tibia & Cementless $(\mathrm{N}=53)$ & Cemented $(\mathrm{N}=52)$ & $P$ value \\
\hline None (n, (\%)) & $44(83)$ & 41 (79) & n.s. \\
\hline Partial (n, (\%)) & $9(17)$ & $11(21)$ & n.s. \\
\hline Complete $(n,(\%))$ & $0(0)$ & $0(0)$ & n.s. \\
\hline Zone 1 (n, (\%)) & $2(4)$ & $6(12)$ & n.s. \\
\hline Zone 2 (n, (\%)) & $2(4)$ & $5(10)$ & n.s. \\
\hline Zone 3 (n, (\%)) & $5(9)$ & $4(8)$ & n.s. \\
\hline Zone 4 (n, (\%)) & $0(0)$ & $1(2)$ & n.s. \\
\hline Zone $5(\mathrm{n},(\%))$ & $1(2)$ & $7(13)$ & 0.031 \\
\hline Zone $6(\mathrm{n},(\%))$ & $4(8)$ & $4(8)$ & n.s. \\
\hline No. of zones (n, (\%)) & $14(4)$ & $27(9)$ & 0.036 \\
\hline
\end{tabular}

Note that in zone 5 more radiolucent lines were found in the cemented group compared to the cementless group and the overall number of radiolucent lines was higher in the cemented group. Only the total number of radiolucent lines in the cemented group was statistically significant compared to the uncemented group.

Operation time was 10 minutes shorter in the cementless group $(p<0.001)$, but other intraoperative data were not significantly different (Table 4). The median follow-up time for the cementless group was 35 months (12-51) and 53 months (26-70) for the cemented group. This difference in follow-up time is statistically significant $(p<0.001)$.

Using any reoperation (Table 2 ) as an endpoint for failure, a survival rate of $90 \%$ at a mean of 34 months of follow up was seen in the cementless group and a survival rate of $77 \%$ at a mean of 54 months of follow up in the cemented group. Using UKA to TKA revision surgery as an endpoint for failure, a survival rate of $90 \%$ at a mean of 34 months of follow up was seen in the cementless group and a survival rate of $84 \%$ at a mean of 54 months of follow up in the cemented group. This is shown in a Kaplan Meier curve (Figure 1). The curves for both groups are not significantly different.

Comparable results in mean outcome of scores were found with a mean OKS of 39 and a KSS of 76 in both groups, a WOMAC of 85 vs. 87, a VAS health status of 75 vs. 72, an EQ 5D of 0.85 vs. 0.82 and a range of motion of 124 vs. 127 for the cementless vs. the cemented group, respectively. The differences were not statistically significant (Table 5). 
Chapter 2

Table 4. Perioperative data.

\begin{tabular}{llll}
\hline & Cementless $(\mathrm{N}=51)$ & Cemented $(\mathrm{N}=61)$ & P value \\
\hline Operation time min (range) & $56(40-99)$ & $66(40-116)$ & $<0.001$ \\
Blood loss ml (range) & $20(0-50)$ & $13(0-100)$ & n.s. \\
HB preoperative mmol/l (range) & $8.9(6.8-10.8)$ & $9.0(7.4-10.3)$ & n.s. \\
HB postoperative mmol/l (range) & $7.7(5.5-9.3)$ & $7.9(6.5-9.5)$ & n.s. \\
HB drop mmol/l (range) & $1.2(0.4-2.8)$ & $1.1(0-2.1)$ & n.s. \\
\hline
\end{tabular}

Table 5. Clinical postoperative results.

\begin{tabular}{llll}
\hline & Cementless $(\mathrm{N}=46)$ & Cemented $(\mathrm{N}=46)$ & P value \\
\hline OKS (range) & $39(10-48)$ & $39(12-48)$ & n.s. \\
KSS (range) & $76(51-100)$ & $76(33-100)$ & n.s. \\
Womac (range) & $85(25-100)$ & $87(24-100)$ & n.s. \\
VAS health status (range) & $75(50-100)$ & $72(0-100)$ & n.s. \\
EQ 5d (range) & $0.85(0.45-1)$ & $0.82(0.19-1)$ & n.s. \\
Range of motion (range) & $124(95-140)$ & $127(110-150)$ & n.s. \\
\hline
\end{tabular}

\section{Survival with revision to TKA as Endpoint}

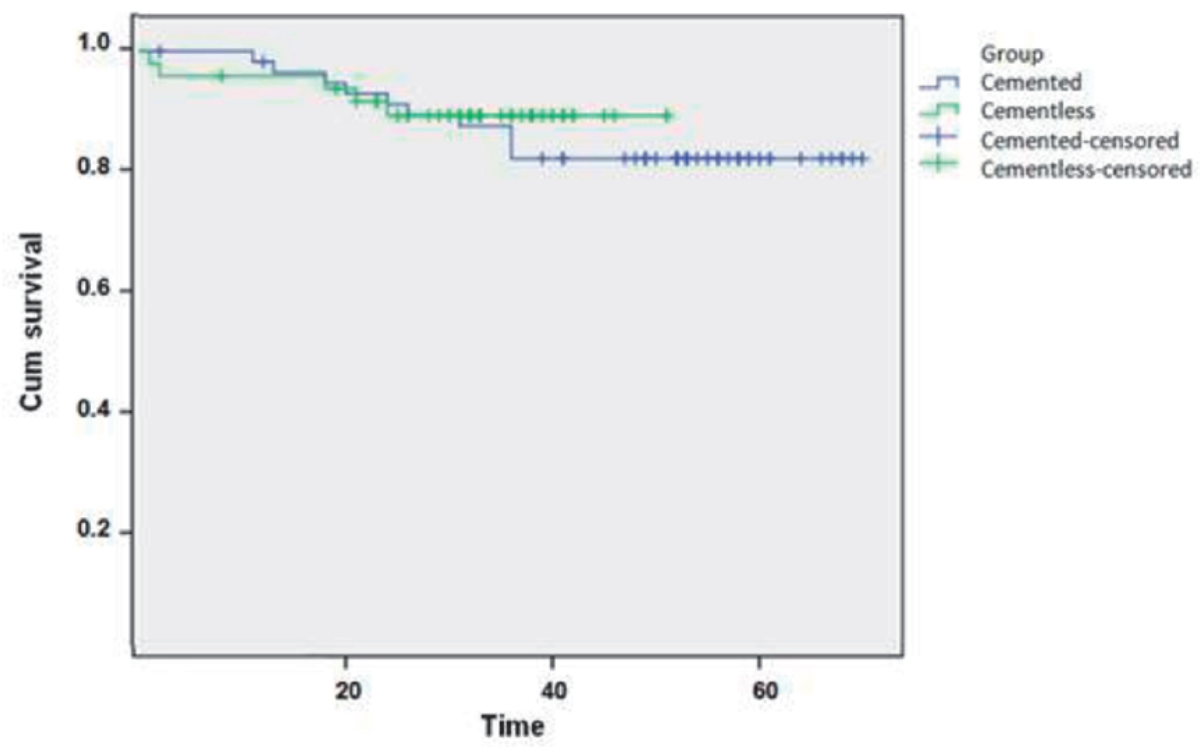

Figure 1. Kaplan Meier curve with UKA to TKA revision surgery as endpoint. 


\section{DISCUSSION}

The most important finding of this study is that our hypothesis that significantly fewer tibial radiolucent lines would be found after cementless Oxford UKA when compared with cemented Oxford UKA was not confirmed. The number of tibial radiolucent zones, however, was significantly smaller in the cementless group. This difference can be explained by the fact that a partial radiolucent line can be due to one zone being radiolucent as well as to all but one zones being radiolucent. In the literature, results are reported in terms of (partial) radiolucent lines. Since according to this definition no significant differences were seen, while the number of radiolucent zones does differ significantly between both groups, the latter result was also reported. In addition, it was found that clinical outcome scores as well as survival rates for both groups are the same. The operation time was shorter in the cementless group.

The 17\% partial and 0\% complete tibial radiolucency rates in the cementless group of our study are slightly larger than in studies by Pandit et al. and Liddle et al., who report $7 \%$ and $9 \%$ partial tibial radiolucency rates, respectively, and a $0 \%$ complete tibial radiolucency rate in both studies $[19,23]$. In the cemented group of our study we found a complete tibial radiolucency in $0 \%$ of cases, whereas reports in the literature show a complete tibial radiolucency rate of about $30 \%[7,23,24]$. The partial tibial radiolucency rate of $21 \%$ is also smaller than reports in the literature by Pandit et al. and Gulati et al. (43\% and $32 \%$, respectively) $[7,23,24]$. Our hypothesis was thus rejected due to the fact that fewer radiolucent lines were found in our cemented group compared with the figures reported in the literature, and not because the results in our cementless group were worse than those reported in the literature.

Regarding the femoral radiolucency rate, a radiolucency rate of $0 \%$ in the cementless group and $9 \%$ in the cemented group is shown by our study, while in the literature no radiolucencies are observed in either group $[19,23,24]$. However, Clarius et al. report that cement interdigitation around the posterior part of the femoral component is often less than expected, since less pressure is present in this zone during cementation [2]. We would thus expect to find studies in the literature describing radiolucent lines at the posterior femoral component bone interface. In all our cases the tibial and femoral radiolucency was not correlated with clinical outcome. This corresponds to findings in the existing literature $[7,11]$.

The reason why the tibial radiolucency rate in the cemented group in our study is smaller than that reported in the literature and why femoral lucencies were found in our study unlike in the recent literature remains unclear. Our screened radiographs were made with the beam of the radiographs parallel to the flat underside of the tibial component on the AP view and parallel to the flat posterior surface of the femoral component on the lateral view, since it is reported that small changes in the direction of the radiographic beam grossly disturb the interpretability of the radiographs $[23,26]$. If wrong radiographic angulation had been the case, however, this would have been 
shown by the projection of the component on the radiograph and a better radiograph would have been made. Furthermore, if this were to be a problem we would expect to observe the same problem in the cementless group, which was not the case. The use of pulse lavage during surgery is also related to radiolucent lines being observed postoperatively [1,3]. Extensive pulse lavage during cemented Oxford UKA was used, but it is expected that others do so as well and thus this parameter cannot used to explain our results. The different follow-up times of both groups could be an issue in the evaluation of radiolucent lines, but according to Pandit et al. the percentage of radiolucent lines does not change significantly between one and five years after UKA surgery [24].

Both surgeons were experienced (each more than 200 cases performed) in cemented Oxford UKA before the inclusion of the first cementless case. However, our study was limited by: (i) A learning-curve effect can be present in the cementless groups, since these were the first cases of cementless Oxford UKA surgery in both hospitals of our study. The fact that some of the prosthesis components in the cementless groups were cemented is due to this learning-curve effect; it is probably a result of the fact that the operating surgeons were unsure about the bone quality needed to receive a cementless component when they just started using these components. Later in our series this uncertainty disappeared, and no more components were cemented. (ii) This is a retrospective study of two cohorts. The patients were not randomized nor matched; rather, cohorts of consecutively performed cases of cemented and cementless Oxford UKA surgery were formed. Since baseline characteristics were not significantly different between both groups, we assume both groups are comparable. Since these cohorts start at different time points, the follow-up time is different for both groups. The higher revision rate in the cemented group can be partially explained by this parameter, especially since the initial part of the Kaplan Meier survival curves for both groups is not significantly different. Our revision rates are higher than those reported by the designer group, but comparable to other independent studies $[9,17,27]$. Another factor in the survival rate is the indication for revision. Pain of unknown origin was the indication for revision in two cases ( $40 \%$ of the revisions) in the cementless group and in five cases (50\% of the revisions) in the cemented group. Recent literature shows, however, that these revisions result in worse outcomes, and it can therefore be questioned whether they should have been performed [15].

This study has two major strengths. (i) This is to our best knowledge the first comparative study by non-designer authors. Other non-designer authors have reported on series of cementless Oxford UKA, but without a cemented control group [10]. Since designers know all the ins and outs of the prosthesis design and usually have had longer experience with the prosthesis, they tend to be more effective in its use. It is important for non-designer groups to report similar results, because this shows that the results reported by the designer group can be extrapolated to all users. (ii) In our study of 120 patients, no patients were lost to follow-up. 
This study shows that the change of cemented Oxford UKA to cementless Oxford UKA surgery can be implemented with good clinical results and a trend to less tibial radiolucent lines.

\section{CONCLUSION}

This study, performed by a non-designer group, confirms the previously reported incidence of radiolucent lines after cementless Oxford UKA. The incidence of tibial radiolucent lines after cemented Oxford UKA in our study is smaller than that reported in the literature, however. The study also shows that cementless Oxford UKA surgery is safe and reliable, with a survival rate comparable to cemented Oxford UKA, and that radiolucent lines do not correlate with clinical outcome.

\section{ACKNOWLEDGEMENTS}

None to be reported.

\section{CONFLICT OF INTEREST}

The authors declare that they have no conflict of interest.

One author (NK) is a paid consultant for Biomet. 


\section{REFERENCES}

1. Clarius M, Hauck C, Seeger JB, James A, Murray DW, Aldinger PR (2009) Pulsed lavage reduces the incidence of radiolucent lines under the tibial tray of Oxford unicompartmental knee arthroplasty: pulsed lavage versus syringe lavage. Int Orthop 33:1585-1590.

2. Clarius M, Mohr G, Jaeger S, Seeger JB, Bitsch RG (2010) Femoral fixation pattern in cemented Oxford unicompartmental knee arthroplasty--an experimental cadaver study. Knee 17:398-402.

3. Dervin GF, Carruthers C, Feibel RJ, Giachino AA, Kim PR, Thurston PR (2011) Initial experience with the oxford unicompartmental knee arthroplasty. J Arthroplasty 26:192-197.

4. Epinette JA, Manley MT (2008) Is hydroxyapatite a reliable fixation option in unicompartmental knee arthroplasty? A 5- to 13-year experience with the hydroxyapatite-coated unix prosthesis. J Knee Surg 21:299-306

5. Forsythe ME, Englund RE, Leighton RK (2000) Unicondylar knee arthroplasty: a cementless perspective. Can J Surg 43:417-424

6. Goodfellow JW, O'Connor JJ, Dodd CA, Murray DW (2006). Unicompartmental arthroplasty with the Oxford Knee First edition. Oxford University Press:190

7. Gulati A, Chau R, Pandit HG, Gray H, Price AJ, Dodd CA, Murray DW (2009) The incidence of physiological radiolucency following Oxford unicompartmental knee replacement and its relationship to outcome. J Bone Joint Surg Br 91:896-902.

8. Hall MJ, Connell DA, Morris HG (2013) Medium to long-term results of the UNIX uncemented unicompartmental knee replacement. Knee 20:328-331.

9. Heller S, Fenichel I, Salai M, Luria T, Velkes S (2009) The Oxford unicompartmental knee prosthesis for the treatment of medial compartment knee disease: 2 to 5 year follow-up. Isr Med Assoc J 11:266-268

10. Hooper GJ, Maxwell AR, Wilkinson B, Mathew J, Woodfield TB, Penny ID, Burn PJ, Frampton C (2012) The early radiological results of the uncemented Oxford medial compartment knee replacement. J Bone Joint Surg $\operatorname{Br}$ 94:334-338.

11. Kendrick BJ, James AR, Pandit H, Gill HS, Price AJ, Blunn GW, Murray DW (2012) Histology of the bonecement interface in retrieved Oxford unicompartmental knee replacements. Knee 19:918-922.

12. Kendrick BJ, Kaptein BL, Valstar ER, Gill HS, Jackson WF, Dodd CA, Price AJ, Murray DW (2015) Cemented versus cementless Oxford unicompartmental knee arthroplasty using radiostereometric analysis: a randomised controlled trial. Bone Joint J 97-B:185-191.

13. Kendrick BJ, Longino D, Pandit H, Svard U, Gill HS, Dodd CA, Murray DW, Price AJ (2010) Polyethylene wear in Oxford unicompartmental knee replacement: a retrieval study of 47 bearings. J Bone Joint Surg $\operatorname{Br}$ 92:367-373.

14. Kerens B, Boonen B, Schotanus M, Kort N (2013) Patient-specific guide for revision of medial unicondylar knee arthroplasty to total knee arthroplasty: beneficial first results of a new operating technique performed on 10 patients. Acta Orthop 84:165-169.

15. Kerens B, Boonen B, Schotanus MG, Lacroix H, Emans PJ, Kort NP (2013) Revision from unicompartmental to total knee replacement: the clinical outcome depends on reason for revision. Bone Joint J 95-B:12041208.

16. Koskinen E, Paavolainen P, Eskelinen A, Pulkkinen P, Remes V (2007) Unicondylar knee replacement for primary osteoarthritis: a prospective follow-up study of 1,819 patients from the Finnish Arthroplasty Register. Acta Orthop 78:128-135

17. Labek G, Sekyra K, Pawelka W, Janda W, Stockl B (2011) Outcome and reproducibility of data concerning the Oxford unicompartmental knee arthroplasty: a structured literature review including arthroplasty registry data. Acta Orthop 82:131-135.

18. Liddle AD, Pandit H, Murray DW, Dodd CA (2013) Cementless unicondylar knee arthroplasty. Orthop Clin North Am 44:261-269. 
19. Liddle AD, Pandit H, O'Brien S, Doran E, Penny ID, Hooper GJ, Burn PJ, Dodd CA, Beverland DE, Maxwell AR, Murray DW (2013) Cementless fixation in Oxford unicompartmental knee replacement: a multicentre study of 1000 knees. Bone Joint J 95-B:181-187.

20. Lisowski LA, van den Bekerom MP, Pilot P, van Dijk CN, Lisowski AE (2011) Oxford Phase 3 unicompartmental knee arthroplasty: medium-term results of a minimally invasive surgical procedure. Knee Surg Sports Traumatol Arthrosc 19:277-284.

21. Magnussen PA, Bartlett RJ (1990) Cementless PCA unicompartmental joint arthroplasty for osteoarthritis of the knee. A prospective study of 51 cases. J Arthroplasty 5:151-158

22. Murray DW, Goodfellow JW, O'Connor JJ (1998) The Oxford medial unicompartmental arthroplasty: a ten-year survival study. J Bone Joint Surg $\mathrm{Br}$ 80:983-989

23. Pandit H, Jenkins C, Beard DJ, Gallagher J, Price AJ, Dodd CA, Goodfellow JW, Murray DW (2009) Cementless Oxford unicompartmental knee replacement shows reduced radiolucency at one year. J Bone Joint Surg $\mathrm{Br}$ 91:185-189.

24. Pandit H, Liddle AD, Kendrick BJ, Jenkins C, Price AJ, Gill HS, Dodd CA, Murray DW (2013) Improved fixation in cementless unicompartmental knee replacement: five-year results of a randomized controlled trial. J Bone Joint Surg Am 95:1365-1372.

25. Pandit HG, Campi S, Hamilton TW, Dada OD, Pollalis S, Jenkins C, Dodd CA, Murray DW (2015) Five-year experience of cementless Oxford unicompartmental knee replacement. Knee Surg Sports Traumatol Arthrosc. (e-pub ahead of print) doi:10.1007/s00167-015-3879-y10.1007/s00167-015-3879-y

26. Tibrewal SB, Grant KA, Goodfellow JW (1984) The radiolucent line beneath the tibial components of the Oxford meniscal knee. J Bone Joint Surg Br 66:523-528

27. Zermatten P, Munzinger $U$ (2012) The Oxford II medial unicompartmental knee arthroplasty: an independent 10-year survival study. Acta Orthop Belg 78:203-209 



\section{Chapter}

Patient-specific guiding for Oxford UKA surgery is accurate. A prospective CT-based shape matching study

B. Kerens, M.G.M. Schotanus, B. Boonen, W.E. Tuinebreijer, P.J. Emans, and N.P. Kort.






\begin{abstract}
Purpose

Patient-specific guiding (PSG) is a technique to plan and position the prosthesis components in unicompartmental knee arthroplasty (UKA) surgery. This study assesses whether the definitive component position in the frontal, sagittal and axial plane is according to the preoperative plan, based on the hypothesis that PSG is accurate.
\end{abstract}

\title{
Methods
}

Twenty-six cases undergoing PSG Oxford UKA surgery were included prospectively. The component position in vivo was compared with the planned component position using CT scan-based digital 3D imaging. Adjustments of the plan in the planning phase and during surgery were recorded.

\section{Results}

The femoral and tibial default plan were changed four times (15\%) and nine times (35\%), respectively, before approval by the surgeon. Intraoperatively, no femoral adjustments were performed; twelve tibial recuts were necessary. The mean absolute deviation from the plan in degrees (SD) in the frontal, sagittal and axial plane was $2.5^{\circ}$ (SD 2.1), $2.8^{\circ}$ (SD 2.2) and $1.3^{\circ}$ (SD 0.9) for the femoral component, and $2.7^{\circ}$ (SD 1.6), $2.9^{\circ}$ (SD 1.3) and $5.7^{\circ}$ (SD 3.7) for the tibial component. The femoral component is positioned 0.6 (0.9) $\mathrm{mm}$ more lateral and 0.4 (1.0) $\mathrm{mm}$ more anterior. The tibial component is positioned $1.4(1.7) \mathrm{mm}$ more lateral and 0.5 (1.5) $\mathrm{mm}$ more distal.

\section{Conclusion}

PSG in Oxford UKA surgery is reliable and accurately translates the preoperative plan into the in vivo situation. The preoperative planning is a crucial step in avoiding recuts that can cause angular deviations in prosthesis position, especially in tibial component rotational position, in vivo compared with the plan. It is advised to avoid recuts and to consider this while planning your PSG procedure. 


\section{INTRODUCTION}

Unicompartmental knee arthroplasty (UKA) is a successful operative procedure with good survival rates $[9,10]$. Several techniques for outlining the prosthesis currently exist. New techniques that try to optimise both the operative procedure itself and the accuracy of prosthesis alignment are still being introduced [5,6]. A relatively new development is the use of patient-specific guides (PSG) to determine the appropriate 3-dimensional resections of femur and tibia in preparation of prosthesis placement $[8,11]$. In total knee arthroplasty (TKA), a direct comparison study shows that the guides act accurateIy[1]. To our knowledge, no studies have yet been conducted concerning UKA surgery to directly compare the preoperative plan with the ultimate position of the prosthesis in vivo in order to assess the accurateness of the guides themselves. We analysed the Signature $^{\mathrm{TM}}$ (Zimmer-Biomet, Warsaw, IN, USA) system that was used together with the Oxford unicompartmental knee prosthesis (Zimmer-Biomet Ltd, Bridgend, UK). In this study, it was hypothesised that there is no significant difference between the preoperative plan and the actual position of the prosthesis components in vivo by comparing CT images after surgery with the MRI-based preoperative plan.

\section{MATERIALS AND METHODS}

A prospective cohort study was performed after obtaining approval by the local ethics committee. A sample size calculation showed that 26 cases had to be included in order to reject the null hypothesis that no difference between preoperative plan and postoperative position exists with a power of 0.8 and an alfa of 0.05 .

Inclusion criteria were: painful and disabled knee joint resulting from unicompartmental medial osteoarthritis; fulfilling the criteria for primary Oxford UKA surgery[2]; body-mass-index (BMI) <39; ability and willingness to follow instructions and to return for follow-up evaluations. Exclusion criteria were: failure of previous joint replacement; pregnancy; previous major knee surgery, except for arthroscopic meniscectomy; metal near knee joint (MRI scan not possible); not able or willing to undergo MRI scan or CT scan. After obtaining informed consent, 26 knees in 25 patients were consecutively recruited.

All patients were operated on by a single surgeon (NK) with extensive experience in conventional as well as PSG-based cementless Oxford UKA surgery.

Patient demographics can be found in Table 1.

Preoperative MRI scanning of the hip, knee and ankle was performed six weeks prior to surgery according to the standard Signature scanning protocol. A digital, virtual plan of the operation to be performed was sent to the surgeon. The surgeon was able to adjust the digital plan satisfactorily and the changes in the plan by the surgeon regarding size and position of the implant were recorded. All plans were evaluated and approved by the operating surgeon. After the digital plan was approved, guides for in- 
traoperative use were created using a rapid prototype engineering technique (Materialise N.V., Leuven, Belgium). All patients were operated on using these guides and intraoperatively. The practical form and fit of the guides was registered as were potential changes to this plan during surgery.

Table 1. Patient demographics.

\begin{tabular}{ll}
\hline No. of patients & 26 \\
\hline Mean age at time of surgery (range) years & 62 \\
Male:Female & $15: 11$ \\
Left:Right & $10: 16$ \\
Mean length at time of surgery (range) $m$ & $1,76(1,57$ to 1,91$)$ \\
Mean weight at time of surgery (range) $\mathrm{kg}$ & $89(50$ to 132$)$ \\
Mean BMI at time of surgery (range) & 28 (19 to 38) \\
HKA angle before surgery (range) degrees varus & 5 (0 to 11) \\
\hline
\end{tabular}

In order to define the difference between the component position in the preoperative digital plan and postoperative component position actually achieved, a postoperative full-leg CT scan has to be compared with the digital plan based on the preoperative MRI scan. However, direct comparison between the preoperative MRI scan and the postoperative CT scan is difficult and inaccurate as the MRI scan is a only a local knee scan and postoperative matching would therefore be difficult since a great many reference points disappear with prosthesis placement. A preoperative full-leg CT scan (using the same scanning protocol as the postoperative full leg CT scan) was made in addition to the preoperative MRI scan to serve as an intermediate step in the registration process. The MRI images could be matched to the preoperative CT images as digital 3D models of both scans were generated for the femur and tibia using software from Materialise NV (Materialise NV, Leuven, Belgium). This type of 3D registration renders the results independent of scan orientation and leg position during scanning. After surgery, 3D reconstruction images of the postoperative $\mathrm{CT}$ scan could be superimposed over the preoperative CTscan images with pre-planned cuts and prosthesis placement (Figure 1 and 2). This could be accurately performed as these scans were made using the exact same scanning protocol and differ only in the implant region. As such, an accurate comparison could be made between preoperatively planned resections and prosthesis placement and ultimate resections and placement in vivo. The accuracy of this measuring technique is within 0.5 degrees [3]. Angular component position and absolute deviations of angular component position in three planes in pre-op planning were thus determined as well as the translational component position along the three axes of the bone and absolute deviations of the planned translational component position.

The planned position for the femoral component was 0 degrees varus relative to the mechanical frontal axis of the femur, 10 degrees of flexion relative to the mechanical sagittal axis of the femur and 3 degrees of exorotation relative to the transepicondylar 
axis. For the femoral component, the accepted deviations from the planned position according to the prosthesis manufacturer are -10 to +10 degrees in the frontal plane, 10 to +5 in the sagittal plane and -5 to +5 in the axial plane. The planned position of the tibial component was 0 degrees of varus relative to the frontal tibial mechanical axis, 3 degrees of posterior slope relative to the sagittal tibial mechanical axis and 0 degrees of exorotation relative to the line perpendicular to the line through the centre of the medial and lateral tibial plateau. For the tibial component, the accepted deviations from the planned position according to the prosthesis manufacturer are -5 to +5 degrees in the frontal plane, -5 to +5 in the sagittal plane and -5 to +5 in the axial plane.



Figure 1. Femoral 3D image of definitive position superimposed on preoperative plan.

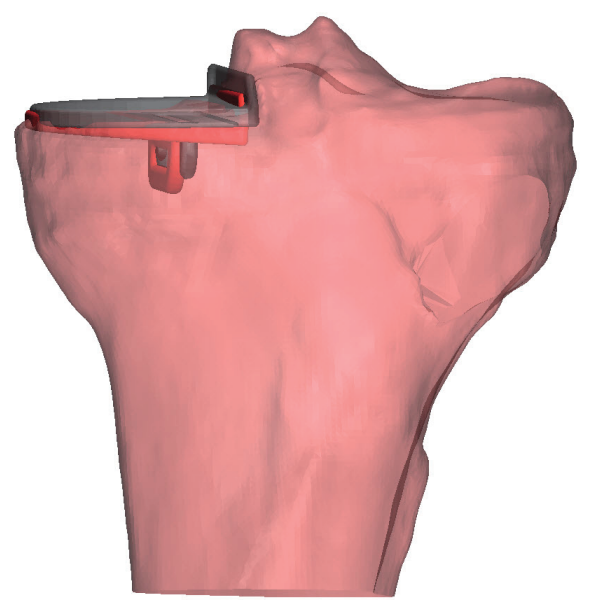

Figure 2. Tibial 3D image of definitive position superimposed on preoperative plan. 
Positive values indicate varus, femoral flexion, posterior tibial slope and exorotation, whereas negative values indicate valgus, femoral extension/anterior tibial slope and endorotation deviations relative to the preoperatively calculated position. For the translation component, positive values indicate anterior translation, lateral translation and distal translation, whereas negative values indicate posterior translation, medial translation and proximal translation. The accepted deviations from the planned position were set arbitrary from $+2 \mathrm{~mm}$ to $-2 \mathrm{~mm}$ since no references in literature concerning this issue are present. Finally, the actual size of the inserted femoral components and tibial components were compared with the preoperative planned sizes.

In order to evaluate the translational accuracy of the guides, extra recuts performed during surgery were used to recalculate the position of the primary cut, which was determined by the guide.

IRB approval was obtained at the METC Atrium-Orbis-Zuyd with log no. 12-T-92.

\section{STATISTICS}

Statistical analysis was performed with SPSS (IBM SPSS Statistics, Version 23. Armonk, NY: IBM Corp.). Means, standard deviations (SD), confidence intervals (CI), ranges and percentage outliers were determined for the difference between pre-op planning and postoperative values for all three anatomical planes. Equivalence testing was performed in two ways. First, by examining if the entire $90 \% 2$-sided $\mathrm{Cl}$ of the mean deviation was in the estimated equivalence margin. Secondly, by determining the P-value for equivalence testing with two one-sided t-tests (TOSTs). In this analysis the null hypotheses $(\mathrm{HO})$ states that the deviation is not equivalent to the estimated margin (deviation is $\leq$ or $\geq$ margin), and the alternative hypothesis $(\mathrm{H} 1)$ states that they are equivalent (between the margins). When the $\mathrm{HO}$ is rejected, the conclusion may be that the $\mathrm{H} 1$ is true.

\section{RESULTS}

\section{-Adjustments default plan before approval}

The default plan of the femoral component, which was made by an engineer and a computer, was changed four times (15\%) by the surgeon before approval and thus before fabrication of the guides. An increase of one step in component size was made twice, and a decrease in component size of one step was also made twice. In these cases, the planned posterior cut was also adjusted automatically to fit the newly planned component size. No other adjustments to the default plan were made by the surgeon before approval regarding position, angulation or rotation of the femoral components. 
The default plan of the tibial component, which was also made by computer and engineer, was changed nine times (35\%) by the surgeon before approval. An increase of one step in component size was made seven times (to guarantee maximal support by the tibial bone) and a decrease of one step in component size was made twice. These changes in component size were also associated with changes in resection level and mediolateral component positioning. No other adjustments to the default plan were made by the surgeon before approval regarding position, angulation or rotation of the tibial components.

\section{-Guide fit during surgery}

All femoral guides and all but one tibial guide fitted well onto the native anatomy of the individual patients and no conversions to traditional alignment techniques had to be performed. The tibial guide that could not be placed in the $100 \%$ fit position was held in the best possible position by pushing the guide laterally on the pressure point of the guide at the time of pin drilling. No complications were encountered when drilling the guide pins and fixing the cutting blocks.

\section{-Adjustments during surgery relative to the approved plan}

In no case $(0 \%)$ was a change in femoral component size made; in eight cases $(31 \%)$ a change in tibial component size (one size smaller in six cases and two sizes smaller in two cases) was made.

No extra posterior femoral resections were necessary. In six cases an additional proximal tibial resection of $2 \mathrm{~mm}$ was performed. In three cases an additional tibial cut towards lateral was performed (twice $1 \mathrm{~mm}$ and once $2 \mathrm{~mm}$ ). A combination of these two additional resections was performed twice (once $2 \mathrm{~mm}$ extra tibia with $1 \mathrm{~mm}$ extra towards lateral and once $2 \mathrm{~mm}$ extra tibia with $2 \mathrm{~mm}$ towards lateral). Finally in one patient (the patient in which the tibial guide did not fit well) an additional $2 \mathrm{~mm}$ of proximal tibia was resected, but the slope was also increased. In this case, the tibial cutting block was repositioned using the conventional technique. These 12 cases of additional tibial resection resulted in five cases of tibial implant size change and in seven cases without implant size change relative to the approved plan.

In all but two cases, a meniscal bearing with a thickness of three was used (once 4 and once 5).

- Results of the angular measurements for the femoral and tibial component are summarised in Table 2 and 3. All angular positions were statistically not significantly different than planned except for the femoral component in the sagittal plane and the tibial component in the axial plane. 
- Results of the translational measurements of the femoral and tibial component are summarised in Table 4 and 5. All translational positions are statistically not significantly different than planned.

Table 2. Femoral angular results in degrees.

\begin{tabular}{|c|c|c|c|}
\hline Femur & Frontal plane & Sagittal plane & Transverse plane \\
\hline $\begin{array}{l}\text { Mean absolute deviation from pre-op } \\
\text { planning (SD) }\end{array}$ & $2.5^{0}(2.2)$ & $2.8^{0}(2.2)$ & $1.3^{0}(0.9)$ \\
\hline $\begin{array}{l}\text { Mean deviation from pre-op planning } \\
\text { (SD) }\end{array}$ & $2.2^{0}(2.5)$ & $0.6^{0}(3.6)$ & $0.8^{0}(1.3)$ \\
\hline 90\% Confidence interval ( $\mathrm{Cl}$ ) for mean & $1.3 ; 3.0$ & $-0.6 ; 1.8$ & $0.4 ; 1.3$ \\
\hline Planned position & $0^{0}$ & $10^{\circ}$ & $3^{0}$ \\
\hline Equivalence margins & $-10 ;+10$ & $0 ;+15$ & $-2 ;+8$ \\
\hline Is entire $\mathrm{Cl}$ within equivalence range? & Yes & $\begin{array}{l}\text { No, lower bound of } \mathrm{Cl} \text { is below } \\
\text { equivalence margin }\end{array}$ & Yes \\
\hline$P$ value equivalence testing ${ }^{* * *}$ & $\begin{array}{l}<10<0.001 \\
>10<0.001\end{array}$ & $\begin{array}{l}<0<0.196 \\
>15<0.001\end{array}$ & $\begin{array}{l}<-2<0.001 \\
>8<0.001\end{array}$ \\
\hline Range & $-1.5^{0} ; 6.5^{0}$ & $-6.5^{0} ; 8^{0}$ & $-1.5^{0} ; 5^{0}$ \\
\hline$\%$ Outliers & 0 & 0 & 0 \\
\hline
\end{tabular}

"When entire $\mathrm{Cl}$ of the mean deviation is in the equivalence range, equivalence can be inferred.

${ }^{* *}$ Mean is in $\mathrm{Cl}$, but $\mathrm{Cl}$ is not within equivalence margin on one side: inconclusive evidence of equivalence.

${ }^{* * *}$ P-value for equivalence tests with two one-sided tests (TOSTS). If both tests are rejected, the nonequivalence hypothesis is rejected, and the alternative hypothesis is concluded at the 0.05 significance level. The frontal axis represents varus/valgus deviation with positive values, indicating varus. The sagittal axis represents flexion/extension deviation with positive values, indicating flexion. The coronal axis represents exorotation/endorotation deviation with positive values, indicating exorotation. 
Table 3. Tibial angular results in degrees.

\begin{tabular}{|c|c|c|c|}
\hline Tibia & Frontal plane & Sagittal plane & Transverse plane \\
\hline $\begin{array}{l}\text { Mean absolute deviation from pre-op } \\
\text { planning (SD) }\end{array}$ & $2.7^{0}(1.6)$ & $2.9^{0}(1.3)$ & $5.7^{0}(3.7)$ \\
\hline Mean deviation from pre-op planning (SD) & $2.6^{0}(1.7)$ & $2.8^{0}(1.5)$ & $4.4^{0}(5.2)$ \\
\hline 90\% Confidence interval ( $\mathrm{Cl}$ ) for mean & $2.0 ; 3.2$ & $2.3 ; 3.3$ & $2.6 ; 6.1$ \\
\hline Planned position & $0^{0}$ & $3^{0}$ & $0^{0}$ \\
\hline Equivalence margins & $-5 ;+5$ & $-2 ;+8$ & $-5 ;+5$ \\
\hline Is entire $\mathrm{Cl}$ within equivalence range?* & Yes & Yes & $\begin{array}{l}\text { No, upper bound of } \mathrm{Cl} \text { is above } \\
\text { equivalence margin }\end{array}$ \\
\hline$P$ value equivalence testing ${ }^{* * *}$ & $\begin{array}{l}<-5<0.001 \\
>5<0.001\end{array}$ & $\begin{array}{l}<-2<0.001 \\
>8<0.001\end{array}$ & $\begin{array}{l}<-5<0.001 \\
>5<0.271\end{array}$ \\
\hline Range & $-1^{0} ; 6^{0}$ & $-1^{0} ; 5^{0}$ & $-6.5^{0} ; 12.5^{0}$ \\
\hline Outliers & $>+5^{0} 3.8 \%$ & 0 & $<-5^{0} 3.8 \% ;>+5^{0} 46.1 \%$ \\
\hline
\end{tabular}

*When entire $\mathrm{Cl}$ of the mean deviation is in the equivalence range, equivalence can be inferred.

${ }^{* *} \mathrm{Mean}$ is in $\mathrm{Cl}$, but $\mathrm{Cl}$ is not within equivalence margin on one side: inconclusive evidence of equivalence.

${ }^{* * *}$ P-value for equivalence tests with two one-sided tests (TOSTS). If both tests are rejected, the nonequivalence hypothesis is rejected, and the alternative hypothesis is concluded at the 0.05 significance level. The frontal axis represents varus/valgus deviation with positive values, indicating varus. The sagittal axis represents flexion/extension deviation with positive values, indicating posterior slope. The coronal axis represents exorotation/endorotation deviation with positive values, indicating exorotation.

Table 4. Femoral translational results in $\mathrm{mm}$.

\begin{tabular}{lll}
\hline Femur & X axis & Z axis \\
\hline Mean absolute deviation from pre-op planning (SD) & $0.8(0.6)$ & $0.8(0.8)$ \\
Mean deviation from pre-op planning (SD) & $0.6(0.9)$ & $0.4(1.0)$ \\
$90 \%$ Confidence interval (Cl) for mean deviation & $0.3 ; 0.8$ & $0.02 ; 0.7$ \\
Equivalence margins & $-2 ;+2$ & $-2 ;+2$ \\
Is entire Cl within equivalence range?* & Yes & Yes \\
P-value equivalence testing & $<-2<0.001 ;$ & $<-2<0.001 ;$ \\
& $>2<0.001$ & $>2<0.001$ \\
Range & $-1 ; 2.5$ & $-1 ; 2.5$ \\
Outliers & $>+2.3 .8 \%$ & $>+2.7 .7 \%$ \\
\hline
\end{tabular}

*When entire $\mathrm{Cl}$ of the mean deviation is in the equivalence range, equivalence can be inferred.

${ }^{* * *}$ P-value for equivalence tests with two one-sided tests (TOSTS). If both tests are rejected, the nonequivalence hypothesis is rejected, and the alternative hypothesis is concluded at the 0.05 significance level. The $X$ axis represents mediolateral deviation with positive values, indicating lateral translation. The $Z$ axis represents anteroposterior deviation with positive values, indicating increased posterior cut. 
Table 5. Tibial translational results in $\mathrm{mm}$.

\begin{tabular}{|c|c|c|c|c|}
\hline \multirow{2}{*}{$\begin{array}{l}\text { Tibia } \\
\text { Mean absolute deviation from } \\
\text { pre-op planning (SD) }\end{array}$} & \multirow{2}{*}{$\frac{X \text { axis }}{1.9(1.2)}$} & \multirow{2}{*}{$\begin{array}{l}\text { Y axis } \\
1.5(1.6)\end{array}$} & \multicolumn{2}{|c|}{$\mathrm{X}$ axis. corrected $\mathrm{Y}$ axis. corrected } \\
\hline & & & $1.8(1.2)$ & $1.2(1.1)$ \\
\hline $\begin{array}{l}\text { Mean deviation from pre-op } \\
\text { planning (SD) }\end{array}$ & $-1.9(1.2)$ & $1.2(1.8)$ & $-1.4(1.7)$ & $0.5(1.5)$ \\
\hline $\begin{array}{l}90 \% \text { Confidence interval }(\mathrm{Cl}) \\
\text { for mean deviation }\end{array}$ & $-2.3 ;-1.4$ & $0.6 ; 1.8$ & $-1.9 ;-0.8$ & $0.03 ; 1.1$ \\
\hline Equivalence margins & $-2 ;+2$ & $-2 ;+2$ & $-2 ;+2$ & $-2 ;+2$ \\
\hline $\begin{array}{l}\text { Is entire } \mathrm{Cl} \text { within equivalence } \\
\text { range? }\end{array}$ & $\begin{array}{l}\text { No, lower bound of } \mathrm{Cl} \text { is below } \mathrm{Y} \\
\text { equivalence margin }\end{array}$ & Yes & Yes & Yes \\
\hline$P$ value equivalence testing ${ }^{* * *}$ & $\begin{array}{l}<-2<0.293 \\
>2<0.001\end{array}$ & $\begin{array}{l}<-2<0.001 \\
>2<0.020\end{array}$ & $\begin{array}{l}<-2<0.036 \\
>2<0.001\end{array}$ & $\begin{array}{l}<-2<0.001 \\
>2<0.001\end{array}$ \\
\hline Range & $-5 ; 0$ & $-3 ; 6$ & $-5 ; 1.5$ & $-3 ; 4$ \\
\hline$\%$ Outliers & $<-2.42 .3 \%$ & $\begin{array}{l}<-2.3 .8 \% ;> \\
+2.26 .9 \%\end{array}$ & $<-2.38 .5 \%$ & $\begin{array}{l}<-2.3 .8 \% \\
>+2.11 .5 \%\end{array}$ \\
\hline
\end{tabular}

\footnotetext{
"When entire $\mathrm{Cl}$ of the mean deviation is in the equivalence range, equivalence can be inferred.

${ }^{* *}$ Mean is in $\mathrm{Cl}$, but $\mathrm{Cl}$ is not within equivalence margin on one side: inconclusive evidence of equivalence.

${ }^{* * *}$ P-value for equivalence tests with two one-sided tests (TOSTS). If both tests are rejected, the nonequivalence hypothesis is rejected, and the alternative hypothesis is concluded at the 0.05 significance level.

The $X$ axis represents mediolateral deviation with positive values, indicating lateral translation. The $Y$ axis represents proximodistal deviation with positive values, indicating increased cut.
}

\section{DISCUSSION}

A statistical significant difference between actual position and planned position is present for the sagittal plane of the femoral component and for the axial plane of the tibial component. For the femoral component, this statistical difference is due to the larger than expected standard deviation. Despite this larger standard deviation, no outliers are present and all components are within the accepted limits. The results thus confirm the hypothesis that the actual prosthesis component position is according to the preoperative plan and that the guides accurately translate the preoperative plan into the in vivo situation except for the tibial rotational position.

The femoral guide works well in particular since the contact area is large and a perfect fit can be found easily. For the tibial guide the contact area is smaller and attention should be addressed to lateral osteofytes of the medial femoral condyl since they can push the guide into exorotation out of the perfect fit position. Another factor that influences tibial component rotation is a re-cut of the lateral wall in cases where medial overhang of the plateau is present since this re-cut is not performed with a slotted device. To prevent this re-cut, it is important to plan the tibial component in a rather lateral position. The third factor concerning tibial rotation is that the definitive rotation- 
al position is not only determined by the lateral cut but also by the cut for the keel, which is made through the test plateau. The optimal position of this test plateau is not always parallel with the lateral cut, but depends on the medial tibial contour as well. This can explain the rotational difference between the planned and definitive tibial component position. The statistical difference for the tibial rotational component between definitive position and planned position thus cannot be attributed to the guide solely.

Since the bearing size depends on intra-operative ligament balancing and the definitive axial position of the tibial component, the size of the bearing could not be planned preoperatively. The $\mathrm{Y}$ axis position of the femoral component also depends on ligament balancing and is not preoperatively planned but determined during surgery using the spigot and spherical mill. Finally, the $Z$ axis position of the tibial component is not planned but defined during surgery by placing the test plateau more anterior or posterior in the best position.

The horizontal cut for the tibial component also determines the size of the bearing. In order to have the required space to insert a bearing with minimal thickness of $3 \mathrm{~mm}$ we had to perform a horizontal re-cut of the proximal tibia of 2 extra $\mathrm{mm}$ in eight cases. With these re-cuts, the final prosthesis components could be placed in the proper position. Since the translation of the plan into the definite position was good, the re-cut cases indicate that these tibial components were not planned in the perfect position to provide sufficient space for a bearing of three. In order to prevent distal recut, which is not slotted and can thus cause angular deviations, in the future, it is important to plan the tibial component in a rather distal position. These recuts explain the need for changes in tibial component size in our cases.

The one case in which the guide did not fit well stresses the importance of the expertise and training of the surgeon. A possible cause for an ill-fitting guide can be soft tissue that is not removed properly and interferes with guide contact points. Another possible cause can be femoral osteofytes as previously discussed. Since the time between MRI planning and actual operation was not more than two months, a progression of anatomic deformity as a cause for bad guide fit is not likely. A final influence on guide fitting is the segmentation of the MRI images. In this process of segmentation, each pixel on the image is identified as bone, cartilage or soft tissue. This process is performed by a human engineer and not by computer. Theoretically, mistakes made during this process can explain bad guide fit. In retrospect, this was not the cause in our case since re-evaluation of the segmentation in individual cases was performed and found to be correct. 


\section{CONCLUSION}

PSG in Oxford UKA surgery is reliable and accurately translates the preoperative plan into the in vivo situation. The preoperative planning is a crucial step in avoiding recuts that can cause angular deviations in prosthesis position in vivo compared with the plan. It is advised to prevent recuts and to consider this while planning your PSG procedure.

\section{CONFLICT OF INTEREST}

One author (NK) is a paid consultant for Zimmer-Biomet. The other authors have no conflict of interest to be reported.

\section{AUTHORS' CONTRIBUTION}

BK participated in the design of the study, acquisition of data and writing of the manuscript. MS participated in the design of the study and acquisition of data and helped to draft the manuscript. BB participated in the design of the study and helped to draft the manuscript. WT participated in the statistical analysis and helped to draft the manuscript. PE participated in the design of the study and helped to draft the manuscript. NK participated in the design of the study and helped to draft the manuscript. All authors read and approved the final manuscript. 


\section{REFERENCES}

1. Boonen B, Schotanus MG, Kerens B, Hulsmans FJ, Tuinebreijer WE, Kort NP (2015) Patient-specific positioning guides for total knee arthroplasty: no significant difference between final component alignment and pre-operative digital plan except for tibial rotation. Knee Surg Sports Traumatol Arthrosc. doi:10.1007/s00167-015-3661-1

2. Goodfellow JWOC, J. Dodd,C. Murray, D. (2006) Unicompartmental arthroplasty with the Oxford Knee. Oxford University Press:190

3. Hirschmann MT, Konala P, Amsler F, Iranpour F, Friederich NF, Cobb JP (2011) The position and orientation of total knee replacement components: a comparison of conventional radiographs, transverse 2D-CT slices and 3D-CT reconstruction. J Bone Joint Surg Br 93:629-633. 10.1302/0301620X.93B5.25893

4. Hooper N, Snell D, Hooper G, Maxwell R, Frampton C (2015) The five-year radiological results of the uncemented Oxford medial compartment knee arthroplasty. Bone Joint J 97-B:1358-1363. 10.1302/0301-620X.97B10.35668

5. Jenny JY, Boeri C (2003) Unicompartmental knee prosthesis implantation with a non-image-based navigation system: rationale, technique, case-control comparative study with a conventional instrumented implantation. Knee Surg Sports Traumatol Arthrosc 11:40-45.

6. Jung KA, Kim SJ, Lee SC, Hwang SH, Ahn NK (2010) Accuracy of implantation during computer-assisted minimally invasive Oxford unicompartmental knee arthroplasty: a comparison with a conventional instrumented technique. Knee 17:387-391.

7. Kendrick BJ, Kaptein BL, Valstar ER, Gill HS, Jackson WF, Dodd CA, Price AJ, Murray DW (2015) Cemented versus cementless Oxford unicompartmental knee arthroplasty using radiostereometric analysis: a randomised controlled trial. Bone Joint J 97-B:185-191.

8. Kerens B, Schotanus MG, Boonen B, Kort NP (2015) No radiographic difference between patient-specific guiding and conventional Oxford UKA surgery. Knee Surg Sports Traumatol Arthrosc 23:1324-1329.

9. Lisowski LA, van den Bekerom MP, Pilot P, van Dijk CN, Lisowski AE (2010) Oxford Phase 3 unicompartmental knee arthroplasty: medium-term results of a minimally invasive surgical procedure. Knee Surg Sports Traumatol Arthrosc. 2011 Feb;19(2):277-84.

10. Pandit H, Hamilton TW, Jenkins C, Mellon SJ, Dodd CA, Murray DW (2015) The clinical outcome of minimally invasive Phase 3 Oxford unicompartmental knee arthroplasty: a 15-year follow-up of 1000 UKAs. Bone Joint J 97-B:1493-1500.

11. Renson L, Poilvache P, Van den Wyngaert $H$ (2014) Improved alignment and operating room efficiency with patient-specific instrumentation for TKA. Knee 21:1216-1220. 



\section{Chapter}

No radiographic difference between patient specific guiding and conventional Oxford UKA surgery

B. Kerens, M.G.M. Schotanus, B. Boonen, N.P. Kort.

Published:

Knee Surg Sports Traumatol Arthrosc. 2015 May;23(5):1324-9.






\begin{abstract}
Purpose

Implant position is an important factor in UKA surgery. Results on conventional UKA alignment are commonly described in literature. Patient specific guiding (PSG) is a new technique for positioning the Oxford UKA. Our hypothesis is that PSG improves component position without affecting the HKA angle.
\end{abstract}

\title{
Methods
}

This prospective study compares the results of our first thirty cases of cementless Oxford UKA using PSG with thirty cases using conventional outlining. Baseline characteristics for both groups were identical. Details on handling of the guide, estimated blood loss and operation time were recorded. Postoperative screened radiographs and standing long-leg radiographs of both groups were compared.

\section{Results}

Median AP position of the femoral component was 3 degrees varus (-5 to 9) using PSG vs. 2 degrees varus (-10 to 8 ) for the conventional group. For the femoral flexion this was 9 degrees flexion ( 0 to 16 ) using PSG vs. 12 degrees flexion (0 to 20). The tibial median AP position was 1 degree varus ( -3 to 7 ) using PSG vs. 2 degrees varus ( -5 to 10 ). The median tibial posterior slope was 5 degrees ( 1 to 10 ) using PSG vs. 5 degrees ( 0 to 12). All guides aligned well. No conversion to conventional outlining was performed, and no significant changes had to be made to the original approved plan. Operation time, estimated blood loss and postoperative $\mathrm{Hb}$ drop was not significantly different between both groups.

\section{Discussion}

Implant position was not different between both groups, even in the early phase of the learning curve. Perioperative results were not different between both groups. 


\section{INTRODUCTION}

The position of the unicompartmental knee arthroplasty (UKA) prosthesis is a factor in prosthesis survival, which is highly dependent on the surgeon[6]. Although intramedular and extramedular reference tools are available the definitive position of the prosthesis strongly depends on the experience of the operating surgeon and patient specific anatomical landmarks. Computer assisted surgery has the potential to be an adjunct in this matter. Alignment accuracy improves in UKA when computer assisted navigation is used, especially numbers of outliers decrease[3,4,5,6]. However, disadvantages of this system include a steep learning curve, increased surgical time, the drilling of holes for tracker positioning and increased costs $[4,5]$. Recently patient specific guiding was introduced in total knee arthroplasty (TKA) and UKA. It is believed but not yet proven that this technique aids in improvement of prosthesis position but also in decreasing operation time and decreasing blood loss[1]. However, limited literature is present on patient specific guiding in UKA[7]. Our first experiences of an experienced conventional UKA surgeon as well as patient specific guiding surgeon in TKA, applying his first patient specific guiding cases in UKA surgery to a cohort of 30 patients are presented in this paper $[1,8,9]$. The scope of this paper is to evaluate operative data, blood loss and postoperative alignment of this cohort and compare these to a cohort of 30 patients undergoing UKA surgery using conventional reference tools with the hypothesis that patient specific guiding improves component position.

\section{MATERIALS AND METHODS}

Thirty consecutive patients were prospectively recruited for Oxford (Biomet, Bridgend, UK) cementless medial UKA surgery using patient specific guiding. The results of these 30 patients were compared with the results of a retrospective cohort of 30 patients undergoing Oxford uncemented medial UKA surgery using conventional reference tools for prosthesis positioning. In this cohort the last 30 cases of medial UKA using conventional Oxford phase III instrumentation before introduction of patient specific guiding were included. All patients had medial osteoarthritis of the knee and fulfilled the preoperative criteria for UKA as described for the Oxford design. All operations were performed by one of the authors (NK) with extensive experience in conventional UKA surgery as well as TKA surgery using patient specific guiding $[1,8,9]$. Patient demographics were recorded for both groups and not significantly different between both groups (Table 1). The patients in the patient specific guiding group underwent an MRI of the entire leg according to the Signature ${ }^{\circledR}$ protocol in order to make a digital plan of the knee [1]. In this plan the position of the prosthesis (Oxford phase III uncemented, Biomet, Bridgend, UK) was determined. After approval of the surgeon, patient specific guides were made for perioperative use (Materialise, Leuven, Belgium). The guides fit the anatomy of the patient 
and determine the position of the cutting blocks. In the conventional group, femoral outlining was performed using the femoral outlining jig, which is positioned free hand with an intramedular pin as a reference. Tibial outlining was performed using the extramedular reference system. This reference system is set parallel to the anterior crest of the tibia and has a built in slope of 7 degrees with respect to the mechanical tibial axis. Desired prosthesis position in both groups in the coronal view was set at 0 degrees varus for the femoral and tibial component with respect to the mechanical axis of femur and tibia respectively. In the sagittal view the tibial component was set at a posterior slope of 7 degrees and the femoral component at 10 degrees flexion with respect to the mechanical axis of tibia and femur respectively. Except for the outlining the operation technique was identical in both groups including the use of a tourniquet during the whole procedure. A digital radiographic evaluation was performed on screened radiographs of the knee 6 weeks after surgery. The outcome of this evaluation was in whole degrees. The coronal position of the femoral component was determined as the angle between the anatomical axis of the femur and the lateral side of the femoral component. On the long leg radiograph the difference between the anatomical and mechanical femoral axis was determined. With these two values the position of the femoral component relative to the mechanical femoral axis was calculated. The sagittal position of the femoral component was determined as the angle between the anterior femoral cortex and the centre of the post of the femoral component. The coronal position of the tibial component was determined as the angle between the mechanical axis of the tibia and the undersurface of the tibial component. The sagittal position was the angle between the posterior tibial cortex and the undersurface of the tibial component. Varus of femoral and tibial component was positive by convention, as was posterior tibial slope and femoral flexion (Figure 1 and 2). This evaluation was performed twice by two assessors (MS and BK) and intra observer as well as inter observer intra class correlation coefficients (ICC) were determined. The analysis was performed by an examiner, who was blinded to the surgical procedure. In both groups also the operation time was recorded as well as the estimated blood loss. In the PSG group, the fit of the guide was also recorded. Hemoglobine ( $\mathrm{Hb})$ levels in $\mathrm{mmol} / \mathrm{l}$ were determined before and one day after surgery and the difference was also used as a marker for blood loss.

\section{IRB APPROVAL}

IRB approval was obtained at METC Artium-Orbis-Zuyd with log nr 13-N-108 
Table 1. Patient demographics.

\begin{tabular}{llll}
\hline & Patient specific guiding & Conventional & P value \\
\hline Mean age at time of surgery (range) & $63(48-85)$ & $61(48-85)$ & n.s. \\
Male : Female & $13: 17$ & $13: 17$ & n.s. \\
Left : Right & $15: 15$ & $17: 13$ & n.s. \\
Height $(\mathrm{m})$ (range) & $1.71(1.51-1.89)$ & $1.69(1.52-1.89)$ & n.s. \\
Weight $(\mathrm{kg})$ (range) & $84(62-115)$ & $82(56-106)$ & n.s. \\
BMI (range) & $29(23-40)$ & $29(20-37)$ & n.s. \\
\hline
\end{tabular}

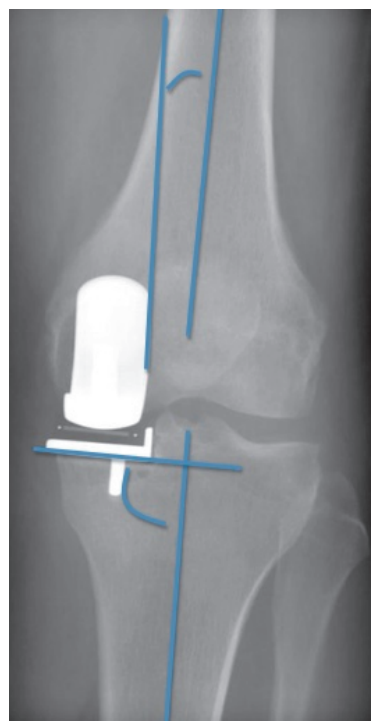

Figure 1. Measurements performed on frontal screened radiograph.

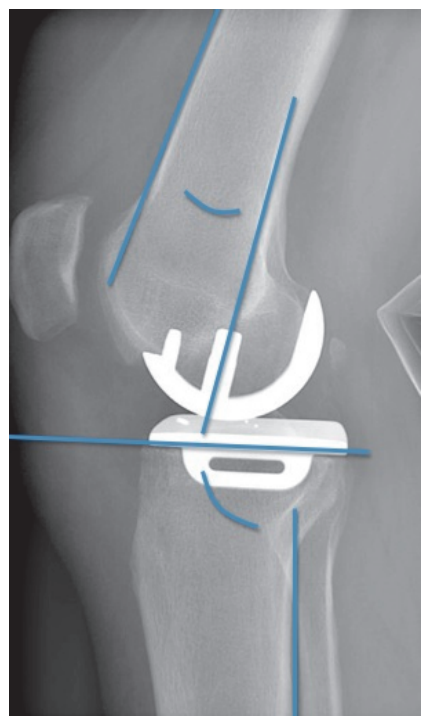

Figure 2. Measurements performed on lateral screened radiograph.

\section{STATISTICAL ANALYSIS}

Statistical analysis was conducted using SPSS for Mac ${ }^{\circledR}$ version 19. Continuous outcome variables and their differences were tested with parametrical statistical techniques, such as t-tests, unless the normality assumption did not seem reasonable for the data, in which case non-parametric techniques were used e.g. Wilcoxon/Mann-Whitney tests. Categorical outcome variables were analysed with the Fisher's exact test. P values of $<0.05$ were considered statistically significant. A power analysis was performed based on the standard deviations in both groups in a pilot patient group. With a clinically relevant difference of 3 degrees on the anteroposterior radiograph, we calculated that we needed to study 30 experimental subjects and 30 control subjects to be able to reject the null hypothesis that the population means of the experimental and control groups 
are equal with probability (power) 0.8. The Type I error probability associated with this test of this null hypothesis is 0.05 with two tails.

\section{RESULTS}

The results of the radiographic evaluation show that component position is not clinically relevantly different nor statistically significantly different between both groups except for the femoral component in the frontal plane. This is statistically significantly different between both groups but not clinically relevantly different (Table 2). The mean HKA angle was 4 degrees varus in the patient specific guiding group (range 2 valgus to 12 varus) and 4 degrees varus in the conventional group (range 2 valgus to 11 varus). They are not statistically different between both groups.

Intra observer and inter observer ICC of the radiographic evaluation were excellent (Table 3). Operation time and blood loss were not significantly different (Table 4). In both groups a drop in $\mathrm{Hb}$ after surgery was noticed but no significant difference between both groups was present (Table 4). All guides in the patient specific guiding group fell in the fit position after removal of soft tissue at the contact area. Since the femoral guide makes contact with the anterior femoral cortex the arthrotomy in the patient specific guiding group is more extensive to proximal when compared to the arthrotomy in the control group. It was observed that the posterior femoral cut was smaller than expected in the initial cases in the PSG group. Furthermore, it was seen that the position of the tibial pins and thus also the cutting block was lateral in two cases. No conversion to conventional outlining was performed.

Table 2. Radiographic evaluations per component per view.

\begin{tabular}{|c|c|c|c|c|}
\hline & & Patient specific guiding & Conventional & $P$ value \\
\hline Femoral component & Mean & 3 & 1 & 0.036 \\
\hline \multirow[t]{3}{*}{ Frontal } & Range & -5 to 9 & -10 to 8 & \\
\hline & Desired & 0 & 0 & \\
\hline & N outliers (\%) & $0(0)$ & $0(0)$ & n.s. \\
\hline Femoral component & Mean & 9 & 11 & n.s. \\
\hline \multirow[t]{3}{*}{ Sagital } & Range & 0 to 16 & 0 to 20 & \\
\hline & Desired & 10 & 10 & \\
\hline & N outliers (\%) & $0(0)$ & $0(0)$ & n.s. \\
\hline Tibial component & Mean & 1 & 2 & n.s. \\
\hline \multirow[t]{3}{*}{ Frontal } & Range & -3 to 7 & -5 to 10 & \\
\hline & Desired & 0 & 0 & \\
\hline & N outliers (\%) & $2(10)$ & $3(10)$ & n.s. \\
\hline Tibial component & Mean & 5 & 5 & n.s. \\
\hline \multirow[t]{3}{*}{ Sagital } & Range & 1 to 10 & 0 to 12 & \\
\hline & Desired & 7 & 7 & \\
\hline & N outliers (\%) & $1(3)$ & $4(10)$ & n.s. \\
\hline
\end{tabular}


Mean is given for each group with the $\mathrm{P}$ value for statistical significance of the mean difference between both groups. The second row in each group shows the range of component position in each group. Positive values indicate varus and negative values indicate valgus in the coronal view. In the sagital view positive values indicate femoral flexion and posterior tibial downslope and negative values indicate femoral extension and anterior tibial downslope. The third row shows the desired position. The last row in each group shows the numbers and percentages of outliers in that group with outlier defined as out of the safe zone as described by the phase III operation manual.

Table 3. Intra observer and inter observer intraclass correlation coefficients.

\begin{tabular}{llll}
\hline & Intra rater MS & Intra rater BK & Inter rater \\
\hline Tibial component AP angle & 0.973 & 0.975 & 0.978 \\
Femoral component AP angle & 0.950 & 0.958 & 0.974 \\
Tibial component sagittal angle & 0.953 & 0.956 & 0.953 \\
Femoral component sagittal angle & 0.992 & 0.993 & 0.991 \\
\hline
\end{tabular}

Table 4. Perioperative data.

\begin{tabular}{llll}
\hline & Patient specific guiding & Conventional & P value \\
\hline Mean operation time (min.) (range) & $59(36-115)$ & $54(40-75)$ & n.s. \\
Mean estimated blood loss (ml) (range) & $23(0-100)$ & $33(0-50)$ & n.s. \\
\hline
\end{tabular}

Table 5. Postoperative $\mathrm{Hb}$ levels were significantly different $(P=0.001)$ within groups. Between groups no significant differences were found.

\begin{tabular}{llll}
\hline & Patient specific guiding & Conventional & P value \\
\hline Mean Hb preop (mmol/L) (SD) & $8.8(0.7)$ & $8.8(0.8)$ & n.s. \\
Mean Hb postop on day 1 (mmol/L) (SD) & $8.0(0.8)$ & $7.8(0.7)$ & n.s. \\
Mean Hb difference (mmol/L) (SD) & $0.8(0.7)$ & $1.0(0.4)$ & n.s. \\
\hline
\end{tabular}

\section{DISCUSSION}

The most important finding of the present study is that patient specific guiding for Oxford UKA results in comparable radiological results when compared with conventional outlining. The ranges and standard deviations are smaller in the patient specific guiding group but the number of outliers is not different between both groups. Outliers were defined as position outside the safe zone as described by the phase III manual, which was available at the time this study was performed. With the recent introduction of microplasty instrumentation however the safe zone for the femoral flexion changed from 0 to 20 degrees of flexion into 5 degrees extension to 10 degrees of flexion. The component position of our control group is comparable with reported results in literature with smaller ranges in some reports and wider ranges in others [2,10]. The measurements were performed on screened radiographs. The advantage of these screened radiographs is that the prosthesis is ideally positioned for measuring. The disadvantage 
is that the centre of the hip and ankle joint is not on the radiograph. The mechanical axis of the tibia and the anatomical axis of the femur can thus only be assessed on the limited area around the knee that is seen on the radiograph. The femoral mechanical axis cannot be accessed directly on these radiographs but can be calculated using the long leg radiograph. Since the intra observer and inter observer variability of these measurements were good, this did not seem to compromise our results. Operation time and mean estimated perioperative blood loss were not statistically significantly different. This may be due to the tourniquet, which was consistently used during the procedure in both groups. For this reason also the postoperative $\mathrm{Hb}$ levels were checked and used as a parameter for blood loss due to surgery. These also showed no statistically significant difference between both groups although the study was not powered for blood loss.

Furthermore, two interesting points were observed in the operative data. Firstly, the posterior femoral cut was smaller in some of the first cases, which can be explained by pressure of the patella on the guide during pin drilling. This pressure pushes the guide a slightly posterior and out of the fit position. After recognizing this problem after the first cases, attention was paid to the placement of the guide to alleviate stress during drilling of the pins. After making this adjustment the problem did not recur. The second problem was the relatively lateral placement of the tibial pinholes. This relative lateral positioning of the pinholes in the tibial guide can cause a cut in more varus than planned due to less support for the saw on the medial side. In our small series this induced two outliers with the tibial component in varus. Using the slotted tibial cutting block solved this problem. With this block it is not possible to slide off on the medial side and the tibial cut was as planned. Both aspects are essential points to reduce the learning curve present in the use of patient specific guiding outlining.

The first limitation of our study is that the 30 cases of patient specific guiding UKA surgery were the first performed in our institution and results can thus be affected by a learning curve effect. The 30 conventional cases in the control group however are not affected by a learning curve effect since the operating surgeon was well experienced with the conventional UKA outlining procedure. Despite the fact that this factor is different for both groups this study shows that the results of this new technique are comparable to the known conventional technique and safe to use in future.

A second limitation is that no randomization was performed since the operating surgeon wanted to get used to this new technique before starting to randomize patients. Instead two cohorts of 30 patients were compared. Inclusion of patients in the PSG cohort was performed prospectively. In the conventional cohort this was done retrospectively however blinded for outcome results. The patients were thus not matched but since baseline characteristics were not significantly different between both groups we assume both groups are comparable.

The main strength of our study is that it is the first study reporting the results of patient specific guiding in Oxford UKA surgery. 


\section{CONCLUSION}

Patient specific guiding seems to be safe and reliable tool in performing Oxford UKA, even during the early learning curve period. The preliminary results are promising hence the use of patient specific guiding will be continued in our institution. Patient specific guiding could be an aid in performing primary UKA surgery, however good training in the system is of utmost importance since minimal errors in use can skew the outcomes heavily.

\section{CONTRIBUTION OF AUTHORS}

BK and MS: collected and analyzed data, performed the statistical analysis, and wrote the manuscript. BB: revised the manuscript. NK: operated on all patients and revised the manuscript.

\section{GRANTS AND ACKNOWLEDGMENTS}

None to be reported.

\section{CONFLICT OF INTERESTS}

One author (NK) lectures on the SPPC operation technique for Biomet. The other authors declare that they have no conflict of interest. 


\section{REFERENCES}

1. Boonen B, Schotanus MG, Kort NP (2012) Preliminary experience with the patient-specific templating total knee arthroplasty. Acta Orthop 83:387-393.

2. Clarius M, Hauck C, Seeger JB, Pritsch M, Merle C, Aldinger PR (2010) Correlation of positioning and clinical results in Oxford UKA. Int Orthop 34:1145-1151.

3. Jenny JY, Boeri C (2002) Accuracy of implantation of a unicompartmental total knee arthroplasty with 2 different instrumentations: a case-controlled comparative study. J Arthroplasty 17:1016-1020.

4. Jenny JY, Boeri C (2003) Unicompartmental knee prosthesis implantation with a non-image-based navigation system: rationale, technique, case-control comparative study with a conventional instrumented implantation. Knee Surg Sports Traumatol Arthrosc 11:40-45.

5. Jung KA, Kim SJ, Lee SC, Hwang SH, Ahn NK (2010) Accuracy of implantation during computer-assisted minimally invasive Oxford unicompartmental knee arthroplasty: a comparison with a conventional instrumented technique. Knee 17:387-391.

6. Keene G, Simpson D, Kalairajah Y (2006) Limb alignment in computer-assisted minimally-invasive unicompartmental knee replacement. J Bone Joint Surg 88:44-48.

7. Koeck FX, Beckmann J, Luring C, Rath B, Grifka J, Basad E (2011) Evaluation of implant position and knee alignment after patient-specific unicompartmental knee arthroplasty. Knee 18:294-299.

8. Kort NP, van Raay JJ, Cheung J, Jolink C, Deutman R (2007) Analysis of Oxford medial unicompartmental knee replacement using the minimally invasive technique in patients aged 60 and above: an independent prospective series. Knee Surg Sports Traumatol Arthrosc 15:1331-1334.

9. Kort NP, van Raay JJ, van Horn JJ (2007) The Oxford phase III unicompartmental knee replacement in patients less than 60 years of age. Knee Surg Sports Traumatol Arthrosc 15:356-360.

10. Parmaksizoglu AS, Kabukcuoglu Y, Ozkaya U, Bilgili F, Aslan A (2010) Short-term results of the Oxford phase 3 unicompartmental knee arthroplasty for medial arthritis. Acta Orthop Traumatol Turc 44:135142. 


\section{Chapter}

\section{Overstuffed medial compartment}

after mobile bearing unicompartmental knee arthroplasty

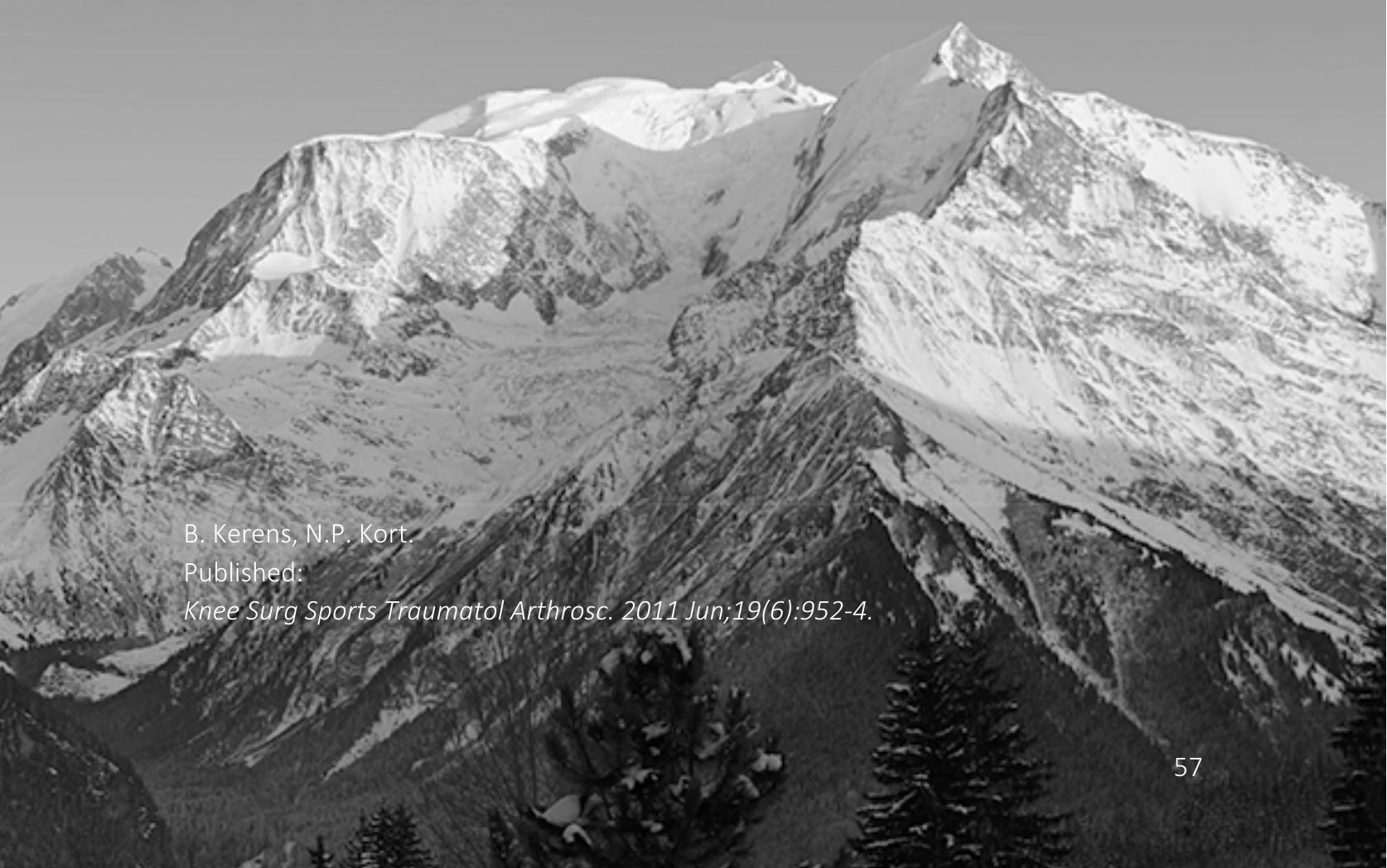


Chapter 5.

\section{ABSTRACT}

Overstuffing of the medial compartment in medial compartmental knee arthroplasty is a known pitfall. Attention to the flexion extension gap should be addressed. If however overstuffing is found it can be corrected by revising the femoral component only. 


\section{INTRODUCTION}

Unicompartmental knee arthroplasty with the Oxford prosthesis for medial compartmental knee osteoarthritis shows good results[19,15,17]. Vorlat et al. described good medium term results[31]. Khanna et al conducted a research in which the good long terms results described by different other authors were confirmed[30,11,22-24]. It is emphasized that it is important to select patients for this procedure taking into account strict indications and to use a consistent operation technique to reduce complications $[12,13,24,26,28,31]$. Mercier et al describe five year survival rates of $90 \%$, ten year survival rates of $74.7 \%$ and fifteen year survival rates of $70 \%$ with the comment that the majority of the failures are due to aseptic loosening, implant related failures and surgeon related failures[18].

Complications reported in literature regarding the Oxford unicompartmental knee prosthesis concern tibial plateau fractures, bearing luxation, compartment syndrome and popliteal vascular injury[14,20,27,29].

Our case report stresses the importance of meticulous surgery during operation to avoid medial overstuffing, valgus load axis and postoperative complaints. If however overstuffing is found it can be corrected by revising the femoral component only.

\section{CASE REPORT}

A fifty three year old female with medial osteoarthritis of the knee was treated with a mobile bearing unicompartmental knee arthroplasty for the right knee. During the operation a flexion extension gap of $2 \mathrm{~mm}$ was documented and a mobile meniscal bearing size 3 was used. Postoperative complaints were pain, function laesa and valgus deformity of the operated knee. Clinical examination showed a well healed wound, a valgus deformity of 10 degrees, a flexion up to 110 degrees and an extension deficit of 10 degrees. The radiographs showed valgus of the knee of 10 degrees and a cemented medial unicompartmental knee prosthesis without signs of loosening. There was no posterior overhang of the femoral component and the tibial component showed a slope of 11 degrees. (Figure 1) Mismatch of the flexion extension gap and the clinical complaints led to the decision to revise the unicompartmental knee prosthesis. During revision surgery a flexion extension gap mismatch of $6 \mathrm{~mm}$ was observed. An extra $6 \mathrm{~mm}$ bone of the medial femoral condyl was removed to match the extension gap to the flexion gap which stayed unaffected during the procedure. A new femoral component was cemented and a new mobile meniscal bearing size 3 was inserted. After this the mobility of the knee was good, with 1+ laxity of the medial collateral ligament (MCL). The postoperative radiographs showed a good position of the femoral component with the advised overhang posteriorly, and a neutral load axis. (Figure 2) Six weeks after the revision surgery the patient has no complaints and mobilisation is without pain. 


\section{DISCUSSION}

Because of the mobile bearing used in the Oxford unicompartmental knee prosthesis intact ligaments are obligatory. Balancing of flexion extension gap has to be performed through bone resection only. Intra operative evaluation of balance has to be performed. A slight under correction of the load axis of the leg is advised[1,2,4-6,9,10]. Excessive varus alignment would cause more load to pass through the prosthesis which increases the risk of long term wear. With excessive valgus the lateral native compartment would be more prone to progression of osteoarthritis[3,5,7,8,25].

In the case of a flexion extension gap mismatch there are 3 options. .

The first option is to revise only the femoral component to create a larger extension gap without affecting the flexion gap. The tibial component is left in place and the excessive slope accepted. The 1+ laxity of this medial collateral ligament after revision surgery is due to the lengthening of the $M C L$ after the first surgery. In this case the ligament provided enough stability to have a stable mobile bearing, which resulted in the patient's good functionality.

The second option is to revise both femoral and tibial component and insert a new unicompartmental knee prosthesis. According to literature however revision of a unicompartmental knee arthroplasty to an unicompartmental knee arthroplasty shows inferior results[16,21].

The third option is a conversion to a total knee arthroplasty. In this case with a young patient and the right indication for a unicompartmental knee prosthesis this would not be the first choice. When the revision of only the femoral component fails, revision to a total knee arthroplasty would be obligatory.

It is important during primary surgery not to overstuff the medial compartment to prevent valgus load axis and clinical complaints. In case of overstuffing in a young patient a revision of the femoral component can be performed with good results. 


\section{REFERENCES}

1. Argenson JN, Chevrol-Benkeddache Y, Aubaniac JM (2002) Modern unicompartmental knee arthroplasty with cement: A three to ten-year follow-up study. J Bone Joint Surg Am 84:2235-2239

2. Cartier P, Sanouiller JL, Grelsamer RP (1996) Unicompartmental knee arthroplasty surgery. 10-year minimum follow-up period. J Arthroplasty 11:782-788

3. Deshmukh RV, Scott RD (2001) Unicompartmental knee arthroplasty: Long-term results. Clin Orthop Relat Res 392:272-278

4. Emerson RH, Jr. (2007) Preoperative and postoperative limb alignment after oxford unicompartmental knee arthroplasty. Orthopedics 30:32-34

5. Emerson RH, Jr., Head WC, Peters PC, Jr. (1992) Soft-tissue balance and alignment in medial unicompartmental knee arthroplasty. J Bone Joint Surg Br 74:807-810

6. Emerson RH, Jr., Higgins LL (2008) Unicompartmental knee arthroplasty with the oxford prosthesis in patients with medial compartment arthritis. J Bone Joint Surg Am 90:118-122

7. Fisher DA, Watts M, Davis KE (2003) Implant position in knee surgery: A comparison of minimally invasive, open unicompartmental, and total knee arthroplasty. J Arthroplasty 18:2-8

8. Gioe TJ, Killeen KK, Hoeffel DP, Bert JM, Comfort TK, Scheltema K, Mehle S, Grimm K (2003) Analysis of unicompartmental knee arthroplasty in a community-based implant registry. Clin Orthop Relat Res 416:111-119

9. Gulati A, Pandit H, Jenkins C, Chau R, Dodd CA, Murray DW (2009) The effect of leg alignment on the outcome of unicompartmental knee replacement. J Bone Joint Surg Br 91:469-474

10. Hernigou P, Deschamps G (2004) Alignment influences wear in the knee after medial unicompartmental arthroplasty. Clin Orthop Relat Res 423:161-165

11. Khanna G, Levy BA (2007) Oxford unicompartmental knee replacement: Literature review. Orthopedics 30:11-14

12. Kort NP, van Raay JJ, Cheung J, Jolink C, Deutman R (2007) Analysis of oxford medial unicompartmental knee replacement using the minimally invasive technique in patients aged 60 and above: An independent prospective series. Knee Surg Sports Traumatol Arthrosc 15:1331-1334

13. Kort NP, van Raay JJ, van Horn JJ (2007) The oxford phase III unicompartmental knee replacement in patients less than 60 years of age. Knee Surg Sports Traumatol Arthrosc 15:356-360

14. Kort NP, van Raay JJ, van Horn JR (2007) Compartment syndrome and popliteal vascular injury complicating unicompartmental knee arthroplasty. J Arthroplasty 22:472-476

15. Koskinen E, Paavolainen P, Eskelinen A, Pulkkinen P, Remes V (2007) Unicondylar knee replacement for primary osteoarthritis: A prospective follow-up study of 1,819 patients from the finnish arthroplasty register. Acta orthop 78:128-135

16. Lewold S, Robertsson O, Knutson K, Lidgren L (1998) Revision of unicompartmental knee arthroplasty: Outcome in 1,135 cases from the swedish knee arthroplasty study. Acta orthop Scand 69:469-474

17. Lisowski LA, van den Bekerom MP, Pilot P, van Dijk CN, Lisowski AE Oxford phase 3 unicompartmental knee arthroplasty: Medium-term results of a minimally invasive surgical procedure. Knee Surg Sports Traumatol Arthrosc DOI: 10.1007/s00167-010-1213-2

18. Mercier N, Wimsey S, Saragaglia D (2009) Long-term clinical results of the oxford medial unicompartmental knee arthroplasty. Int orthop DOI: 10.1007/s00264-009-0869-z

19. Murray DW, Goodfellow JW, O'Connor JJ (1998) The oxford medial unicompartmental arthroplasty: A ten-year survival study. J Bone Joint Surg Br 80:983-989

20. Pandit H, Murray DW, Dodd CA, Deo S, Waite J, Goodfellow J, Gibbons CL (2007) Medial tibial plateau fracture and the oxford unicompartmental knee. Orthopedics 30:28-31

21. Pearse AJ, Hooper GJ, Rothwell A, Frampton C (2010) Survival and functional outcome after revision of a unicompartmental to a total knee replacement: The new zealand national joint registry. J Bone Joint Surg $\operatorname{Br} 92: 508-512$ 
Chapter 5.

22. Price AJ, Dodd CA, Svard UG, Murray DW (2005) Oxford medial unicompartmental knee arthroplasty in patients younger and older than 60 years of age. J Bone Joint Surg Br 87:1488-1492

23. Price AJ, Waite JC, Svard U (2005) Long-term clinical results of the medial oxford unicompartmental knee arthroplasty. Clin Orthop Relat Res 435:171-180

24. Rajasekhar C, Das S, Smith A (2004) Unicompartmental knee arthroplasty. 2- to 12-year results in a community hospital. J Bone Joint Surg Br 86:983-985

25. Ridgeway SR, McAuley JP, Ammeen DJ, Engh GA (2002) The effect of alignment of the knee on the outcome of unicompartmental knee replacement. J Bone Joint Surg Br 84:351-355

26. Skowronski J, Jatskewych J, Dlugosz J, Skowronski R, Bielecki M (2005) The oxford II medial unicompartmental knee replacement. A minimum 10-year follow-up study. Ortop traumatol rehab 7:620-625

27. Sloper PJ, Hing CB, Donell ST, Glasgow MM (2003) Intra-operative tibial plateau fracture during unicompartmental knee replacement: A case report. Knee 10:367-369

28. Verdonk R, Cottenie D, Almqvist KF, Vorlat P (2005) The oxford unicompartmental knee prosthesis: A 214 year follow-up. Knee Surg Sports Traumatol Arthrosc 13:163-166

29. Verhaven E, Handelberg F, Casteleyn PP, Opdecam P (1991) Meniscal bearing dislocation in the oxford knee. Acta Orthop Belg 57:430-432

30. Vorlat P, Putzeys G, Cottenie D, Van Isacker T, Pouliart N, Handelberg F, Casteleyn PP, Gheysen F, Verdonk R (2006) The oxford unicompartmental knee prosthesis: An independent 10-year survival analysis. Knee Surg Sports Traumatol Arthrosc 14:40-45

31. Vorlat P, Verdonk R, Schauvlieghe H (2000) The oxford unicompartmental knee prosthesis: A 5-year follow-up. Knee Surg Sports Traumatol Arthrosc 8:154-158 


\section{Chapter}

\section{Revision from unicompartmental to total knee arthroplasty; clinical outcome depends on reason for revision}

B. Kerens, B. Boonen, M.G.M. Schotanus, H. Lacroix, P.J. Emans, N.P. Kort.

Published:

Bone Joint J. 2013 Sep;95-B(9):1204-8.



\section{ABSTRACT}

Although it is suggested in literature that results of UKA to TKA revision surgery improve when the mechanism of failure is understood, a comparative study regarding this topic is lacking.

Fifteen cases with unexplained pain were listed in group $A$ and 15 cases with a cause for pain in group B. Oxford knee scores (OKS), visual analogue scores (VAS) and patient satisfaction one year after revision surgery were compared.

OKS improved from 19 to 25 within group A and from 23 to 38 within group B. VAS improved from 7,7 to 5,4 within group $A$ and from 7,4 to 1,7 within group $B$. The difference in outcome between both groups is statistically significant, $p=0,022$ for OKS and $p=0,002$ for VAS. Subgroup analysis in group A, performed in order to define a patient factor that predicts outcome of revision surgery in case of unexplained pain, showed no preoperative differences between both subgroups.

These results are important to properly inform patients about what to expect of revision surgery, highlighting that UKA to TKA revision for unexplained pain generally results in a less favourable outcome. 


\section{INTRODUCTION}

Medial unicompartmental knee arthroplasty (UKA) is a known therapy for medial osteoarthritis of the knee with good short, medium and long term results with ten year and fifteen year survival rates of $94 \%$ to $97 \%$ and $87 \%$ respectively ${ }^{(1)}$. Revision surgery, however can be obligatory in some cases ${ }^{(2,3)}$. Causes for revision are femoral or tibial loosening, bearing luxation or impingement, progression of osteoarthritis and pain of unknown origin ${ }^{(2-4)}$. Patients are satisfied after UKA to TKA revision surgery but less satisfied than after primary TKA ${ }^{(5-7)}$. Especially revision surgery for pain of unknown origin seems to generate inferior results when compared to revision surgery for a well defined reason $^{(2,3,6)}$. The main aim of these studies was to describe reasons for revision surgery. These studies only mention inferior results in case of pain of unknown origin without quantifying these inferior results or directly compare them with results after revisions performed for a known origin of pain. To the best of our knowledge, a study in which results after revision from UKA to TKA for pain of unknown origin are compared to results of revision with a well defined cause of pain cannot be found in recent literature. The aim of this study is to compare clinical outcome and the patient satisfaction at one year post revision surgery. For this purpose 15 consecutive cases of UKA to TKA revision due to pain of unknown origin were compared with 15 consecutive cases of UKA to TKA revision with a well defined reason for revision surgery.

\section{MATERIALS AND METHODS}

All patients with a medial UKA undergoing revision surgery to TKA between January 2008 and January 2011 in two hospitals, the Orbis Medical Park in Sittard (OMP) and Elkerliek Hospital in Helmond (EH) in the Netherlands were listed retrospectively. The indication for initial UKA was medial compartmental osteoarthritis of the knee in all patients. Patient demographics of both groups are listed in Table 1. All revisions were divided into two groups. In the first group (group $\mathrm{A}$ : $\mathrm{N}=15$ ) reason for revision surgery was pain of unknown origin.

Table 1. Patient demographics.

\begin{tabular}{llll}
\hline & Group A & Group B & P value \\
\hline Patients included & 15 & 15 & 0,034 \\
Mean age at primary surgery in years (range) & $55(40-72)$ & $63(46-78)$ & 0,022 \\
Mean age at revision surgery in years (range) & $57(42-73)$ & $66(54-83)$ & 0,575 \\
Mean time between primary and revision surgery in months (range) & $28(5-107)$ & $34(1-79)$ & 0.715 \\
Male : female & $6: 9$ & $7: 7$ & 0.264 \\
\hline
\end{tabular}

In the last column the $p$ value for difference between the two groups is shown. 
Pain of unknown origin was defined as pain without a demonstrable cause during preoperative work up. This was confirmed during surgery as no cases of loosening, impingement, infection, malposition or osteoarthritis of other compartments were observed. Table 2 shows the pre revision work up that was performed for each patient in group $A$ individually. This preoperative work up, which was performed by the attending orthopaedic surgeon, was the same in both hospitals and included a repetitive history and clinical examination, multiple screened radiographs (Figure $1 \mathrm{a}$ and $1 \mathrm{~b}$ ) and weight bearing long leg radiographs of the knee, to assess mechanical problems of the prosthesis and progression of osteoarthritis. Also patellofemoral pain without radiographic signs of osteoarthritis was excluded. Furthermore, infection was excluded using serum BSE, CRP and WBC count values. Aspiration for culture was not routinely performed. In the second group (group B: $\mathrm{N}=15$ ) all other reasons for revision were listed. Reasons for revision surgery in group $\mathrm{B}$ were progression of osteoarthritis of the lateral or patellofemoral compartment $(\mathrm{N}=8)$, femoral component loosening $(\mathrm{N}=2)$, tibial component loosening $(\mathrm{N}=2)$, malposition $(\mathrm{N}=1)$, infection $(\mathrm{N}=1)$ and osteonecrosis of the lateral compartment $(\mathrm{N}=1)$. Table 3 shows the pre revision work up that was perfomed for each patient in group B individually. All revised UKA were of the Oxford design (Biomet UK Ltd, Bridgend, UK ) except one in group A which was of the Miller Galante design (Zimmer, Warsaw, IN) Revision surgery was performed using the Vanguard ${ }^{\mathrm{TM}}$ Complete Knee System (Biomet Inc, Warsaw, IN) in one hospital (OMP) (9 revisions for unexplained pain and 9 revisions for pain with a cause) and the LCS Total Knee System (Depuy Orthopaedics Inc, Warsaw, IN) in the other hospital (EH) (6 revisions for unexplained pain and 6 revisions for pain with a cause). These cases of revision surgery were performed by a single surgeon in each hospital. The Oxford Knee Score (OKS) (0 to 48, 48 being the best outcome) and Visual Analogue Score (VAS) (0 to 10,10 being most pain) prior to revision surgery and one year post revision surgery were compared. Also the results for the questions in the OKS regarding pain (question 1,4,5,8 and 9 ) were pooled ( 0 to 20, 20 being the best outcome) and compared. Additionally all patients were contacted and asked to answer four questions regarding their pain status prior to revision surgery and at least one year post revision surgery (Table 4). These questions could only be answered by "yes" or "no". Flexion and extension pre and post revision surgery were listed. This evaluation was performed using a goniometer. Post revision radiographic evaluation of component position was performed electronically by one person for both centres. In the frontal view the position of the femoral and tibial component was defined with the femoral and tibial mechanical axis respectively as a reference. In the sagital view the anterior femoral cortex was used as a reference for the femoral component flexion and the posterior tibial cortex for the tibial component slope.

Statistics were performed using SPSS for $\mathrm{Mac}^{\circledR}$ version 19. Since small groups are present, the normality assumption does not seem reasonable for the data. Thus significance was determined using non parametric tests e.g. Wilcoxon/Mann Whitney tests. Categorical outcome variables were analysed using the Fisher's exact test. P values of $<0.05$ were considered statistically significant. 
Revision from unicompartmental to total knee arthroplasty

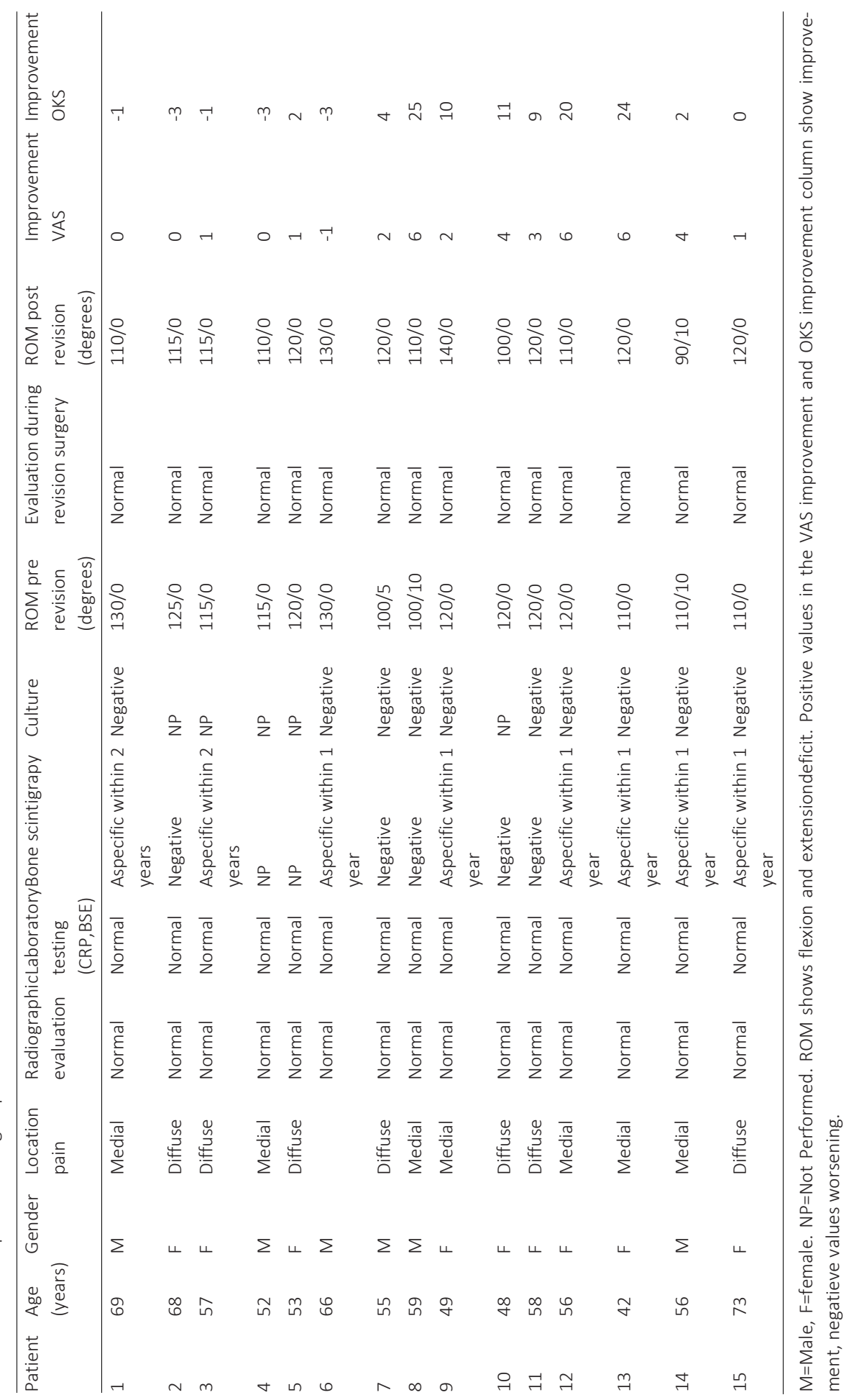




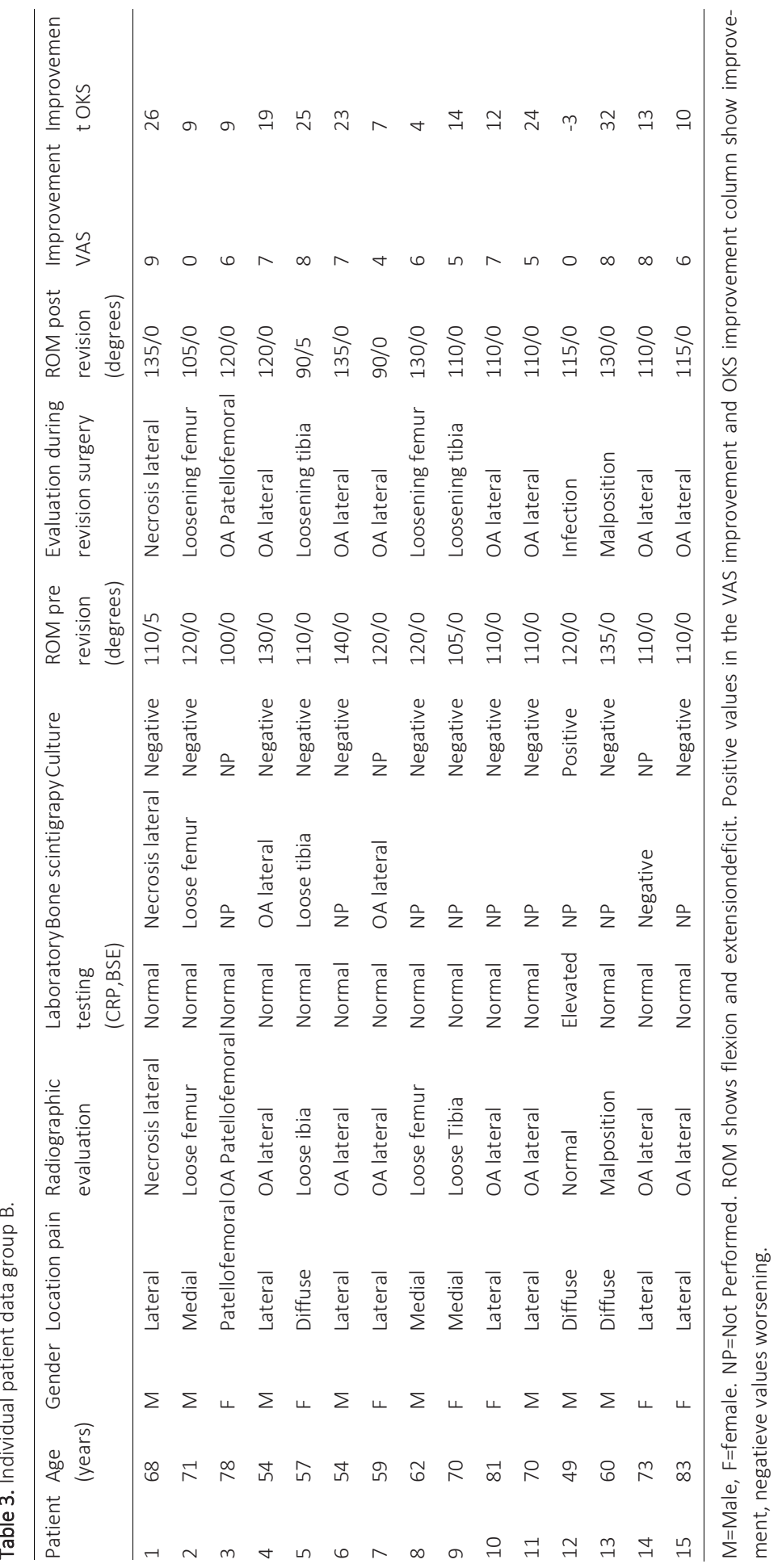



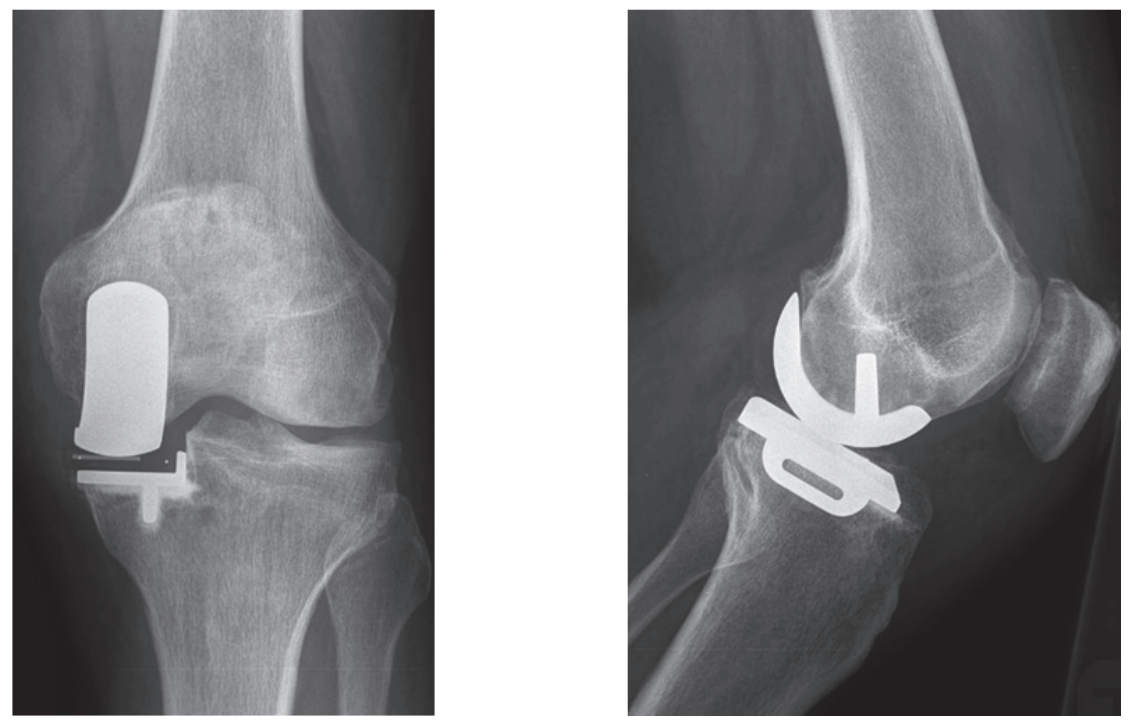

Figure $1 \mathrm{a}$ and $1 \mathrm{~b}$. Anteroposterior and lateral screened $\mathrm{X}$ ray of the knee with the UKA in situ.

Table 4. Subjective questions one year post revision surgery with number and percentage of patients answering yes per group

\begin{tabular}{|c|c|c|c|c|}
\hline & & $\begin{array}{l}\text { Group A } \\
\text { N (\%) } \\
\text { yes }\end{array}$ & $\begin{array}{l}\text { Group B } \\
\text { N (\%) } \\
\text { yes }\end{array}$ & $p$ value \\
\hline 1 & $\begin{array}{l}\text { Did the knee pain for which you underwent revision surgery disappear } \\
\text { totally? }\end{array}$ & $2(13)$ & $11(73)$ & 0.003 \\
\hline 2 & $\begin{array}{l}\text { Did the knee pain for which you underwent revision surgery disappear } \\
\text { partially? }\end{array}$ & r $7(47)$ & $14(93)$ & 0.014 \\
\hline 3 & $\begin{array}{l}\text { Did the revision surgery meet the expectations you had before this } \\
\text { surgery? }\end{array}$ & $3(20)$ & $13(87)$ & 0.001 \\
\hline 4 & Would you undergo revision surgery again? & $7(47)$ & $14(93)$ & 0.014 \\
\hline
\end{tabular}

Significance of the difference is shown in the last column.

\section{RESULTS}

Results of OKS, VAS and OKS pain with their improvement are shown in Table 5 with $p$ value for improvement per group in the last row and the $p$ value for difference between the groups in the last column. The results of the answers to the "yes" or "no" questions are shown in Table 4. Significantly more patients in group B answered the questions affirmative. Degrees of flexion pre and post revision are shown in table 6 with $p$ value for improvement per group in the last row and the $p$ value for difference between the groups in the last column. No statistically significant differences between both groups were seen. 


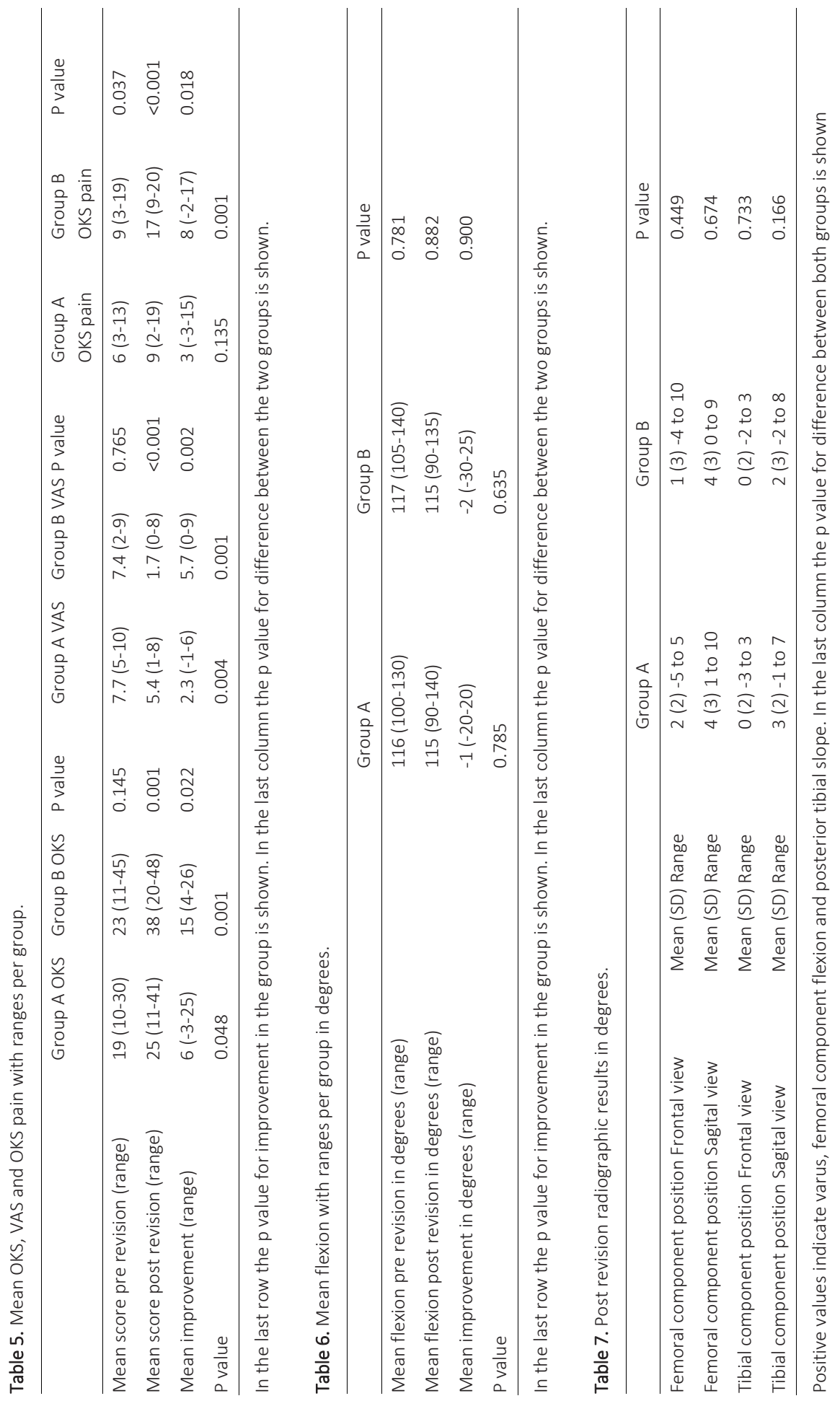


Stability post revision was good in all cases. The radiographic results post revision are shown in Table 7. No statistical significant differences between both groups were seen. In each group 3 revisions were performed using a stem and a wedge, in all other cases stemless components were used without wedges

The OKS improved an average 6 points in group $A(p=0,048)$ and an average 15 points in group $B(p=0,001)$. The improvement in OKS was statistically significantly better $(p=0.022)$ for group $B$ compared to group $A$. The VAS improved an average 2 points in group $A(p=0,004)$ and average 5,7 points in group $B(p=0.001)$. The improvement in VAS was statistically significantly better $(p=0.002)$ for group $B$ compared to group $A$. The OKS pain score improved an average 3 points in group $A(p=0.135)$ and an average 8 points in group $B(p=0.001)$. The improvement in OKS pain score was statistically significantly better $(p=0.018)$ for group $B$ compared to group $A$.

In each group a subdivision was made depending on clinical relevant improvement of OKS and VAS. Results are shown in table 8. An improvement of 5 points or more on the OKS was defined as clinically relevant ${ }^{(8)}$. This was seen in 6 patients $(40 \%)$ of group $A$ and 13 patients (87\%) of group B. An improvement of 3 points or more on the VAS was defined as clinically relevant ${ }^{(9)}$. This was seen in 6 patients (40\%) of group $A$ and 13 patients (87\%) of group B. In group A we observed that some patients didn't improve and others improved a lot. A subgroup analysis was performed for which this group was divided into two parts, clinical improvers and clinical non improvers. No preoperative parameters that could predict outcome between both subgroups were significantly different.

Table 8. Group A divided in two subgroups, clinical improvers and clinical non improvers according to OKS improvement and VAS improvement with range of improvement.

\begin{tabular}{llll}
\hline & N (\%) & Mean improvement & Range of improvement \\
\hline OKS improvers group A & $6(40)$ & 17 & 9 to 25 \\
OKS non improvers group A & $9(60)$ & 1 & -3 to 4 \\
VAS improvers group A & $6(40)$ & 5 & 3 to 6 \\
VAS non improvers group A & $9(60)$ & 1 & -1 to 2 \\
\hline
\end{tabular}

A positive value indicates improvement and a negative value indicates worsening.

\section{DISCUSSION}

Our results show that the improvement in OKS and VAS after UKA to TKA revision surgery depends on the preoperative diagnosis. According to Murray et al. a clinically relevant improvement on the OKS is five points or more ${ }^{(8)}$ and Lee et al. report that an improvement of 3 or more points on the VAS is clinically relevant ${ }^{(9)}$. When these cut-off points are used, both groups show an average clinically relevant improvement in OKS. In group A this improvement is just clinically relevant and statistically significant whereas in group B it is obviously clinically relevant and statistically significant. For the VAS the 
improvement is statistically significant $(p=0,004)$ but not clinically relevant (average decrease in VAS only 2 points) in group $A$ and clinically relevant and statistically significant in group B. Although the preoperative OKS and VAS are not significantly different in both groups, the power of these parameters is low due to the small numbers per group ( $1-\beta=0.31$ for OKS and $1-\beta=0.08$ for VAS).

The diagnosis "pain of unknown origin" was made in all patients that were confined to group A after repeated clinical examination and radiological evaluation. Laboratory testing was performed to exclude a low-grade infection. Some patients underwent bone scintigraphy although this is not a reliable tool to diagnose loosening or a low grade infection in the first two years after knee arthroplasty surgery ${ }^{(10-13)}$. According to Hoffmann et al. aspiration of the knee with cultures is an important step in excluding a low grade infection ${ }^{(14)}$. This was not performed in all cases and, although unlikely since no infection was diagnosed during follow-up, it cannot be completely excluded that some of the patients in group A suffered from pain caused by a low grade infection. CRPS was not seen in either group.

According to Simpson et al. pain of unknown origin can be caused by a large increase in strain in the proximal tibia after UKA insertion ${ }^{(15)}$. This strain diminishes with bone remodelling. The 3 cases in our series of unexplained pain that were revised within one year after primary surgery could be subject to this theory and influence our data. This was not the case thus these 3 cases were included in the study. Next to the OKS and VAS prior to revision surgery and post revision surgery, four other questions were added. They all involve a comparison of the post revision status compared to the pre revision status and show the subjective opinion of how patients experience the results of revision surgery. These questions are not validated but show the same trend as the OKS and VAS.

Range of motion and radiological evaluation showed no significant differences between both groups.

For the subgroup analysis other factors such as age, sex, time between revision from UKA to TKA etc. were analyzed but these factors could not explain the difference between responders versus non-responders in group $A$. The numbers to analyze such factors are also too small in the current study and this was not our primary aim.

There is evidence in literature that TKA to TKA revision surgery should only be performed if the mechanism of failure is understood ${ }^{(16-18)}$. For UKA to TKA revision surgery a few small reports are published that show similar inferior results when revision is performed for pain of unknown origin ${ }^{(2,3,6)}$. This study particularly compares the subjective results of UKA to TKA revision surgery for pain of unknown origin to the results of UKA to TKA revision for a well defined cause. Our results show that although the mean OKS and VAS scores improve significantly the probability of pain reduction after UKA to TKA revision for pain of unknown origin is rather small. This implies that revision surgery is not necessarily the solution for pain of unknown origin after UKA. When patients in group $\mathrm{A}$ are subdivided according to clinical relevant improvement or not, we notice 
that some patients do not improve at all and others show a large improvement. These results are important in order to properly inform patients about what to expect of results of revision surgery, highlighting that revision for unexplained pain generally results in less favourable outcome. Our groups, however, are small and larger studies are needed in future, particularly focussing on identifying a possible patient-related factor that can predict outcome of revision surgery for pain of unknown origin.

\section{CONFLICT OF INTEREST STATEMENT}

The author or one or more of the authors have received or will receive benefits for personal or professional use from a commercial party related directly or indirectly to the subject of this article.

\section{AKNOWLEDGEMENTS}

None to be reported. 


\section{REFERENCES}

1. Lisowski LA, van den Bekerom MP, Pilot P, van Dijk CN, Lisowski AE. Oxford Phase 3 unicompartmental knee arthroplasty: medium-term results of a minimally invasive surgical procedure. Knee Surg Sports Traumatol Arthrosc 2011;19:277-84.

2. Oduwole KO, Sayana MK, Onayemi F, McCarthy T, O'Byrne J. Analysis of revision procedures for failed unicondylar knee replacement. Ir J Med Sci 2010;179:361-4.

3. Vardi G, Strover AE. Early complications of unicompartmental knee replacement: the Droitwich experience. Knee 2004;11:389-94.

4. Lindstrand A, Stenstrom A, Ryd L, Toksvig-Larsen S. The introduction period of unicompartmental knee arthroplasty is critical: a clinical, clinical multicentered, and radiostereometric study of 251 Duracon unicompartmental knee arthroplasties. J Arthroplasty 2000;15:608-16.

5. Becker R, John M, Neumann WH. Clinical outcomes in the revision of unicondylar arthoplasties to bicondylar arthroplasties. A matched-pair study. Arch Orthop Trauma Surg 2004;124:702-7.

6. Chatain F, Richard A, Deschamps G, Chambat P, Neyret P. [Revision total knee arthroplasty after unicompartmental femorotibial prosthesis: 54 cases]. Rev Chir Orthop Reparatrice Appar Mot 2004;90:49-57.

7. Pearse AJ, Hooper GJ, Rothwell A, Frampton C. Survival and functional outcome after revision of a unicompartmental to a total knee replacement: the New Zealand National Joint Registry. J Bone Joint Surg Br 2010;92:508-12.

8. Murray DW, et al. The use of the Oxford hip and knee scores. J Bone Joint Surg Br 2007;89:1010-4.

9. Lee JS, Hobden E, Stiell IG, Wells GA. Clinically important change in the visual analog scale after adequate pain control. Acad Emerg Med 2003;10:1128-30.

10. Hofmann AA, et al. Bone scans after total knee arthroplasty in asymptomatic patients. Cemented versus cementless. Clin Orthop Relat Res 1990;251:183-8.

11. Rosenthall L, Lepanto L, Raymond F. Radiophosphate uptake in asymptomatic knee arthroplasty. J Nucl Med 1987;28:1546-9.

12. Rubello $\mathrm{D}$, et al. Three-phase bone scan pattern in asymptomatic uncemented total knee arthroplasty. Eur J Nucl Med 1996;23:1400-3.

13. Savarino L, Tigani D, Baldini N, Bochicchio V, Giunti A. Pre-operative diagnosis of infection in total knee arthroplasty: an algorithm. Knee Surg Sports Traumatol Arthrosc 2009;17:667-75.

14. Hofmann S, Seitlinger G, Djahani O, Pietsch M. The painful knee after TKA: a diagnostic algorithm for failure analysis. Knee Surg Sports Traumatol Arthrosc 2011;19:1442-52.

15. Simpson DJ, Price AJ, Gulati A, Murray DW, Gill HS. Elevated proximal tibial strains following unicompartmental knee replacement--a possible cause of pain. Med Eng Phys 2009;31:752-7.

16. Jacofsky DJ, Della Valle CJ, Meneghini RM, Sporer SM, Cercek RM. Revision total knee arthroplasty: what the practicing orthopaedic surgeon needs to know. J Bone Joint Surg Am 2010;92:1282-92.

17. Mandalia V, Eyres K, Schranz P, Toms AD. Evaluation of patients with a painful total knee replacement. J Bone Joint Surg Br 2008;90:265-71.

18. Piedade SR, Pinaroli A, Servien E, Neyret P. Revision after early aseptic failures in primary total knee arthroplasty. Knee Surg Sports Traumatol Arthrosc 2009;17:248-53. 


\section{Chapter}

Patient specific guiding for revision of medial unicondylar knee arthroplasty to total knee arthroplasty.

Beneficial first results of a new operating technique performed on 10 patients

B. Kerens. B. Boonen. M.G.M. Schotanus, N.P. Kort.

Published:

Acta Orthop. 2013 Apr;84(2):165-9.

6 


\section{ABSTRACT \\ Background and purpose}

Unicompartmental to total knee arthroplasty revision surgery can be technically demanding. Joint line restoration, rotation and augmentations can cause difficulties. We describe a new technique in which single way fitting guides serve to position the knee system cutting blocks.

\section{Methods}

Preoperatively images of the distal femur and proximal tibia are taken using CTscanning. These images are used to create a patient specific guide that fits in one single position on the contours of the bone and the prosthesis in situ. The guides are fixed with pins and thereafter removed. The pins determine the position of the cutting blocks. 10 consecutive revisions were performed using this technique and followed for six weeks. Results

All guides fitted well. 7 of 10 femoral prostheses were within the desired AP and sagittal angle $\pm 3^{\circ} .1$ proximal tibia did however not have enough bone stock on the medial plateau for adequate fixation of the guide so conversion to intramedular referencing was performed. This was to be expected after the preoperative planning. All tibial components were within the desired AP angle $\pm 3^{\circ}$ and 7 of 10 within the desired sagittal angle. HKA was within $0 \pm 3^{\circ}$ in 8 of 10 cases.

\section{Interpretation}

This new technique makes preoperative planning and execution of this plan during surgery less demanding. Problems such as the need for augmentations can be predicted at the preoperative planning. The instrumentation needs to be redesigned in order to make this technique work in cases with minimal bone stock present. 


\section{INTRODUCTION}

Unicompartmental knee arthroplasty (UKA) is a widely used procedure for medial compartmental osteoarthritis of the knee. Revision rates of 6 to $13 \%$ are reported (Vardi and Strover 2004, Oduwole et al. 2009). Oduwole et al. (2009) reported that due to possible bone loss, the potential need of augmentations and use of long stem prostheses, insertion of a new total knee arthroplasty (TKA) in the proper position can be technically demanding although others found it to be straightforward and less technically demanding than revision TKA (McAuley et al. 2001, Dudley et al. 2008, Oduwole et al. 2009). Both Dudley et al. (2008) and Oduwole et al. (2009) report that in $43 \%$ of UKA to TKA revision surgery a femoral or tibial long stem, metal augments or bonegrafting was needed. Proper preoperative planning can make revision less difficult (Saragaglia et al. 2009) and peroperative computer assisted surgery may be of value (Confalonieri et al. 2010). Recently, a patient specific alignment guide, Signature personalized patient care (SPPC) (Biomet, Inc., Warsaw, In) was developed based on MRI-imaging of the knee. A preoperative plan is made in which problems to be expected can be anticipated. Next a template is formed that can be used as an alignment guide during the operation in order to improve correct positioning of the newly implanted TKA. We describe a new application of this templating technique for revision of UKA to TKA and the operative results of the first 10 patients treated.

\section{MATERIAL AND METHODS}

SPPC was initially developed for primary TKA. The technique uses MRI-imaging to create templates for both the tibia and the femur that can be used as alignment guides intraoperatively (Lombardi et al. 2008). Since a prosthesis is in situ in case of revision, MRI-imaging cannot be used. CT-imaging can replace MRI-imaging in these cases. We performed preoperative low dose CT-imaging of the leg 6 weeks prior to surgery according to a standard scanning protocol to determine the mechanical axis of the leg and anatomy of the knee. Software (Materialise NV, Leuven, Belgium) was used to create virtual 3-dimensional models of femur and tibia using this CT-scan. The same software was used to determine appropriate implant size and optimal positioning of the prosthesis (Vanguard ${ }^{\text {тм }}$ Complete Knee System, Biomet, Inc., Warsaw, IN) for each patient individually. Calculations were performed to minimize bone loss during the revision. Position of the prosthesis was further determined to obtain a neutral mechanical axis and a neutral position of both femoral and tibial components to the mechanical axis in the frontal plane. In the sagittal plane, posterior slope of the tibial component and flexion of the femoral component were set at $3^{\circ}$. Calculations were performed to avoid notching of the femoral component. The distal femoral cut was set at $9 \mathrm{~mm}$ proximal of the most distal femoral point. Femoral component rotation was set parallel to the transepi- 
condylar axis in the coronal plane and tibial component rotation was determined using the medial third of the tibial tuberosity and the posterior sulcus as a reference point. Component sizing was determined by measuring the anteroposterior dimension of the distal femur and the contour of the proximal tibia. A digital, virtual plan of the operation to be performed was sent to the surgeon (Figure 1).


Figure 1: digital, virtual plan of the operation to be performed and actual postoperative radiographs. 
The surgeon could adjust the digital plan satisfactorily by changing implant size and position, rotation, translation, flexion and resection level. Thereafter the patientspecific, disposable guides made of polyamide were manufactured. These guides have one single fitting position specific to the anatomy of the patient's knee as determined by CT-scan (Figure 2). In all patients, the incision was made using the old scar with extensions to proximal and distal. A medial parapatellar arthrotomy was performed and standard exposure of the femur and tibia was carried out with patellar eversion. The fixation of the prosthesis was checked. Soft tissue interfering with placement of the guides was removed.

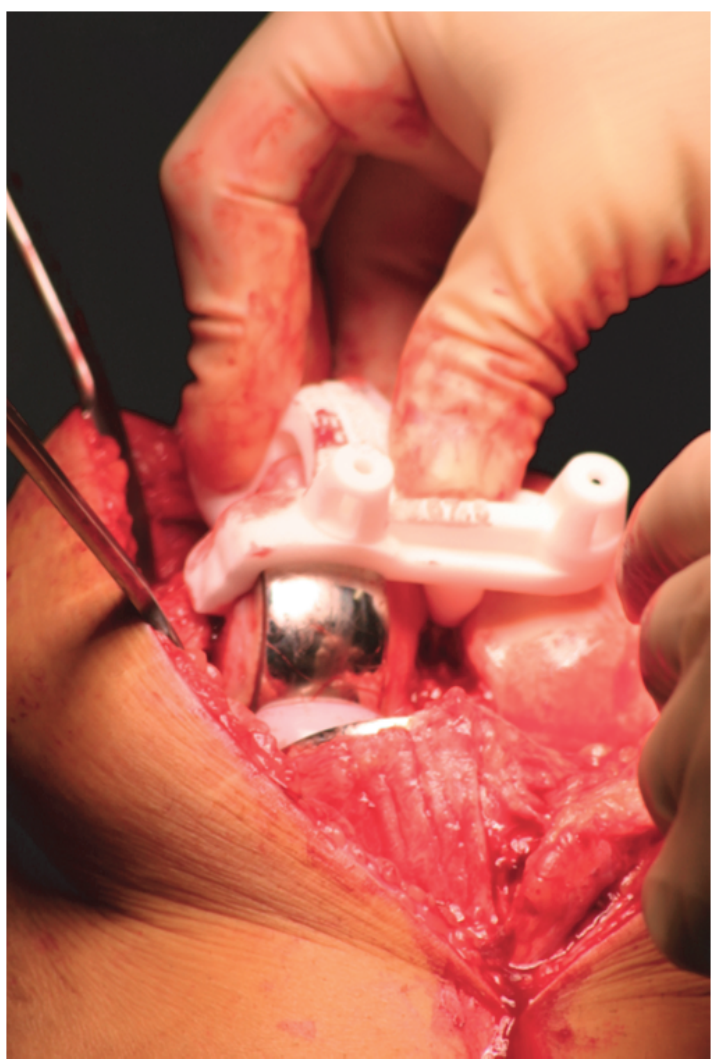

Figure 2: single way fitting position of guides on the patients individual anatomy.

The guide was created to fit on both UKA and native bony reference points since cartilage is not shown on CT scanning. Therefore, no contact existed between either the cartilage of lateral femoral condyle or lateral tibial plateau and the guide (Figure 3). The femoral guide was placed in the fit position and fixed to the bone with 3 pins. 



Anatomic Points of Guide Contact



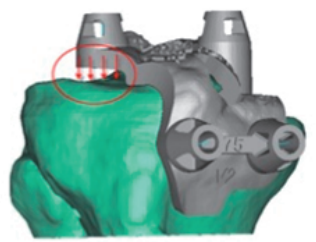

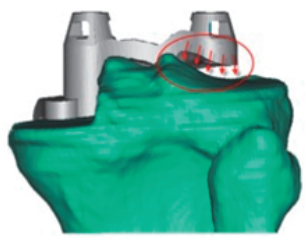

Anatomic Points of Guide Contact

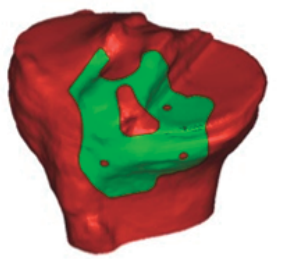

Figure 3: illustration showing that no contact existed between either the cartilage of the lateral femoral condyle or the lateral tibial plateau and the guide.

The fourth pin could not be inserted due to the prosthesis still in situ. The guide was taken off and the femoral component of the prosthesis was carefully removed using osteotomes to break the cement prosthesis interface. Next the cement was removed with a rongeur and the guide was replaced on the distal femur according to the position of the three predrilled holes and thereafter the fourth pinhole was drilled (Figure 4). The guide was removed and the pins were used to position the femoral cutting blocks to make bone resections for the new TKA (Figure 5). The same procedure was performed on the tibial side. Further operative procedure was standard for TKA and included applying a tourniquet prior to extensively rinsing the knee with a pulse lavage system. Patellar resurfacing was not performed in any case. Ligament balancing was performed as needed. All procedures were performed by one knee surgeon (NK) with extensive experience in performing both primary Oxford UKA, Signature and conventional Vanguard TKA as well as conventional UKA to TKA revision surgery. 


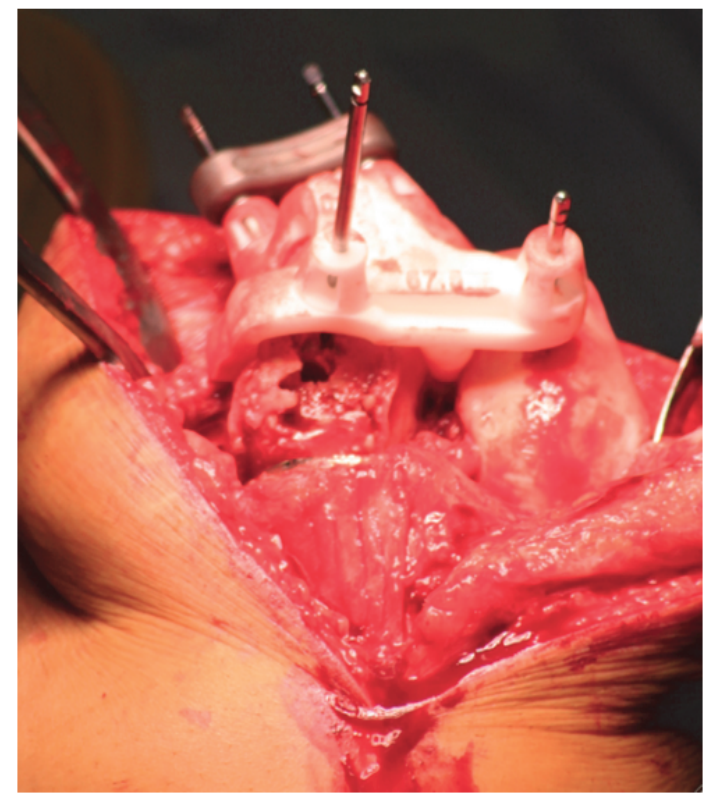

Figure 4: repositioning of the guide after removal of the prosthesis using the three predrilled holes and insertion of the fourth pin.

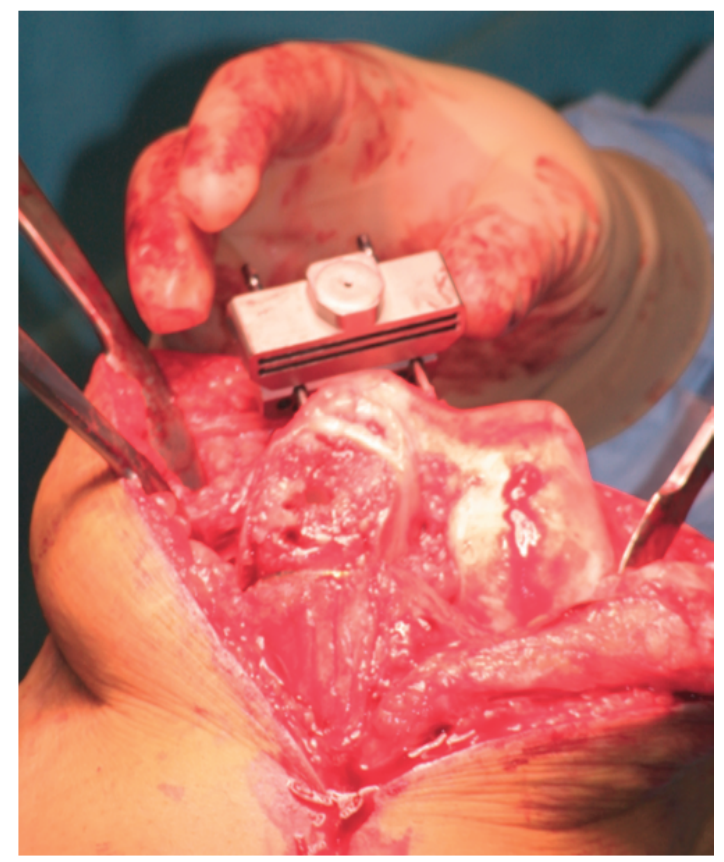

Figure 5: pins were used to position the femoral cutting blocks to make bone resections for the new TKA. 
10 consecutive patients, 4 males and 6 females, with an indication for UKA to TKA revision surgery were included in this study. 4 right and 6 left knees were operated on. Mean age at time of primary surgery was 57 (39-69) years and mean time between primary and revision surgery was 37 (7-79) months. Reason for revision was pain of unknown origin in 4 cases, tibial component loosening in 3 cases, femoral component loosening in 1 case, femoral component impingement in 1 case and progression of osteoarthritis in 1 case. Blood loss and operation time were obtained from the operative records, completed by an independent OR-nurse. A function test was performed 6 weeks postoperatively and measurements were performed using a goniometer. Radiographic measurements were performed electronically on standing long-leg radiographs and standard lateral radiographs using digital calculations. Hip knee ankle angle (HKA) and varus/valgus position of the individual prosthesis components were assessed on the long-leg radiographs. Flexion/extension of the femoral component and anterior/posterior slope of the tibial component were measured on the lateral radiographs. Radiographic assessment was performed twice by 3 assessors (BB, MS and BK). The attending surgeon (NK) was not involved in these assessments. The mean value obtained from these measurements was used as our definitive value. Reliabilities of the measured angles were determined by calculating intra assessor and inter assessor reliabilities using intraclass correlation coefficients (ICC). ICC can range between 0 and 1 . An ICC greater than 0.75 indicates good to excellent reliability. Intra rater reliabilities for each assessor and inter rater reliabilities were good (Table 1).

Table 1. Intra assessor and inter assessor ICC per measured angle.

\begin{tabular}{lllll}
\hline & Intra rater BB & Intra rater MS & Intra rater BK & Inter rater \\
\hline HKA angle & 0.90 & 0.97 & 0.98 & 0,97 \\
Tibial component AP angle & 0.79 & 0.91 & 0.92 & 0.81 \\
Femoral component AP angle & 0.93 & 0.81 & 0.75 & 0.85 \\
Tibial component sagittal angle & 0.98 & 0.91 & 0.87 & 0.77 \\
Femoral component sagittal angle & 0.96 & 0.95 & 0.89 & 0.83
\end{tabular}

\section{ETHICS}

This study was approved by the local ethics committee and performed in compliance with the Helsinki Declaration of 1975, as revised in 2000. All patients were informed and consented to providing data for anonymous use. 


\section{RESULTS}

All individual guides fitted well on all patients. No excessive bone loss was observed and only 1 patient needed a long stem tibial component with metal augmentation. In this case only 2 lateral pins could be inserted in the tibia using the guide. The third, medial anterior pin could not be inserted into the bone since the prosthesis was in a distal position. This resulted in inadequate and unstable positioning of the guide. At this stage the use of the guide was abandoned and a conversion to standard intramedular outlining was performed. This was expected since the preoperative planning already revealed the situation (Figure 6). No further complications occurred.

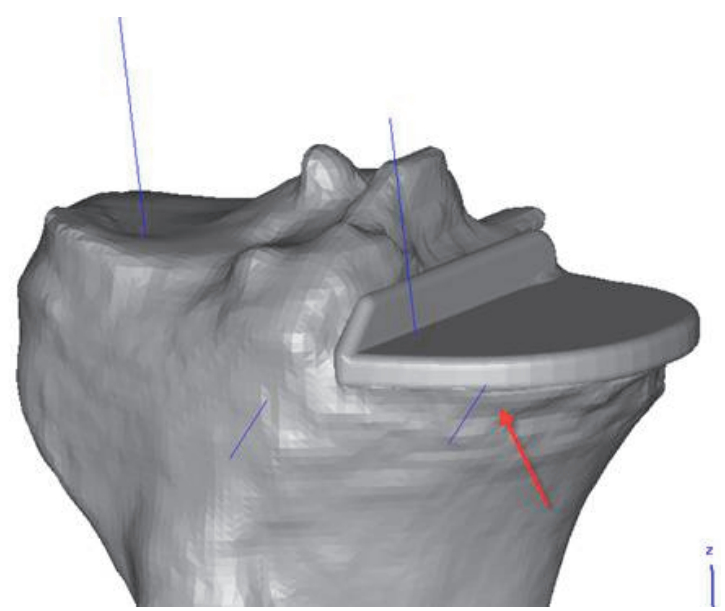

Figure 6: Preoperative planning shows that the medial anterior pin cannot be drilled into bone in a stable way.

Mean operation time was 83 (59-120) min. The mean estimated blood loss was 270 (150-500) $\mathrm{ml}$.

A mean HKA angle of $2^{\circ}$ varus was observed, the tibial component showed a mean of $1^{\circ}$ valgus and the femoral component $3^{\circ}$ varus. In the sagital view the mean posterior slope of the tibial component was $1^{\circ}$ and the mean femoral component flexion was $5^{\circ}$ (Table 2). All patients were mobilised on day 1 postoperative with a physiotherapist and direct full weight bearing was allowed in all cases. At 6 weeks all patients had good stability of the knee with less than $5 \mathrm{~mm}$ anteroposterior motion in all cases and a mediolateral slack of also less than $5 \mathrm{~mm}$ except for 2 patients in which the mediolateral slack was between 5 and $10 \mathrm{~mm}$. The mean postoperative flexion was 111 (90 to 135) degrees. All but 2 patients could fully extend the knee. Of these 2, one had an extension deficit of 5 degrees and the other a deficit of 10 degrees. 
Table 2: HKA angle, varus/valgus position of tibial and femoral component (tibia AP and femur AP), flexion/extension of tibial and femoral component (tibia sagittal and femur sagittal).

\begin{tabular}{llllllc}
\hline & Mean (SD) & Range & Desired & \multicolumn{2}{c}{ Outlier 1 deg Outlier 2 deg Outlier total } \\
\hline HKA angle & $2(1.7)$ & 0 to 5 & 0 & 1 & 1 & 2 \\
Tibial component AP angle & $-1(1.1)$ & -2 to 1 & 0 & 0 & 0 & 0 \\
Femoral component AP angle & $3(0.9)$ & 1 to 4 & 0 & 3 & 0 & 3 \\
Tibial component sagittal angle 1 (2.5) & -2 to 6 & 3 & 2 & 1 & 3 \\
$\begin{array}{l}\text { Femoral component sagittal } \\
\text { angle }\end{array}$ & $5(2.7)$ & -1 to 8 & 3 & 1 & 2 & 3 \\
\hline
\end{tabular}

Positive values indicate varus, posterior tibial slope and femoral component flexion. Negative values indicate valgus, anterior tibial slope and femoral component extension. Outliers are defined as more than 3 degrees off of the desired position and number of outliers are shown depending on the degree of being more than 3 degrees off the ideal position.

\section{DISCUSSION}

Depending on the cause for which UKA revision is needed, a single component can be revised, revision to a new UKA can be performed or revision to a TKA can be obligatory (Kerens and Kort 2010, Pearse et al. 2010). Revision of UKA to TKA shows better results than revision of UKA to UKA (Pearse et al. 2010). Some report that the revision procedure of UKA to TKA is technically not more difficult than TKA to TKA revision (McAuley et al. 2001, Johnson et al. 2007, Saldanha et al. 2007). Others however report that revision of UKA to TKA is a technically demanding procedure with possible bone loss (Chatain et al. 2004, Springer et al. 2006). Preoperative planning and computer assisted surgery can help decrease peroperative problems (Confalonieri et al. 2010). Our purpose was to create patient specific single way fitting guides for intra operative use that were created preoperatively from CT-imaging of the patient's leg. Planning of the operation was done using a virtual overview of the patient specific anatomy with the prosthesis in situ. With this technique the need for augmentation or long stem prosthesis can be accurately predicted prior to surgery.

Since the guide is specific for the anatomy of the patient with the UKA prosthesis in situ as well as for the bony anatomy of the patient without the UKA prosthesis in situ the technique can be used with the prosthesis in a stable position in situ but also when the prosthesis is loose or removed.

The implant position was good in all cases and no joint line restoration problems were observed.

Improvement of the procedure includes the formation of guides with the possibility of more distal pin positioning in cases of medial tibial bone loss when observed during the preoperative planning. This is an UKA revision specific change in design and instru- 
mentation that needs to be performed in the future to make this technique successful in all cases.

For primary TKA, SPPC uses MRI-imaging to create single way fitting guides. With the metal of an UKA in situ MRI-scanning is not possible. Low resolution CT-imaging can replace $\mathrm{MRI}$-imaging for this purpose. A side effect, however, is exposure to a mean radiation of 5,7 $\mathrm{mSv}$ on the patient's leg. The amount of radiation is slightly less than that of a single CT scan of the abdomen or cerebrum. The costs of creating the guides are minor and are, in our opinion, compensated by the fact that more thorough preoperative planning can be performed, which may decrease operation time and logistic problems.

We believe that this new, commercially available technique can aid in making UKA to TKA revision surgery less technically demanding. It appears to be a reliable tool, although our reference group is limited. Larger patient series are needed to confirm our preliminary results as is fine-tuning of the technique for cases in which more loss of bone stock is observed preoperatively.

\section{GRANTS AND ACKNOWLEDGMENTS}

None to be reported.

\section{CONFLICT OF INTERESTS}

One author (NK) lectures on the SPPC operation technique for Biomet. The other authors declare that they have no conflict of interest.

\section{AUTHOR CONTRIBUTION}

BK: collected and analysed data, performed statistical analysis and wrote the manuscript. BB: collected and analysed data and wrote the manuscript. MS: collected and analysed data, performed statistical analysis and revised the manuscript. NK: operated on all the patients mentioned in the manuscript and revised the manuscript. 


\section{REFERENCES}

1. Chatain F, Richard A, Deschamps G, Chambat P, Neyret P. Revision Total Knee Arthroplasty after Unicompartmental Femorotibial Prosthesis: 54 Cases. Rev Chir Orthop Rep Appar Mot 2004; 90(1):4957.

2. Confalonieri N, Manzotti A, Chemello C, Cerveri P. Computer-Assisted Revision of Failed Unicompartmental Knee Arthroplasty. Orthopedics. 2010; 33(10):52-7.

3. Dudley TE, Gioe TJ, Sinner P, Mehle S. Registry Outcomes of Unicompartmental Knee Arthroplasty Revisions. Clin Orthop Relat Res 2008; 466(7):1666-70.

4. Johnson S, Jones P, Newman JH. The Survivorship and Results of Total Knee Replacements Converted from Unicompartmental Knee Replacements. The Knee 2007; 14(2):154-7.

5. Kerens B, Kort NP. Overstuffed Medial Compartment after Mobile Bearing Unicompartmental Knee Arthroplasty. Knee Surg Sports Traumatol Arthroscop 2011; 19(6):952-4.

6. Lombardi AV, Jr., Berend KR, Adams JB. Patient-Specific Approach in Total Knee Arthroplasty. Orthopedics 2008; 31(9):927-30.

7. McAuley JP, Engh GA, Ammeen DJ. Revision of Failed Unicompartmental Knee Arthroplasty. Clin Orthop Relat Res 2001; (392):279-82.

8. Oduwole KO, Sayana MK, Onayemi F, McCarthy T, O'Byrne J. Analysis of Revision Procedures for Failed Unicondylar Knee Replacement. Irish J Med Science 2009; 179(3):361-4.

9. Pearse AJ, Hooper GJ, Rothwell A, Frampton C. Survival and Functional Outcome after Revision of a Unicompartmental to a Total Knee Replacement: The New Zealand National Joint Registry. J Bone Joint Surg (Br) 2010; 92(4):508-12.

10. Saldanha KA, Keys GW, Svard UC, White SH, Rao C. Revision of Oxford Medial Unicompartmental Knee Arthroplasty to Total Knee Arthroplasty - Results of a Multicentre Study. The Knee 2007; 14(4):275-9.

11. Saragaglia D, Estour G, Nemer C, Colle PE. Revision of 33 Unicompartmental Knee Prostheses Using Total Knee Arthroplasty: Strategy and Results. Int Orthop 2009; 33(4):969-74.

12. Springer BD, Scott RD, Thornhill TS. Conversion of Failed Unicompartmental Knee Arthroplasty to TKA. Clin Orthop Relat Res 2006; (446):214-20.

13. Vardi G, Strover AE. Early Complications of Unicompartmental Knee Replacement: The Droitwich Experience. The Knee 2004; 11(5):389-94. 


\section{Chapter}

Popliteal lesion due to traction during unicompartmental knee revision surgery.

Case report and literature overview

B. Kerens, B. Boonen, M.G.M. Schotanus, N.P. Kort.

Published:

J Orthop. 2013 Mar 1;10(1):38-40.

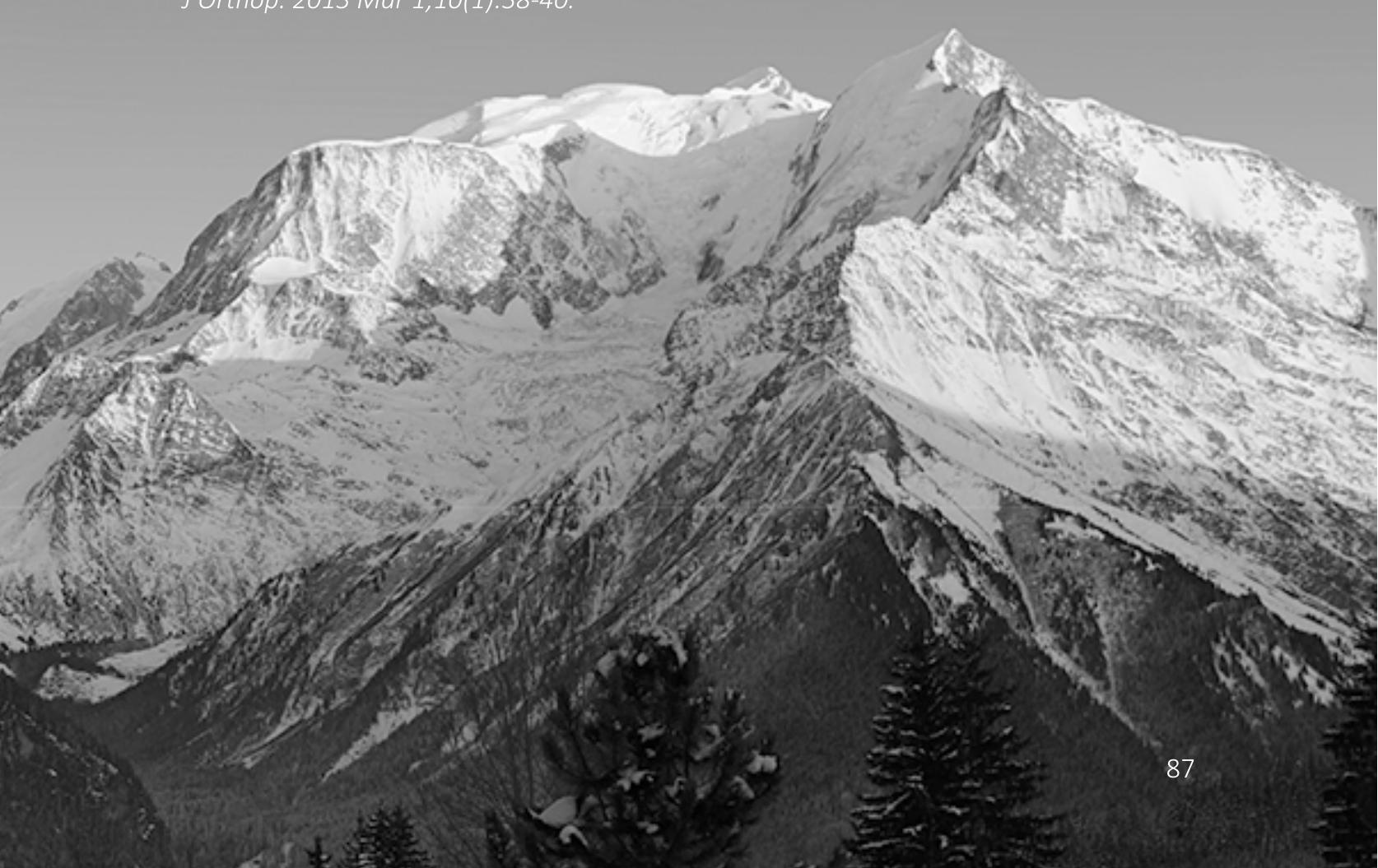




\section{ABSTRACT}

Popliteal artery injury is a rare but known complication in knee surgery. Only one article in current literature reports that the risk increases during revision knee surgery. A new case is described in which an injury to the popliteal artery occurred during lateral unicompartmental to total knee arthroplasty revision surgery. This vascular injury occurred five to ten centimetres below the tibial resection level in a healthy patient with a history of cruris fracture with plate osteosynthesis and lateral unicompartmental knee arthroplasty. This paper stresses the importance of being aware that trauma and surgery can create fibrosis in which the popliteal artery can get fixated, thus reducing the scope for safe manipulation of the knee during secondary surgery. 


\section{INTRODUCTION}

Vascular lesions of the popliteal artery are rare but have been described after total knee arthroplasty (TKA), unicompartmental knee arthroplasty (UKA), revision TKA, correction osteotomy procedures and dislocations of the knee (1-9). Aetiology can be thrombosis, direct trauma or indirect trauma $(3,6,7,10-16)$. Our case shows an indirect popliteal lesion five centimeters distal to the operation area in a patient during revision knee surgery and stresses the importance of meticulous surgery in order to prevent indirect trauma especially in cases in which fibrosis could be present due to prior surgery or trauma.

\section{CASE REPORT}

A fifty one year old healthy female was treated for lateral compartmental osteoarthritis of the right knee in another hospital. A lateral UKA was performed. Because of complaints on the lateral side of the knee she visited us two years after primary surgery. The diagnosis of tibial component overhang was made and revision surgery was planned. The aim was to remove the lateral UKA and insert a TKA. Pre operative planning did not show any problems. Her history however included a cruris fracture of the right leg. An open reduction and internal fixation with a plate and screw osteosynthesis was performed forty years ago with an operation for removal of the plate and screws a few years later. Scar tissue with local skin retractions on the lower leg was present. During revision surgery no tourniquet was used and removal of the prosthesis and bone resection for the new TKA occurred without problems. However, after preparing the tibia for the stem of the prosthesis bleeding from the posterior side of the knee was noted during extension of the knee. The knee was held in hyperflexion while preparing the tibia for the stem of the prosthesis with a posterior blunt retractor on the medial side of the posterior cruciate ligament in order to luxate the proximal tibia anteriorly thus creating a better view of the tibial plateau. A vascular surgeon was consulted directly after the bleeding was noted and stepped in during surgery to evaluate the cause of the bleeding. The bleeding stopped spontaneously and no focus was found at that time. The cruciate retaining TKA was correctly inserted and the wound was closed. Immediately following the operation, a doppler ultrasound examination was performed. This examination showed good patency of the posterior tibial and dorsal pedal artery. Initially conservative treatment was started but during re-evaluation with doppler ultrasound the next day absent distal pulses were observed and an angiogram was performed. A popliteal lesion was diagnosed and the patient was operated on by the vascular surgeon. A lesion of four millimeters in the popliteal artery five to ten $\mathrm{cm}$ below the tibial resection level was observed. This lesion showed signs of bleeding and a local dissection with secondary thrombosis. An embolectomy was performed and the lesion was closed 
with a $6 \mathrm{~mm}$ thinwall ptfe interposition graft. After this surgery the patient had no complaints and showed good knee function with an intact vascular status of the leg. One year after this surgery the patient had no complaints of the knee.

\section{DISCUSSION}

The incidence of vascular complications after knee replacement is between $0.03 \%$ and $0.2 \%$ (12). These complications include acute ischemia, thrombosis, hemorrhage, fistula, recurrent haemartrosis, pseudo aneurysm and aneurysm formation $(3,7,10,12,17,18)$.

Direct trauma can cause haemorrhage, acute ischaemia, recurrent haemartrosis and aneurysm forming. It can be caused by the oscillating saw, posteriorly placed retractors and perforating fixation pins $(3,6,11,16)$. The popliteal artery is situated direct on the lateral side of the posterior cruciate ligament and posterior retractor positioning should be medial to this posterior cruciate ligament in order to reduce the risk of a lesion due to the position of this retractor (14). Anatomical anomalies however are reported and should be kept in mind (19). Indirect trauma is also described (15). The popliteal artery is especially at risk during hyperextension while patellar preparation is performed and during hyperflexion (14).

Some authors report that arterial thrombosis is associated with tourniquet use $(6,7$, $10,12,13)$. Others report that it can also occur when no tourniquet is used $(6,13)$. Patients compromised by peripheral vascular disease are more at risk of developing complications and should be evaluated preoperatively by a vascular surgeon (20).

It is reported that preoperative selection could reduce the risk of vascular lesions during surgery $(7,12)$. Others however report that no specific measures can be taken to prevent it (15). Our patient was a young female with no risk factors for vascular impairment preoperatively such as smoking, intermittent claudication or hypercholesterolemia. During preoperative physical examination she had good palpable pulses of the dorsal pedal artery and posterior tibial artery and a good capillary refill of the foot. Also the scar tissue with skin retractions due to the fixation of the cruris fracture was noted. Further preoperative planning included the forming of patient specific instrumentation guides for peroperative placement of the cutting blocks for resection of the femur and tibia using preoperative CT-imaging according to the Signature personalized patient care (Biomet, Inc., Warsaw, In) protocol (21). This allows correct cutting block positioning with minimal detachment of structures or manipulation of the knee.

Care was taken during the whole procedure and especially while manipulating the knee, while using the oscillating saw and during placement of the posterior blunt retractor. Postoperative findings, especially a distinct lesion of the popliteal artery, do postulate an operation related cause of the lesion. The fact that it was obviously distal to the operation area does not exclude a direct trauma but presumes an indirect trauma. Since adequate care was taken and manipulation of the knee did not exceed standard manip- 
ulation as usually performed in TKA an additional factor seems to be present in this case. In our opinion the problem may have been caused by pre-existent traumatic fibrosis of the structures surrounding the knee on the level of the lower leg in this case. This is supported by previous literature which notes an increased incidence of vascular complications in redo arthroplasty (22). The patient however had not been operated on this leg once but three times. The osteosynthesis of the tibial fracture and subsequent removal of plate and screws might even be of more importance in the forming of fibrosis in the polpiteal area than the previous TKA. This fibrosis may involve the posterior vascular structures and thus reduce the scope for safe manipulation of the knee during secondary surgery. In order to prevent vascular lesions around the knee, it is in our opinion important to be aware of possible pre-existent fibrosis that can cause problems during consecutive knee surgery.

\section{AKNOWLEDGEMENTS}

None to be reported.

\section{CONFLICT OF INTEREST STATEMENT}

None to be reported. 


\section{REFERENCES}

1. Boisrenoult $P$, Lustig $S$, Bonneviale $P$, Leray $E$, Versier $G$, Neyret $P$, et al. Vascular lesions associated with bicruciate and knee dislocation ligamentous injury. Orthop Traumatol Surg Res. 2009;95:621-6.

2. Bonnevialle $P$, Chaufour X, Loustau O, Mansat P, Pidhorz L, Mansat M. [Traumatic knee dislocation with popliteal vascular disruption: retrospective study of 14 cases]. Rev Chir Orthop Reparatrice Appar Mot. 2006;92:768-77.

3. D'Angelo F, Carrafiello GP, Lagana D, Reggiori A, Giorgianni A, Zatti G, et al. Popliteal artery pseudoaneurysm after a revision of total knee arthroplasty: endovascular treatment with a stent graft. Emerg Radiol. 2007;13:323-7.

4. Kirby L, Abbas J, Brophy C. Recanalization of an occluded popliteal artery following posterior knee dislocation. Ann Vasc Surg. 1999;13:622-4.

5. Kort NP, van Raay JJ, van Horn JR. Compartment syndrome and popliteal vascular injury complicating unicompartmental knee arthroplasty. J Arthroplasty. 2007;22:472-6.

6. Kumar SN, Chapman JA, Rawlins I. Vascular injuries in total knee arthroplasty. A review of the problem with special reference to the possible effects of the tourniquet. J Arthroplasty. 1998;13:211-6.

7. Smith DE, McGraw RW, Taylor DC, Masri BA. Arterial complications and total knee arthroplasty. J Am Acad Orthop Surg. 2001;9:253-7.

8. Spinelli F, Spinelli R, Stilo F, De Caridi G, Mirenda F. Vascular lesions secondary to osteotomy by corticotomy. Chir Ital. 2007;59:575-9.

9. Witz M, Witz S, Tobi E, Shnaker A, Lehmann J. Isolated complete popliteal artery rupture associated with knee dislocation. Case reports. Knee Surg Sports Traumatol Arthrosc. 2004;12:3-6.

10. Bayne CO, Bayne O, Peterson M, Cain E. Acute arterial thrombosis after bilateral total knee arthroplasty. J Arthroplasty. 2008;23:1239 e1-6.

11. Da Silva MS, Sobel M. Popliteal vascular injury during total knee arthroplasty. J Surg Res. 2003 ;109:170-4.

12. Langkamer VG. Local vascular complications after knee replacement: a review with illustrative case reports. Knee. 2001;8:259-64.

13. Matziolis G, Perka C, Labs K. Acute arterial occlusion after total knee arthroplasty. Arch Orthop Trauma Surg. 2004;124:134-6.

14. Ninomiya JT, Dean JC, Goldberg VM. Injury to the popliteal artery and its anatomic location in total knee arthroplasty. J Arthroplasty. 1999;14:803-9.

15. Parvizi J, Pulido L, Slenker N, Macgibeny M, Purtill JJ, Rothman RH. Vascular injuries after total joint arthroplasty. J Arthroplasty. 2008;23:1115-21.

16. Sandoval E, Ortega FJ, Garcia-Rayo MR, Resines C. Popliteal pseudoaneurysm after total knee arthroplasty secondary to intraoperative arterial injury with a surgical pin: review of the literature. J Arthroplasty. 2008;23:1239 e7-11.

17. Maheshwari R, Kelley SP, Langkamer VG, Loveday E. Spontaneous recurrent haemarthrosis following unicompartmental knee arthroplasty and its successful treatment by coil embolisation. Knee. 2004;11:413-5.

18. Thomas R, Agarwal M, Lovell M, Welch M. An unusual presentation of a popliteal arteriovenous fistula after primary total knee arthroplasty. J Arthroplasty. 2008;23:945-8.

19. Metzdorf A, Jakob RP, Petropoulos P, Middleton R. Arterial injury during revision total knee replacement. A case report. Knee Surg Sports Traumatol Arthrosc. 1999;7:246-8.

20. Abu Dakka M, Badri H, Al-Khaffaf H. Total knee arthroplasty in patients with peripheral vascular disease. Surgeon. 2009; 7:362-5.

21. Ng VY, Declaire JH, Berend KR, Gulick BC, Lombardi AV, Jr. Improved Accuracy of Alignment With Patientspecific Positioning Guides Compared With Manual Instrumentation in TKA. Clin Orthop Relat Res. 2012;470:99-107.

22. Abularrage CJ, Weiswasser JM, Dezee KJ, Slidell MB, Henderson WG, Sidawy AN. Predictors of lower extremity arterial injury after total knee or total hip arthroplasty. J Vasc Surg. 2008;47:803-7; discussion 7-8. 


\section{Chapter \\ Conclusion}

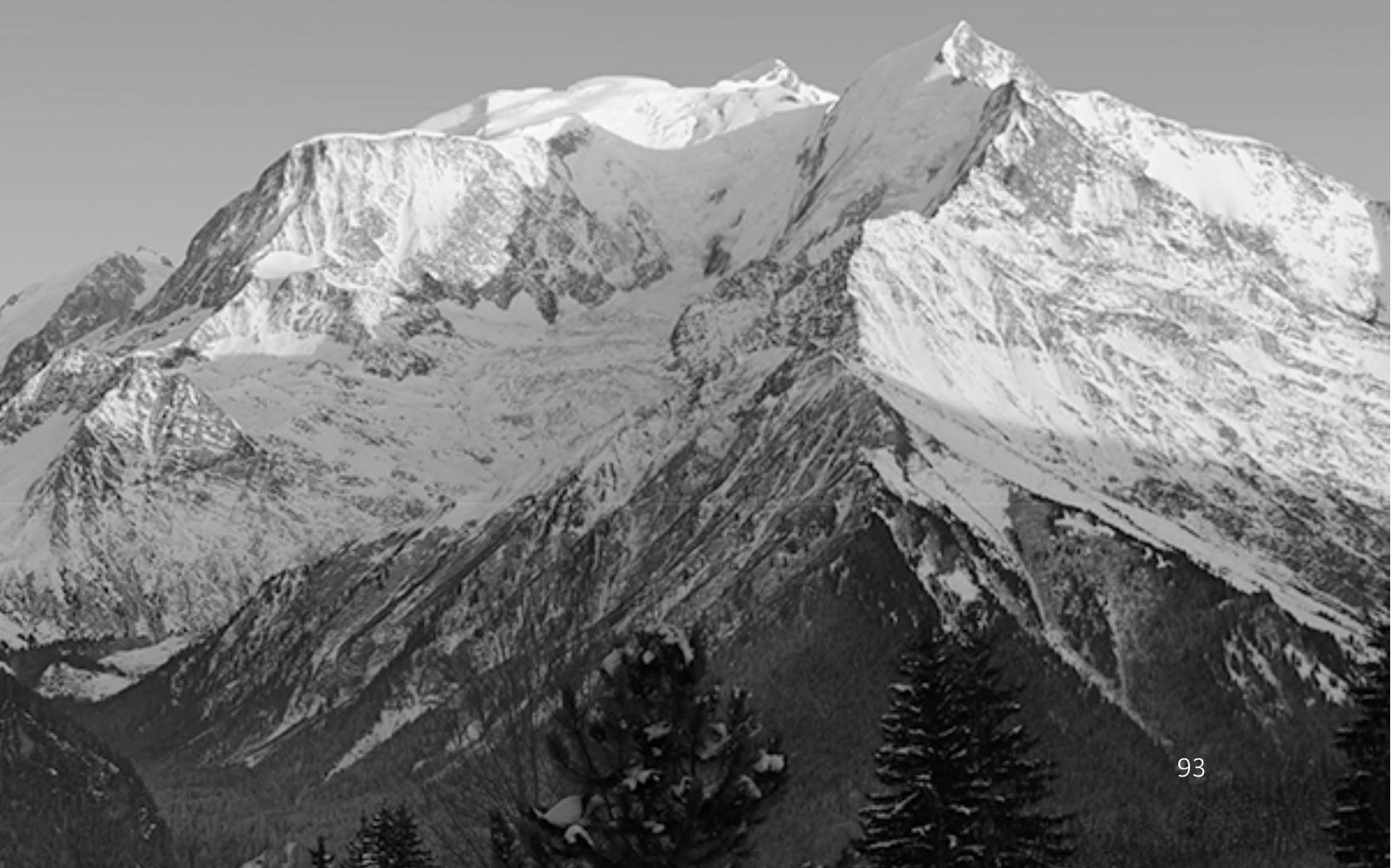




\section{INTRODUCTION AND AIMS}

Osteoarthritis of the knee is a well-known condition which decreases the quality of life of many patients.[1] It can be treated in a non-operative or an operative way, depending on the individual patient. When the non-operative treatment fails, tibial osteotomy or knee arthroplasty are options. Depending on which compartments of the knee are affected, unicompartmental knee arthroplasty (UKA) or total knee arthroplasty (TKA) can be performed with good results.[8]

The aim of this dissertation includes answering questions regarding primary UKA surgery as well as UKA to TKA revision surgery.

Questions regarding primary UKA surgery:

1: "Does cementless Oxford UKA show similar clinical and radiological results when compared to cemented Oxford UKA?"

2: "Is the position of prosthesis components on the digital plan the actual position of the components after UKA surgery using PSG?"

3: "Is PSG a useful and reliable tool in positioning prosthesis components in primary UKA surgery?"

4: "Is the role of the operating surgeon still an important factor in the outcome of primary UKA surgery?"

Questions regarding UKA to TKA revision surgery:

5: "Is UKA to TKA revision surgery for anteromedial pain of unknown origin after UKA a successful procedure?"

6: "Is PSG a useful tool in UKA to TKA revision surgery?"

7: "Is the role of the operating surgeon still an important factor in the outcome of UKA to TKA revision surgery?"

\section{INNOVATIONS IN PRIMARY UKA SURGERY}

\section{Fixation in primary UKA surgery}

The first aim was to investigate whether cementless UKA fixation has an influence on the loosening rate and on the tibial radiolucency rate after UKA. The first question to be answered was: "Does cementless UKA show similar clinical and radiological results when compared to cemented UKA?" A retrospective multicentre study was conducted. Sixty cases of cementless UKA were compared with sixty cases of cemented UKA. Baseline characteristics for both groups were the same. Radiolucent lines under the tibial 
component, perioperative data, clinical outcome and survival were evaluated. The results show that the number of total and partial radiolucent lines were not statistically significantly different, although a trend to less radiolucency in the cementless group was observed. The operation time was 10 minutes shorter in the cementless group, but no other perioperative differences were observed. Clinical outcome and early survival were also not statistically significantly different. Cementless UKA surgery thus seems reliable and safe. However, the study has a relative short follow-up time and long-term results are not known yet. It is thus not clear whether the UKA to TKA revision rate decreases with this innovation.

\section{Patient-specific guiding in primary UKA surgery}

In addition to fixation, the issue regarding component positioning using PSG in primary UKA surgery was investigated. The second aim was to answer the question: "Is the position of prosthesis components on the digital plan the actual position of the components after UKA surgery?" A prospective single-centre CT-based study was conducted. Twenty-six cases of Oxford UKA surgery were consecutively included. In addition to the preoperative MRI scan, a CT scan was made. Postoperatively a new CT scan was made and, using 3D digital imaging, these images were superimposed on each other. This made it possible to determine whether the actual position of the prosthesis components was according to the preoperative plan. The results show that the guides are accurate in translating this preoperative plan to the definitive component position. An additional result is that the tibial component should be planned in a rather distal and lateral position to avoid re-cuts during surgery. Due to these re-cuts tibial rotation especially can be affected.

After establishing that the guides are accurate, a comparative study was conducted to answer the third question: "Is PSG a useful and reliable tool in primary UKA surgery?" A prospective single-centre cohort study was conducted. Thirty cases of primary UKA using PSG outlining were compared with thirty cases of primary UKA using conventional outlining. Baseline characteristics for both groups were the same. Perioperative clinical data and postoperative radiographic data were compared. The results show that perioperative data and radiographic component position were not different between both groups, even during the learning curve of the new technique. PSG thus seems a reliable and safe tool to use in UKA surgery. The long-term results of this innovation on UKA survival are also not known yet due to the short follow-up time.

\section{The surgeon as a factor in primary UKA surgery}

Despite these innovations, the operation is still performed by a surgeon, who can follow the plan or not. This decision depends on the expertise of the surgeon with the present situation. The case report in chapter 5 shows that good balancing during primary sur- 
gery is important to prevent overstuffing. This ligament balancing is performed by the surgeon and cannot be planned using PSG. If this is not done properly, the correct component size is placed in a distal position with a bad result. On the other hand it shows that, with good clinical evaluation and preoperative planning, some problems can be solved using a rather small operation (femoral component revision) instead of a full UKA to TKA revision procedure, with good results.

\section{INNOVATIONS IN UKA TO TKA REVISION SURGERY}

\section{Decision-making and results in UKA to TKA revision surgery}

Regarding decision-making and results in case of UKA to TKA revision surgery, the next aim was to answer the question: "Is UKA to TKA revision for anteromedial pain of unknown origin after UKA a successful procedure?" A retrospective multicentre study was conducted. All cases of UKA to TKA revision surgery were listed and divided into two groups. In one group all patients $(\mathrm{N}=15)$ with unexplained pain before revision surgery were listed and in the other group all patients $(\mathrm{N}=15)$ with a clear cause for pain, such as loosening, progression of osteoarthritis, infection, component malposition and osteonecrosis were included. Patient satisfaction after revision surgery was assessed and compared between both groups. The results show that clinical outcome was clinically relevantly better as well as statistically significant when a clear cause for the pain was found before revision surgery. This is the first study to be published that compares these results and it confirms the hypothesis that UKA to TKA revision surgery shows better results when the reason of failure is understood. UKA to TKA revision surgery is thus usually not the solution for unexplained pain.

\section{Operation technique in UKA to TKA revision surgery}

Another issue concerning UKA to TKA revision surgery is the operation technique. During primary UKA surgery, bony landmarks are removed to insert the UKA in the proper position. These landmarks cannot be used anymore during revision surgery, which can make the procedure technically demanding. Therefore, the next aim is to answer the question: "Is PSG a useful tool in UKA to TKA revision surgery?" A prospective singlecentre study was conducted. Ten cases of UKA to TKA revision surgery were performed using CT-based PSG. The results show that all guides fitted well and all newly inserted components were in good position. The guides were proven to translate this plan to the actual anatomy during surgery well. The combination of both these qualities make PSG a substantial aid in UKA to TKA revision surgery. 
The surgeon as a factor in UKA to TKA revision surgery

The surgeon is also an important factor in UKA to TKA revision surgery. The second case report shows that, despite all precautions and the introduction of PSG in revision surgery, problems such as a vascular lesion can occur. The surgeon is the key person to recognise and acknowledge these problems and address them in the proper way. The orthopaedic surgeon is thus still a key factor in UKA to TKA revision surgery, despite the introduction of these innovations.

\section{DISCUSSION}

The primary goal in the treatment of osteoarthritis of the knee is improve the quality of life for the patient. Pain management is crucial in these cases. If the patient is satisfied with conservative treatment this is preferable, since it is less invasive when compared with surgery. When conservative treatment options prove not to reduce disease-related complaints such as pain sufficiently, operative treatment is the next step. In patients with polycompartmental osteoarthritis of the knee, TKA is often the best treatment. In patients with unicompartmental osteoarthritis of the knee more options are available. Unloading of the affected compartment by performing an osteotomy can be a good option in younger patients. By using this technique the possible need for a TKA is transferred to the future, and possible complications such as TKA revision surgery are avoided. This is especially important in young patients, since the probable lifetime of a TKA is possibly less than the probable lifetime of the patient. The disadvantage of this procedure, however, is that the rehabilitation period after the procedure can be difficult. In this regard, it is also important to prevent unicompartmental osteoarthritis of the knee in cases of (sub)total meniscectomy. Meniscal transplant with donor meniscus or artificial meniscus such as Actifit report good results in the literature, especially in the lateral compartment.[4,16,18] For medial unicompartmental osteoarthritis of the knee, UKA surgery is also a proven good alternative to improve quality of life with preservation of bonestock relative to TKA. For the lateral compartment this is a more difficult issue, since the lateral compartment is more mobile and has less intrinsic stability than the medial compartment due to greater posterior roll-back during flexion. Speciallydesigned lateral unicompartmental knee prostheses are commercially available. Rehabilitation after UKA surgery is usually less demanding than after osteotomy or TKA. UKA also mimics the natural movement of the knee better than TKA and due to this natural movement, patients with a UKA forget they have been operated and have UKA in situ more often after UKA surgery compared to after TKA surgery.

The best treatment cannot be defined and depends on individual factors. Medial UKA is a good option for many patients and shows good results. As previously discussed, improvements are possible to prevent loosening and radiolucent lines under the tibial 
component. These lines can be normal findings but in some cases they are associated with loosening incorrectly.

Cementless fixation was one of the innovations introduced to decrease the revision rate and tibial radiolucency rate. The cementless versus cemented study was conducted to corroborate reported results in the literature by the prosthesis designer group. Our findings support these short-term results in the literature concerning cementless UKA radiographically as well as clinically. $[9,13,20]$ Concerning cemented UKA, the literature shows inferior radiographical short-time results compared to the results in our study. Recent literature suggests that mid-term results are better in cementless cases radiologically as well as clinically.[10,21] These first reports are published by prosthesis designers, who are often high-volume surgeons familiar with the potential pitfalls. These results have to be checked by non-designer groups in future to establish whether they are applicable to all user groups. This issue was beyond the scope of this dissertation, but the cohorts that were used for short-term evaluation can be used in future after a longer follow-up period for this purpose.

The other innovation that might influence prosthesis survival rates is the position of the components.[5] Both our studies on the application of PSG in primary UKA surgery show that this technique is reliable and safe. PSG is an innovation that only concerns the way the prosthesis is positioned during surgery. Oxford UKA using conventional instrumentation can be demanding, and the experience of the surgeon is an important factor.[17] However, if the position after PSG surgery is not significantly different from the prosthesis position after conventional surgery, no difference in short- or long-term outcome is to be expected. Although no significant differences in prosthesis position between both groups were found in our results, the range of prosthesis position was smaller in the PSG group, which indicates that the probability that more components are in a correct position is higher. This might especially be the case in less experienced Oxford UKA surgeons.[6,17,22] PSG can thus be an aid for these surgeons in placing more components in a proper position. A limitation of our study is that the conventional "Phase 3" instruments were used to position the components in the control group. The prosthesis manufacturer has meanwhile changed the " $3^{\text {rd }}$ generation" instruments to the new "Microplasty" instruments, and " ${ }^{\text {rd }}$ generation" instruments are not widely used anymore. The preoperative planning is an important step in PSG surgery. The reported result is that the guides correctly translate this preoperative plan to the actual patient anatomy during surgery in Oxford PSG UKA. If this were not the case, there would be no reason to use PSG in Oxford UKA in the future. Tibial rotation does not solely depend on the bonecut, which is determined by the guide, but also on the shape of the medial tibial plateau and fit during surgery. The clinical relevance of planning this parameter is thus limited. Additionally, there is no control group value for this parameter, since it can only be determined on $\mathrm{CT}$ and not on plain radiographs. The impact of the use of PSG on prosthesis survival seems to be small, however, since both the conventional way of positioning the components as well as PSG show results with the com- 
ponents within the safe limits as described by the manufacturer. A prospective study comparing PSG with "Microplasty" instruments might be performed in future to compare these two new techniques. Besides affecting the radiological position of the prosthesis components, PSG also reduces operation time, and in 70\% of cases the preoperatively planned component size was actually implanted. Both these effects might affect the routing of patients and resources perioperatively, and thus cost effectiveness, but evaluating this parameter was also not within the scope of this dissertation.

Despite the fact that this innovation aids in positioning the components, the tibial rotation and proximal-distal position of the Oxford UKA still depend on the experience of the surgeon and not on the PSG technique. The case report stresses this. The finding that surgeon experience is an important factor in UKA surgery is not surprising, and it is supported by recent literature, which shows that revision rates after UKA surgery are lower for high-volume surgeons[3,12].

UKA to TKA revision surgery however still has to be performed in certain cases but an important step before performing this type of surgery is the decision whether to perform this revision surgery or not. Pain of unknown origin after UKA surgery is a big issue in this matter. Recent literature shows that in the United Kingdom, pain of unknown origin is the second most frequent cause for UKA to TKA revision surgery after aseptic loosening (20\% of all UKA to TKA revisions are for pain of unknown origin).[11] Pain of unknown origin after TKA shows a significantly smaller revision rate $(10 \%$ of all TKA to TKA revisions) according to the same authors.[11] For TKA revision surgery, it is known that the results after revision are better when a clear cause for failing of the primary TKA prior to revision surgery is known.[15] This seems to be a logical conclusion. According to common sense, an analogy for patients with pain after a UKA should be present. In these cases, however, the idea that this is only a partial knee replacement might lead the surgeon to conclude that a total knee replacement might resolve the problem. After TKA this idea does not occur, since this seems to be a more final situation. This can partially explain the higher revision rate for pain of unknown origin after UKA surgery.[2] The problem after UKA to TKA revision surgery, however, is that some patients are still suffering pain. Our results clearly demonstrate, for the first time in the literature, that UKA to TKA revision surgery is rather not the solution for the problem of pain of unknown origin after UKA surgery and thus prove common sense to be right. The results, however, are of great importance for surgeons in explaining the issue to the patient and to inform this patient in a proper way of what to expect (and rather not to expect) of this kind of surgery.

The last innovation discussed in this dissertation is UKA to TKA revision surgery using CT-based PSG. Revision surgery can be especially technically demanding due to the loss of anatomic landmarks, and proper preoperative planning is important. $[7,14,19,23]$ PSG makes it possible to properly plan the surgery preoperatively using 3D reconstructions of the actual anatomy. Since these reconstructions are based on CT imaging, more anatomic landmarks can be used to position the components than during actual surgery. 
Problems due to bone loss can also be expected during this preoperative plan period and the need for additional special equipment during surgery can be anticipated. In these cases of revision PSG can certainly be an aid.

\section{CONCLUSIONS}

Cementless fixation of Oxford UKA and PSG Oxford UKA are reliable and safe to use, with good short-term results. Long-term results are not clear yet, however, and future research is needed to establish whether they decrease revision rates and increase patient satisfaction.

The results of UKA to TKA revision surgery are better when a clear cause for the pain before revision surgery is known. UKA to TKA revision surgery is not the best solution for pain of unknown origin after UKA surgery. PSG is a substantial aid in UKA to TKA revision surgery.

Despite all innovations, the surgeon is still the key factor in primary UKA surgery as well as UKA to TKA revision surgery. 


\section{REFERENCES}

1. Abhishek A, Doherty M (2013) Diagnosis and clinical presentation of osteoarthritis. Rheum Dis Clin North Am 39:45-66. doi:S0889-857X(12)00119-6 [pii] 10.1016/j.rdc.2012.10.007

2. Baker PN, Petheram T, Avery PJ, Gregg PJ, Deehan DJ (2012) Revision for unexplained pain following unicompartmental and total knee replacement. The Journal of bone and joint surgery 94:e126. doi:1356143 [pii] 10.2106/JBJS.K.00791

3. Bini S, Khatod M, Cafri G, Chen Y, Paxton EW (2013) Surgeon, implant, and patient variables may explain variability in early revision rates reported for unicompartmental arthroplasty. The Journal of bone and joint surgery 95:2195-2202. doi:1787533 [pii] 10.2106/JBJS.L.01006

4. Bouyarmane H, Beaufils P, Pujol N, Bellemans J, Roberts S, Spalding T, Zaffagnini S, Marcacci M, Verdonk P, Womack M, Verdonk R (2014) Polyurethane scaffold in lateral meniscus segmental defects: clinical outcomes at 24 months follow-up. Orthop Traumatol Surg Res 100:153-157. doi:S1877-0568(13)00243-0 [pii] 10.1016/j.otsr.2013.10.011

5. Burnett RS, Nair R, Hall CA, Jacks DA, Pugh L, McAllister MM (2014) Results of the Oxford Phase 3 mobile bearing medial unicompartmental knee arthroplasty from an independent center: 467 knees at a mean 6-year follow-up: analysis of predictors of failure. J Arthroplasty 29:193-200. doi:S0883-5403(14)00334-9 [pii] 10.1016/j.arth.2014.01.035

6. Clarius M, Hauck C, Seeger JB, Pritsch M, Merle C, Aldinger PR (2010) Correlation of positioning and clinical results in Oxford UKA. International orthopaedics 34:1145-1151. doi:10.1007/s00264-009-0881-3

7. Dudley TE, Gioe TJ, Sinner P, Mehle S (2008) Registry outcomes of unicompartmental knee arthroplasty revisions. Clinical orthopaedics and related research 466:1666-1670. doi:10.1007/s11999-008-0279-3

8. Goodfellow JWOC, J. Dodd,C. Murray, D. (2006) Unicompartmental arthroplasty with the Oxford Knee. Oxford University Press:190

9. Hooper GJ, Maxwell AR, Wilkinson B, Mathew J, Woodfield TB, Penny ID, Burn PJ, Frampton C (2012) The early radiological results of the uncemented Oxford medial compartment knee replacement. J Bone Joint Surg Br 94:334-338. doi:94-B/3/334 [pii] 10.1302/0301-620X.94B3.27407

10. Kendrick BJ, Kaptein BL, Valstar ER, Gill HS, Jackson WF, Dodd CA, Price AJ, Murray DW (2015) Cemented versus cementless Oxford unicompartmental knee arthroplasty using radiostereometric analysis: a randomised controlled trial. Bone Joint J 97-B:185-191. doi:97-B/2/185 [pii] 10.1302/0301620X.97B2.34331

11. Liddle AD, Judge A, Pandit H, Murray DW (2014) Adverse outcomes after total and unicompartmental knee replacement in 101,330 matched patients: a study of data from the National Joint Registry for England and Wales. Lancet 384:1437-1445. doi:S0140-6736(14)60419-0 [pii] 10.1016/S01406736(14)60419-0

12. Liddle AD, Pandit H, Judge A, Murray DW (2015) Optimal usage of unicompartmental knee arthroplasty: a study of 41,986 cases from the National Joint Registry for England and Wales. Bone Joint J 97-B:15061511. doi:97-B/11/1506 [pii] 10.1302/0301-620X.97B11.35551

13. Liddle AD, Pandit H, O'Brien S, Doran E, Penny ID, Hooper GJ, Burn PJ, Dodd CA, Beverland DE, Maxwell AR, Murray DW (2013) Cementless fixation in Oxford unicompartmental knee replacement: a multicentre study of 1000 knees. Bone Joint J 95-B:181-187. doi:95-B/2/181 [pii] 10.1302/0301-620X.95B2.30411

14. McAuley JP, Engh GA, Ammeen DJ (2001) Revision of failed unicompartmental knee arthroplasty. Clinical orthopaedics and related research:279-282

15. McDowell M, Park A, Gerlinger TL (2016) The Painful Total Knee Arthroplasty. Orthop Clin North Am 47:317-326. doi:S0030-5898(15)00166-2 [pii] 10.1016/j.ocl.2015.09.008

16. McNicholas MJ, Rowley DI, McGurty D, Adalberth T, Abdon P, Lindstrand A, Lohmander LS (2000) Total meniscectomy in adolescence. A thirty-year follow-up. The Journal of bone and joint surgery 82:217-221

17. Mercier N, Wimsey S, Saragaglia D (2009) Long-term clinical results of the Oxford medial unicompartmental knee arthroplasty. International orthopaedics 
18. Moran CJ, Withers DP, Kurzweil PR, Verdonk PC (2015) Clinical Application of Scaffolds for Partial Meniscus Replacement. Sports Med Arthrosc 23:156-161. doi:10.1097/JSA.0000000000000072 00132585-201509000-00011 [pii]

19. Oduwole KO, Sayana MK, Onayemi F, McCarthy T, O'Byrne J (2009) Analysis of revision procedures for failed unicondylar knee replacement. Irish journal of medical science 179:361-364. doi:DOI 10.1007/s11845-009-0454-x

20. Pandit H, Liddle AD, Kendrick BJ, Jenkins C, Price AJ, Gill HS, Dodd CA, Murray DW (2013) Improved fixation in cementless unicompartmental knee replacement: five-year results of a randomized controlled trial. J Bone Joint Surg Am 95:1365-1372. doi:1719859 [pii] 10.2106/JBJS.L.01005

21. Pandit HG, Campi S, Hamilton TW, Dada OD, Pollalis S, Jenkins C, Dodd CA, Murray DW (2015) Five-year experience of cementless Oxford unicompartmental knee replacement. Knee Surg Sports Traumatol Arthrosc. doi:10.1007/s00167-015-3879-y 10.1007/s00167-015-3879-y [pii]

22. Parmaksizoglu AS, Kabukcuoglu Y, Ozkaya U, Bilgili F, Aslan A (2010) Short-term results of the Oxford phase 3 unicompartmental knee arthroplasty for medial arthritis. Acta Orthop Traumatol Turc 44:135142. doi:10.3944/AOTT.2010.2296

23. Saragaglia D, Estour G, Nemer C, Colle PE (2009) Revision of 33 unicompartmental knee prostheses using total knee arthroplasty: strategy and results. Int Orthop 33:969-974. doi:10.1007/s00264-008-0585-0 


\section{Chapter \\ 10}

Summary and valorisation
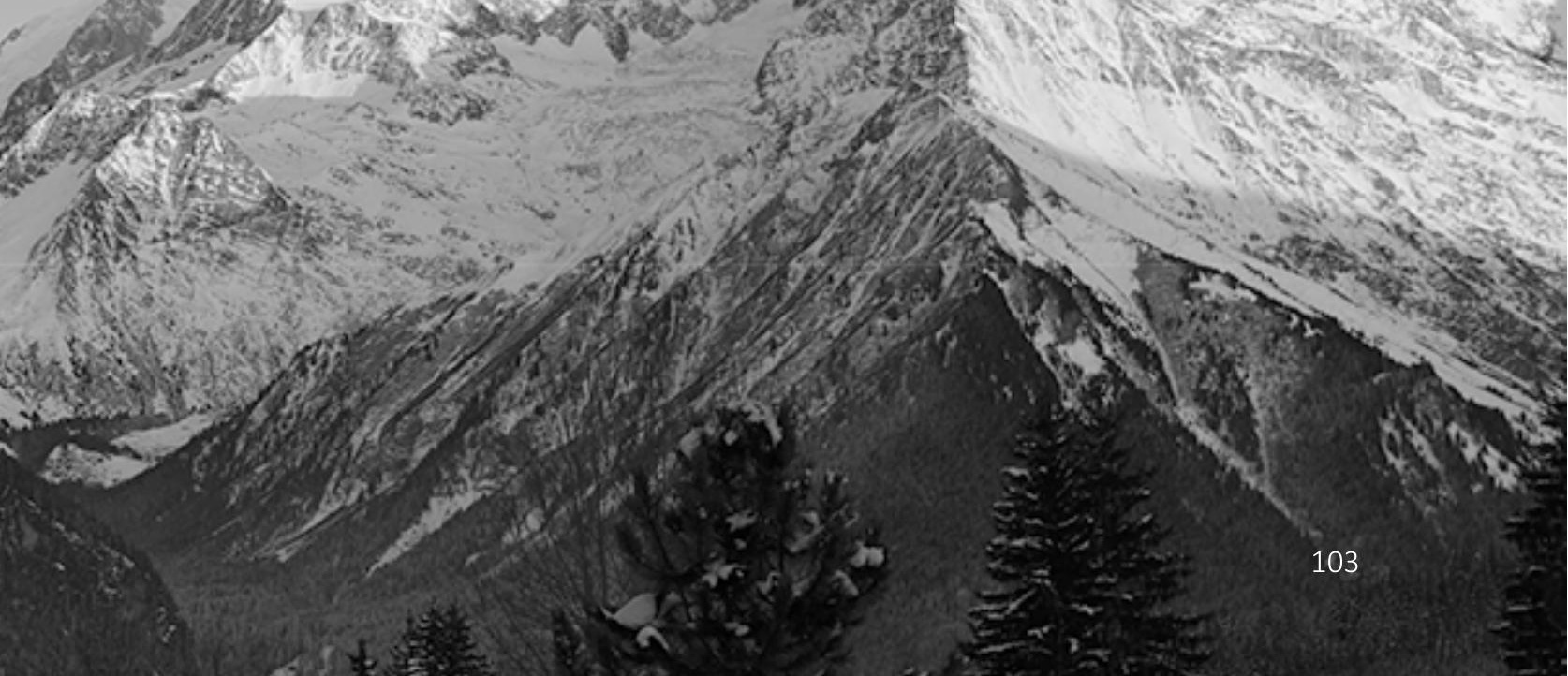


\section{SUMMARY AND VALORISATION}

Medial unicompartmental knee arthroplasty (UKA) is a known procedure for medial osteoarthritis of the knee with good results. Recently innovations were introduced to improve patient satisfaction and survival rates after primary UKA as well UKA to TKA revision surgery. First of all this dissertation discusses the short term results of cementless fixation in primary Oxford UKA surgery and positioning of the components using patient specific guiding (PSG) in primary Oxford UKA Surgery. Additionally new insights in decision making for UKA to TKA revision surgery are discussed with results of UKA to TKA revision surgery for specific cases. Also an innovative technique using PSG for UKA to TKA revision surgery is presented. Finally it is demonstrated that despite these innovations in primary UKA surgery as well as UKA to TKA revision surgery, the surgeon is still a key factor during these procedures.

\section{INNOVATIONS IN PRIMARY UKA SURGERY}

UKA components are usually fixated to the bone using bone cement. An innovation using cementless fixation for these components, with reported good results by the designing team was evaluated propectively. The short term results confirm the results reported by the designing team regarding the cementless components. Long term results are not known yet. Cementless fixation in primary Oxford UKA surgery thus seems reliable and safe to use.

Next innovation in primary Oxford UKA surgery is component positioning using PSG. A prospective study was performed which shows that the guide that translates the position of the component on the preoperative plan to the actual position in the patient is accurate. Proper planning is important to prevent re-cuts, which can cause deviations of the definitive component position compared with the planned position. The second study regarding this topic is a cohort study in which PSG is compared with conventional component positioning. The results show that no statistical significant difference is seen between both groups. Both studies confirm that PSG is safe, reliable and accurate in Oxford UKA surgery.

\section{INNOVATIONS IN UKA TO TKA REVISION SURGERY}

Although results of primary UKA surgery are good, some patients have problems and need UKA to TKA revision surgery. Next to loosening, fracture and bearing luxation, pain of unknown origin is a complaint for which revision surgery is performed. Since a UKA in situ seems not to be an endpoint, pain of unknown origin can be reason for revision to TKA. A retrospective multicentre study was performed and shows that in case of pain of 
unknown reason revision surgery is rather not the solution for the problem and that pain is often still present after revision surgery. It is thus important to inform the patient properly and advise against revision surgery in these cases. A second innovation in UKA to TKA revision surgery is PSG. A prospective study was performed and the results show that PSG can be an aid in this technically demanding procedure in order to put the definitive new components in the proper position.

Despite all these innovations the surgeon is still the key factor. Two case reports show that this is the case during primary UKA surgery as well as UKA to TKA revision surgery.

\section{VALORISATION}

The studies regarding primary UKA surgery show orthopaedic surgeons that short term results after cementless fixation of Oxford UKA components are good in a non-designer orthopaedic centre and that the technique thus can be used in a safe way by other nondesigner orthopaedic surgeons. Long-term results however are not yet reported by nondesigner groups. Both the studies concerning PSG show that in primary Oxford UKA surgery PSG is a safe, reliable and accurate tool with final results regarding component position comparable with conventional instrumentation.

The study regarding decision making and outcome of UKA to TKA revision surgery is important for orthopaedic surgeons as well as patients with pain of unknown origin after UKA surgery. Revision surgery shows good results when a cause for the complaints is present before the surgery but in case of pain of unknown origin, revision surgery is rather not the solution for the pain.

Regarding PSG in UKA to TKA revision surgery, the reported results are important for orthopaedic surgeons since this is an introduction of a new technique, which makes this potentially difficult procedure less demanding.

The final remark that despite all these innovations the surgeon is still the key factor in primary UKA surgery as well as UKA to TKA revision surgery is important for orthopaedic surgeons that use new techniques. 



\section{Dankwoord}




Promoveren naast dagelijks klinisch werk is iets dat je niet alleen kunt. Vandaar dat ik devolgende personen graag wil bedanken voor hun bijdrage.

Promotor, Prof. Van Rhijn, beste Lodewijk, bedankt dat je promotor van mijn proefschrift wilde zijn. Je klare kijk op zaken en snelle feedback hebben me geleerd dat er verschillende manieren zijn om een berg die je op je pad tegenkomt te beklimmen.

Co-promotor, Dr. Kort, beste Nanne, de initiele opzet voor dit proefschrift werd geschreven op een regenachtige zondag ochtend in jouw tuin onder het afdak. Graag wil ik je bedanken voor de onaflatende steun, het opzetten van studies, het redigeren van manuscripts, het beschikbaar stellen van de patientendata en het bewaken van de tijdslijn ondanks aanpassingen in inhoud ten opzichte van het initiele plan.

Co-promotor, Dr. Emans, beste Pieter, dank je wel voor de praktische steun en snelle en correcte feedback bij kleine en grote vragen. Veel waardering gaat ook uit naar jou als mens, een mooi voorbeeld van iemand die laat zien dat het mogelijk is om kliniek met wetenschap op een goede manier te combineren.

Leden van de manuscriptcommissie, prof. Heyligers, prof. Delport, prof. Geesink, prof. Smeets en prof Verdonk, hartelijk dank voor het beoordelen en goedkeuren van dit proefschrift.

Drs. Lacroix, beste Herman, enerzijds bedankt voor het openstellen van de gegevens over de patienten die door jou geopereerd werden. Anderzijds wil ik je ook bedanken voor het actief meedenken in meerdere fases van het onderzoek en voor je altijd positieve ingesteldheid.

Drs. Schotanus, beste Martijn, ook jij was vanaf het begin betrokken, enerzijds met plannen van studies en anderzijds met het redigeren van manuscripten. Daarnaast wil ik je danken voor het opvolgen van patienten en data op momenten dat ik niet zelf ter plaatse was. Zonder jouw inzet was de binnengehaalde informatie niet van dezelfde waarde geweest.

Drs. Boonen, beste Bert, we zijn ongeveer op hetzelfde moment begonnen met elk ons eigen traject dat we nu op dezelfde dag gaan afsluiten. Het was fijn om samen te zitten en in te zien dat bepaalde moeilijkheden op de weg door iedereen ervaren worden en er gewoon bij horen. Dit bespreken en gezamenlijk naar oplossingen zoeken is voor mij belangrijk geweest. Ook als mens heb ik je in deze periode leren kennen en waarderen. Dank hiervoor. 
Polimedewerkers en OK medewerkers in het Zuyderland ziekenhuis Sittard en Elkerlieck ziekenhuis Helmond. Ik wil julie bedanken voor alle medewerking. Ik weet dat het soms vervelend was wanneer ik weer eens kwam vragen om een patient extra te bellen of een operatiedetail kwam bespreken maar ik heb altijd een vriendelijk antwoord gekregen en denk met een goed gevoel terug aan deze samenwerking.

De patienten die meegewerkt hebben in de studies wil ik natuurlijk ook bedanken. Zonder hen zou dit onderzoek enerzijds niet mogelijk en anderzijds ook niet zinvol zijn.

Collega's in Sittard, Maastricht en Deurne. Allen dank voor alles wat ik heb mogen zien en leren bij julie op klinisch gebied maar ook voor de mogelijkheid om dit proefschrift te kunnen schrijven naast dat dagelijkse klinische werk.

Pap, mam, Brigitte en familie, dank je wel voor het vormen van een warm gezin om in op te groeien. Een plek met respect voor elkaar, met ruimte voor trial and error en het creëren van zelfvertrouwen.

Kristel, Wout en Ella, zonder julie steun en opoffering, ook tijdens de moeilijke momenten, zou de realisatie van dit proefschrift niet mogelijk zijn geweest. Nu dit hoofdstuk afgesloten is zal er meer tijd zijn om samen andere dingen te gaan doen. 



\section{Curriculum vitae}

Bart Kerens was born on the $24^{\text {th }}$ of May 1978 in Born. After graduating from high school (College Sittard) in 1996 he started his medical studies at K.U. Leuven in Belgium. In 2003 he started as orthopaedic resident (ANIOS) at Maastricht University Medical Centre in Maastricht (prof. Geesink) followed by a residency at Maasland Hospital in Sittard (dr. Verburg) where he met Kristel Janssen. In 2006 he started his orthopaedic training at Orbis medical Centre in Sittard (dr. Hoofwijk and dr. Kort) and Maastricht University Medical Centre in Maastricht (prof. Walenkamp and prof. van Rhijn). The research for this PhD thesis was started during this period under supervision of $\mathrm{dr}$. Kort, dr Emans and prof van Rhijn. During this period he also married Kristel Jansen Together they have a son Wout and a daughter Ella. After his residency he went to Deurne in Belgium (dr. Michielsen) and Vierssen Germany (prof. König) for an orthopaedic fellowship. In 2014 he started his job as orthopaedic surgeon at A.Z. Sint Maarten in Mechelen and Duffel in Belgium. 



\section{Publications}

No difference in clinical outcome between patient-matched positioning guides and conventional instrumented total knee arthroplasty two years post-operatively: a multicentre, double-blind, randomised controlled trial.

Boonen B, Schotanus MG, Kerens B, van der Weegen W, Hoekstra HJ, Kort NP. Bone Joint J. 2016 Jul;98-B(7):939-44.

Cementless versus cemented Oxford unicompartmental knee arthroplasty: early results of a non-designer user group.

Kerens B, Schotanus MG, Boonen B, Boog P, Emans PJ, Lacroix H, Kort NP.

Knee Surg Sports Traumatol Arthrosc. 2016 May 9. [Epub ahead of print]

Inter-observer reliability of measurements performed on digital long-leg standing radiographs and assessment of validity compared to 3D CT-scan.

Boonen B, Kerens B, Schotanus MG, Emans P, Jong B, Kort NP.

Knee. 2016 Jan;23(1):20-4.

Patient-specific positioning guides for total knee arthroplasty: no significant difference between final component alignment and pre-operative digital plan except for tibial rotation.

Boonen B, Schotanus MG, Kerens B, Hulsmans FJ, Tuinebreijer WE, Kort NP. Knee Surg Sports Traumatol Arthrosc. 2015 Jun 9. [Epub ahead of print]

No radiographic difference between patient-specific guiding and conventional Oxford UKA surgery.

Kerens B, Schotanus MG, Boonen B, Kort NP.

Knee Surg Sports Traumatol Arthrosc. 2015 May;23(5):1324-9.

Knee examination, Emedicine

Boonen B, Kerens B.

http://emedicine.medscape.com/article/1909230-overview

Optimale plaatsing van de totale knieprothese

Kerens B, Boonen B, Kort NP

Orthopedie Actueel. 2013 Maart; jaargang 5, nr 1. 
Popliteal lesion due to traction during unicompartmental knee revision surgery.

Kerens B, Boonen B, Schotanus MG, Kort NP.

J Orthop. 2013 Mar 1;10(1):38-40.

Compartment syndrome, femoral nerve lesion and recurrent haemarthrosis in one and the same patient after total knee arthroplasty. A report of a dramatic case.

B. Boonen, B. Kerens, MGM. Schotanus, NP. Kort

Journal of Case Reports in Medicine 2013 doi:10.5171/2013.996704

Revision from unicompartmental to total knee replacement: the clinical outcome depends on reason for revision.

Kerens B, Boonen B, Schotanus MG, Lacroix H, Emans PJ, Kort NP.

Bone Joint J. 2013 Sep;95-B(9):1204-8.

Intra-operative results and radiological outcome of conventional and patient-specific surgery in total knee arthroplasty: a multicentre, randomised controlled trial.

Boonen B, Schotanus MG, Kerens B, van der Weegen W, van Drumpt RA, Kort NP.

Knee Surg Sports Traumatol Arthrosc. 2013 Oct;21(10):2206-12.

Patient-specific guide for revision of medial unicondylar knee arthroplasty to total knee arthroplasty: beneficial first results of a new operating technique performed on 10 patients.

Kerens B, Boonen B, Schotanus M, Kort N.

Acta Orthop. 2013 Apr;84(2):165-9.

Overstuffed medial compartment after mobile-bearing unicompartmental knee arthroplasty.

Kerens B, Kort NP.

Knee Surg Sports Traumatol Arthrosc. 2011 Jun;19(6):952-4.

Neonatal Distal Femoral Epiphysiolysis. A case report and review of the literature.

Bolink SAAN, Kerens B, Staal HM, Robben SGF, van Rhijn LW.

http://www.jortho.org/2010/7/1/e4/index.htm

Is minimally invasive surgery less invasive in total hip replacement? A pilot study.

Pilot P, Kerens B, Draijer WF, Kort NP, ten Kate J, Buurman WA, Kuipers H.

Injury. 2006 Dec;37 Suppl 5:S17-23.

Atypical tuberculous osteomyelitis of the humeral shaft caused by Mycobacterium avium.

Kerens B, Gans EH, Pilot P, van der Tempel H, Verburg AD.

Ned Tijdschr Geneeskd. 2006 Aug 5;150(31):1728-31. 
SPONSORS

\section{Maastricht UMC+ Maastricht University}

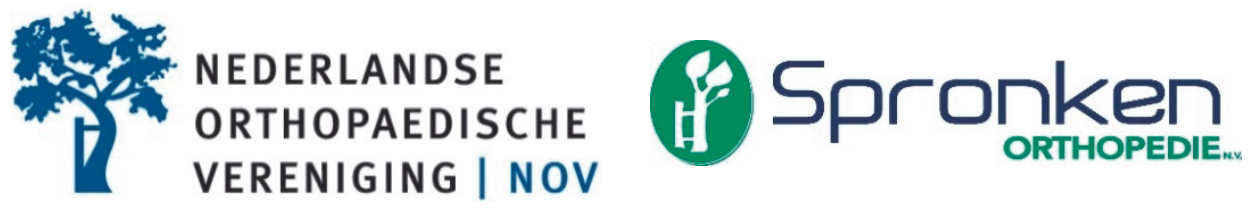

Wellspect :3 zuyderland

(2) ZIMMER Biomet



弓BAUERFEIND IISPORTHO
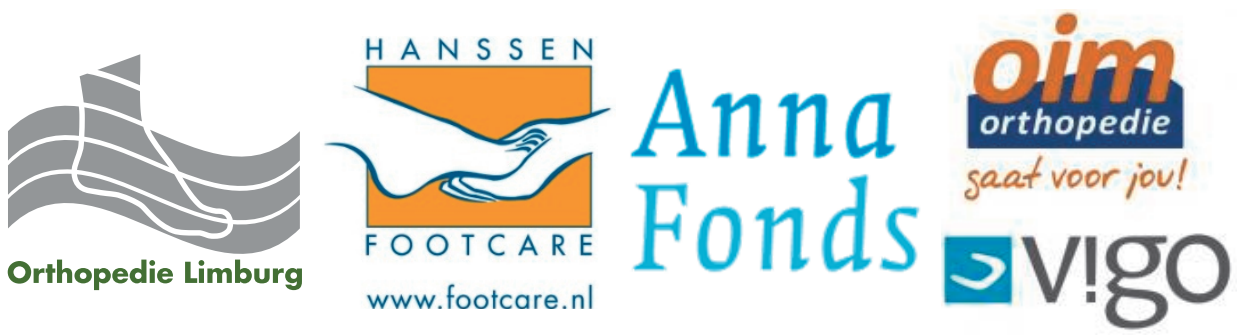


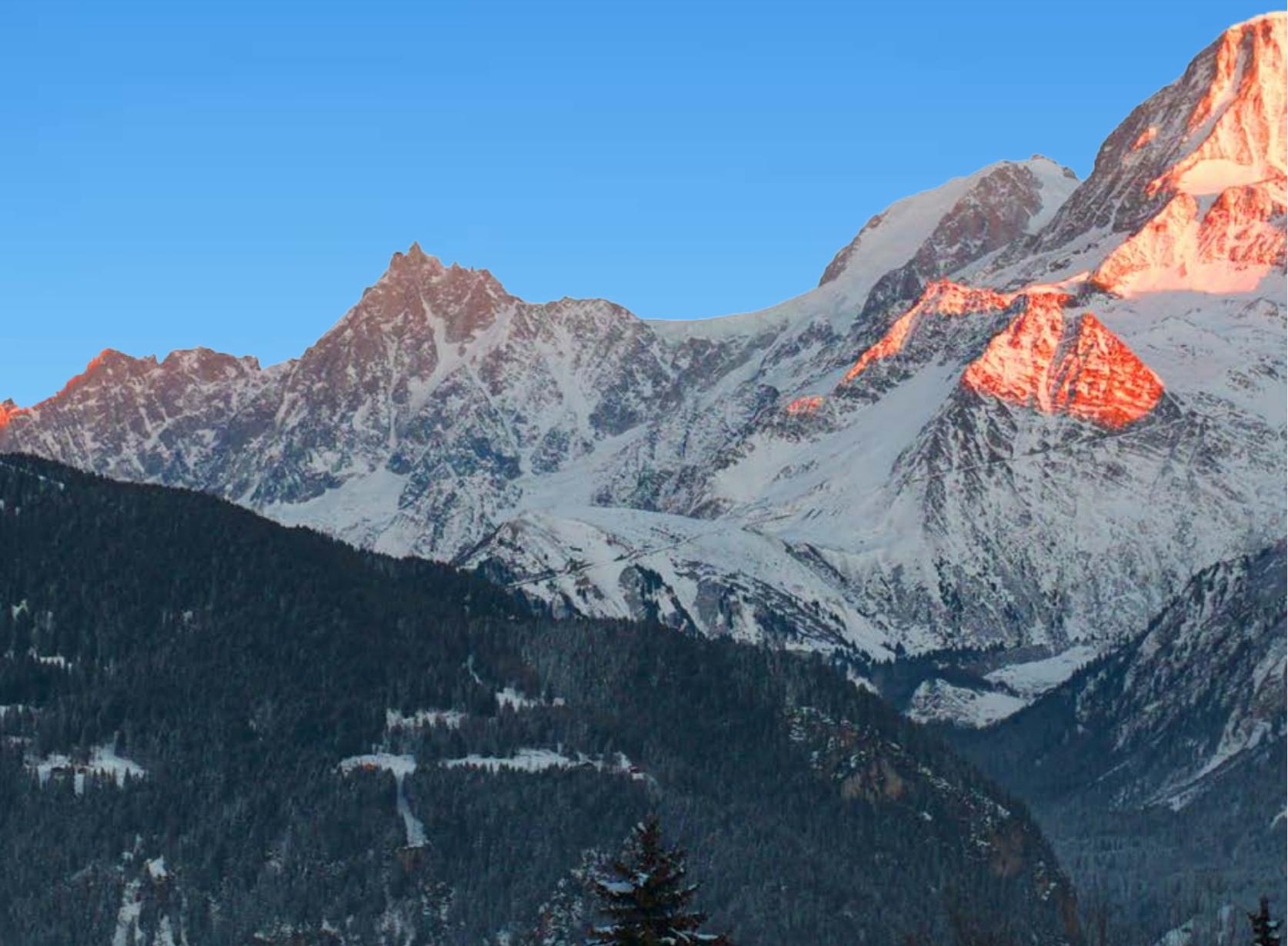

